\title{
POSSIBILIDADE DE EMPREGO DE SELEÇÃO NAS COLHEITAS INICIAIS DE CAFÉ (Coffea arabica L. cv. Acaiá)
}

\author{
TUMORU SERA \\ Engenheiro Agrônomo
}

Orientador: Prof. Dr. NATAL ANTONIO VELLO

Tese apresentada à Escola Superior de Agricultura "Luiz de Queiroz", da Universidade de São Paulo, para obtenção do título de Doutor em Agronomia. Área de concentração: Genética $\theta$ Melhoramento de Plantas.

\footnotetext{
PIRACICABA

Estado de São Paulo - Brasil Junho - 1987
} 


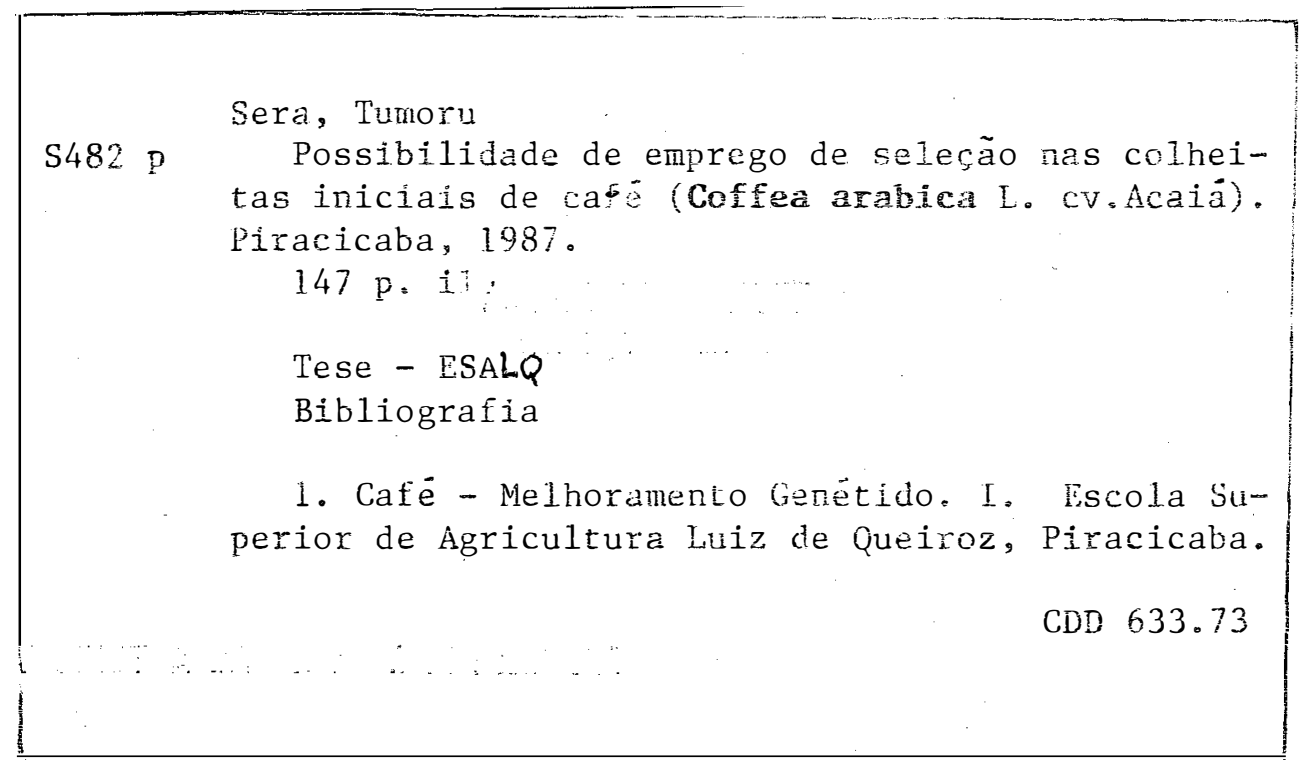


POSSIBILIDADE DE EHPREGO DE SELEÇÃO NAS COLHEITAS

INICIAIS DE CAFÉ (Coffea arabica L。 CV。 Acaiá)

TUMORU SERA

$\begin{array}{ll}\text { Aprovado em: } 13.08 .1987 & \\ \text { Comissão julgadora: } & \text { ESALQ/USP } \\ \text { Prof. Dr. Natal Antonio Vello } & \text { ESALQ/USP } \\ \text { Prof. Dr. Roland Vencovsky } & \text { ESALQ/USP } \\ \text { Prof.Dr. Cássio Roberto de Melo Godoi } & \text { ESALQ/USP } \\ \text { Prof.Dr. Cyro Paulino da Costa } & \text { IAC/S.Gen. } \\ \text { Dr.Alcides Carvalho } & \end{array}$

Prof. Dr。 NATAL ANTONIO VELLO

Orientador 
。ii。

OFEREÇO

aos meus pais,

DEDICO

à minha esposa Alice

e aos meus filhos

Rogério e

Gustavo。 


\section{AGRADECIMENTOS}

Agradecimentos a todos que de algum modo contribuiram para a realização deste trabalho e, em partí cular:

- Ao Prof. Dr. Natal Antonio Vello pela orientação, apoio e estímulo no decorrer do curso;

- Ao Instituto Agronômico de Campinas, IAC, e a sua Seção de Genética pela cessão de dados de produção e de outros caracteres agronômicos que possibilitaram a realização desta pesquisa;

- Ȧ Fundação Instituto Agronômico do Paraná - IAPAR, pela oportunidade concedida para a realização deste curso;

- Ȧ Coordenação de Aperfeiçoamento de Pessoal de Nível Su perior - CAPES, pela bolsa de estudo concedida;

- A Empresa Brasileira de Pesquisa Agropecuária-EMBRAPA, pelo auxilio custeio concedido;

- Aos pesquisadores Luiz Carlos Fazuoli e Alcides CarvaIho da Seção de Genética do Instituto Agronômico de Cam pinas pelo apoio, estímulo e sugestões na realização des ta pesquisa e na revisão dos originais;

- Ao professor Dr. Cássio Roberto de Melo Godoi, do Depar tamento de Matemática pela orientação em análise estatística; 
- Aos analistas de sistemas Gabriel Adriān Sarriēs e Carlos Henrique Matioli e aos operadores de sistemas Evandro Hayashi e José Celso Carriel de Abreu do Centro de Informática na Agricultura - CIAGRI/ESALQ/USP, pelas análises estatísticas realizadas;

- À Bibliotecária Nilce T.P. Sigrist pela revisão da Literatura Citada;

- Ao Engenheiro Agrônomo Túlio Ribeiro Rocha, chefe da Es tação Experimental de Mococa do Instituto Agronômico de Campinas, pela condução do ensaio e coleta de dados;

- Ao Técnico em Agricultura Antonio Guerreiro e outros co legas da Fundação Instituto Agronômico do Paraná (IAPAR), pela continuidade dos trabalhos de condução dos experimentos em melhotamento genético do cafeeiro durante o período do curso. 


\section{SURÁRIO}

página

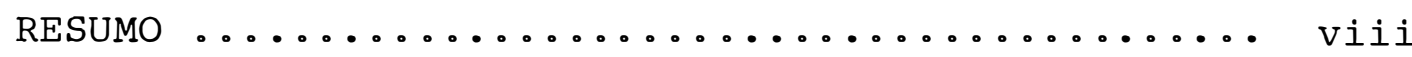

SUMMARY $\ldots \ldots \ldots \ldots \ldots \ldots \ldots \ldots \ldots \ldots \ldots \ldots \ldots \ldots \ldots \ldots \ldots \ldots$

1. INTRODUÇÃO $\ldots \ldots \ldots \ldots \ldots \ldots \ldots \ldots \ldots \ldots \ldots \ldots \ldots \ldots \ldots \ldots$

2. REVISÃO DE LITERATURA ............... 3

2.1. Herdabilidade e avaliação precoce da produ

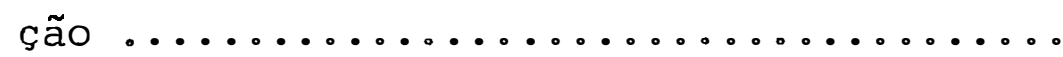

2.2. Fisiologia da produção e caracteres correlacionados com a produção ............ 11

2.3. Herdabilidade dos caracteres correlacionados com a produção ............... 20

2.4. Indice de seleção prara produção ........ 25

2.5. Origem do cultivar 'Acaiá' .......... 30

3. MATERIAL E METODOS ................... 34

3.1. Análises como látice retangular $8 \times 9 \ldots 36$

3.2. Variabilidade, coeficiente de determinação genotípica e progresso genético esperado na seleção para o caráter produção cereja. 37

3.3. Estabilidade fenotípica da produção anual. 41

3.4. Variabilidade, coeficiente de determinação genotípica e progresso genético esperado na seleção para outros caracteres agronômị $\cos \ldots \ldots \ldots \ldots \ldots \ldots \ldots \ldots \ldots \ldots \ldots \ldots \ldots \ldots \ldots \ldots \ldots \ldots$

3.5. Correlações entre a produção total e as combinações de anos de produção ........

3.6. Correlação entre a produção total e outros caracteres agronômicos 
3.7. Seleção antecipada com base em caracteres agronômicos avaliáveis até o terceiro ano

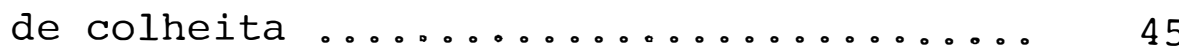

4. RESULTADOS ...................... 47

4.1. Análises como lātice retangular 8 x $9 \ldots 47$

4.2. Variabilidade, coeficiente de determinação genotípica e progresso genético esperado na seleção para o caráter produção .

4.3. Estabilidade fenotípica da produção anual

4.4. Variabilidade, coeficiente de determina ção genotípica e progresso genético esperado na seleção para outros caracteres a-

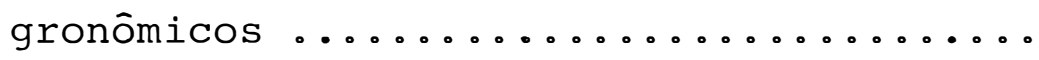

4.5. Correlações entre a produção total e as combinações de anos de produção .......

4.6. Correlações entre produção total e outros

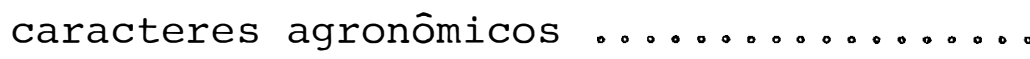

4.7. Seleção antecipada com base em caracteres agronômicos avaliáveis até o terceiro ano

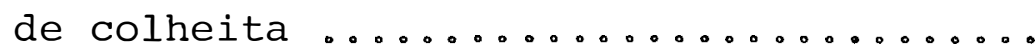

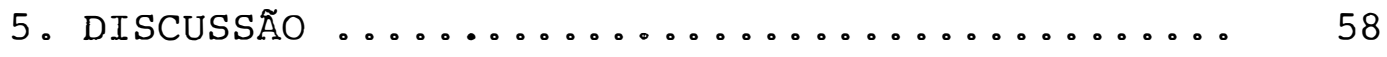

5.1. Análise como látice retangular $8 \times 9 \ldots 58$

5.2. Variabilidade, coeficiente de determina ção genotípica e progresso genético esperado na seleção para o caráter produção •

5.3. Estabilidade fenotípica da produção anual 
.vii。

pāgina

5.4. Variabilidade, coeficiente de determinação genotípica e progresso genético esperado na seleção para outros caracteres agronômi

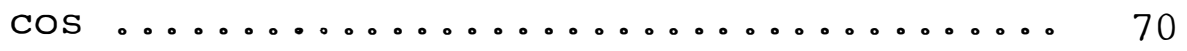

5.5. Correlações entre a produção total e as combinações de anos de produção ....... 73

5.6. Correlação entre a produção total e outros caracteres agronōmicos ............... 74

5.7. Seleção antecipada com base em caracteres agronômicos avaliāveis até o terceiro ano

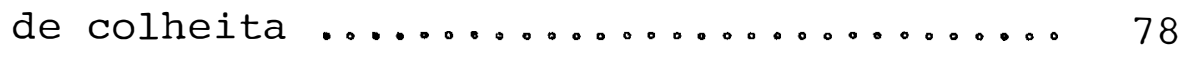

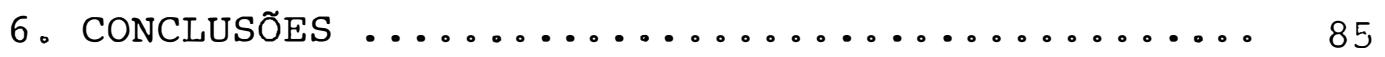

7. REFERENCIAS BIBLIOGRÁFICAS ............. 88

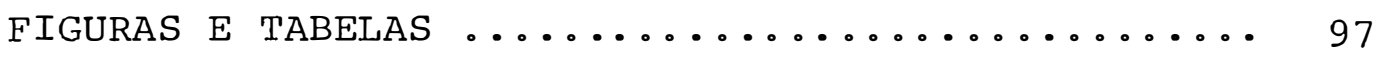




\title{
POSSIBILIDADE DE ERPREGO DE SELEÇÃO NAS COLHEITAS INICIAIS DE CAFE (Coffea arabica L。cv。 Acaiá)
}

\author{
Autor: TUMORU SERA \\ Orientador: Prof.Dr. NATAL ANTONIO VELLO
}

\section{RESUMO}

Esta pesquisa visa verificar a possibilida de de antecipar a seleção de plantas para produção de grãos para as colheitas iniciais de café lCoffea arabica L.). Avaliaram-se a produção die grãos por planta e outros caracteres agronômicos durante 1972-79 em 12 plantas (4 plantas/parcela x 3 repetições) de 72 progênies do cuI tivar Acaiá, provavelmente na geração $F_{5}{ } \mathrm{O}$ experimento foi conduzido pela Seção de Genética do Instituto Agronômico de Campinas, IAC, em Mococa, Estado de são Paulo, Brasil. Confirmou-se a adeguuação da análise da variância como parcelas sub-divididas no tempo de dados bienais de produção para superar o problema decorrente da acentuacia oscilação anual de produção e para isolar a componente de interação genótipo x biēnios ảe colheitas do efeito genótípico das prộ̣nies.Em razão da correlação não significa tiva e com tendência negativa entre os parâmetros predizi bilidade de comportamento produtivo (EBERHART \& RUSSEL, 1966) e a oscilação anual de produção, este último cará- 
ter deve ser empregaảo diretamente na seleção. A seleção antecipacia para produtividade pode basear-se nos seguintes caracteres avaliados nos três primeiros anos de colheita: produção, oscilação anual da produção, tamanho dos grãos, altura da copa, incremento anual da produção e diâmetro da copa. Para garantir que as p̣rogênies selecio nadas antecipadamente incluam as progênies realmente superiores em produção total é aconselhável utilizar intensidades de seleção mais brandas tanto entre como dentro de progênies. 


\title{
POSSIBILITY OF SELECTION BY USING INITIAL HARVESTS OF COFFEE (Coffea arabica L。cv. Acaiā)
}

\author{
Author: TUMORU SERA \\ Adviser: Prof.Dr. NATAL ANTONIO VELLO
}

\section{SURMARY}

This research aims to verify the possibility of anticipating the selection for grain yield to the inicial harvests of coffee (Coffea arabica L。). Grain yield per plant and other agronomic characters were evaluated during 1972-79 in 12 plants (4 plants/plot x 3 replications) of 72 progenies from the Acaiá cultivar, probably in $F_{5}$ generation. The experiment was carried out by the Genetic Section of "Instituto Agronômico de Campinas, IAC" at Mococa, State of São Paulo, Brazil. It was confirmed that the analysis scheme as split-plot in time using biennial data is appropriated to overcome the trouble originated from very high annual oscillation of yield and to isolate the interaction component genotypes $\mathrm{x}$ biennial yield from the genotypic effect of progenies. Because of not significative correlaction having negative tendency between the parameter predictability of behaviour (EBERHART \& RUSSEL, 1966) and the annual oscillation of production, this last trait should be used 
directly in selection. The anticipate selection can be based on following characters evaluated in the first three years of harvest: yield, height and diameter of canopy, grain size, increment and annual oscillation of yield. In order to assure that anticipatively selected progenies would includ those progenies actually superior in total yield it is advisable to use less intense selection both among and within progenies. 


\section{INTRODUCÃO}

A longevidade do cafeeiro (Coffea arabica L.) transpõe vinte ou mais anos de colheitas com valor econômico, dependendo dos tratos culturais dispensados . Um ciclo tão longo torna necessário um período experimental de vários anos consecutivos de avaliação da produção para se poder estimar o potencial produtivo total. Es te longo periodo experimental constitui-se na principal dificuldade para melhoramento da produtividade do cafeeiro.

Nas condições brasileiras, o cultivo do café é feito a pleno sol e sem poda programada, originando uma grande oscilação anual de produção e os ciclos bienais representam uma dificuldade adicional ao processo de seleção para produtividade. Apesar das dificuldades mencionadas, os programas de seleção executados em vārios centros de pesquisas tem levado a grandes progressos genéticos.

No Brasil, o melhoramento genético do cafeeiro iniciou-se em 1933 no Instituto Agronômico de Campinas; este programa tem resultado em cultivares notáveis como por exemplo,'Bourbon Vermelho','Bourbon Amarelo' e 'Mundo 
Novo'. Estes cultivares produzem respectivamente 21\%, $12 \%$ e $60 \%$ a mais do que os seus respectivos materiais originais sem seleção e 108\%, $147 \%$ e $240 \%$ a mais do que 'Arā bica', o primeiro cultivar plantado largamente no Brasil (FONSECA et aliii , 1978).

Em geral, a seleção para produtividade entre progênies de café tem exigido um período mínimo de nove anos, incluindo-se os três anos iniciais de crescimento vegetativo e seis anos de avaliação da produção de grãos. A seleção de plantas individuais,dentro de progênies, tem sido normalmente praticada após 12 anos de produção. Estes períodos podem ser menores nos casos de materiais mais variáveis ejou com maior precocidade de produção; todavia, para os materiais menos variáveis e/ou mais tardios, têm sido ampliados os períodos antes mencionados para a prática da seleção. Portanto, o tempo dispendido é muito longo, principalmente quando comparado com espécies anuais, como as de soja e de feijão, que permitem conduzir até três gerações por ano. Assim, para abreviar o tempo gasto para conduzir uma geração de seleção, há necessidade de se desenvolver critérios de seleção baseados na produção e outros caracteres agronômicos correlacionados com a produção nas primeiras colheitas.

Esta pesquisa tem por objetivo o estudo da produtividade e outros caracteres agronômicos, para se verificar a possibilidade de se reduzir o período envolvido em um ciclo de seleção de café, arábica. 


\section{REVISÃO DE LITERATURRA}

O cafeeiro é um arbusto perene, de origem tropical e cle granảe importância econômico-social para muitos paises que dependem primordialmente de suas exportações para obtenção de divisas. Sua popularidade como bebida pode ser atribuida às propriedades estimulantes e organolépticas que possui.

As plantas apresentam dois tipos de ramos, os ortotrópicos que quase não produzem frutos e os plagiotrópicos ou laterais,que são os ramos produtivos. Plantas inteiras podem ser obtidas somente a partir de ramos ortotrópicos.

Dentre as espēcies conhecidas, duas são amplamente cultivadas: Coffea arabica L. ou café arábica, que é de reprodução predominantemente autógama e a única tetraplóide, com 44 cromossomos somáticos e, c. camephora Pierre ou café robusta, que é alógama e diplóide. c. arabica é a que apresenta a melhor qualidade de bebida e é a mais cultivada no mundo e na quase totalidade da América Latina.

Segundo CANNEL (1985), existem basicamente 
duas regiões de cultivo de café arábica. A primeira, não equatorial, compreende o sul da India e o Centro Sul do Brasil, onde os cafeeiros seguem um único ciclo concentrado de crescimento vegetativo e frutificação. A segunda, região equatorial, compreende parte de Quênia e da Colômbia, onde os cafeeiros seguem dois ciclos de vegetação e frutificação.

O melhoramento genético do cafeeiro, especialmente para a produção, não tem sido fácil. Isto se deve à existência de um período juvenil, à necessidade de se avaliar vārios anos de produções consecutivas para se conhecer a capacidade produtiva a longo prazo e à existência da acentuada oscilação anual de proỏução onde o cafezal é conduzido a plero sol e sem poda. Apesar disso, os programas de seleçāio executados em vários centros de pesquisa tem levado a grandes progressos genéticos. No Brasil, segundo FONSECA et alii (1978), o programa de melhoramento iniciado em 1933 no Instituto Agronômico de Campinas resultou na obtenção de linhagens alta mente produtivas de 'Bourbon Vermelho', 'Bourbon Amarelo' e 'Mundo Novo', entre outros, que produzem respectivamente $108 \%, 147 \%$ e $240 \%$ a mais do que o primeiro cultivar in troduzido no Brasil, 'Arábica'.

Os métodos de melhoramento empregados no Brasil, consistem na seleção de plantas individuais seguida da avaliação de progênies, ou ainda de hibridação intra e interespecífica e seleção genealógiica (IEDINA et alii, 1984) • Em adição, 
o método de retrocruzamento tem sido aplicado para a'trans ferência de caracteres específicos, tais como internódios cur tos e resistência a pragas e doenças, presentes em outros cultivares ou em espécies relacionadas a c. arabica. A se leção de plantas individuais pode ser realizada tanto em uma plantação comercial, como em parcelas experimentais especialmente plantadas com o propósito de melhoramento. Neste último caso, a produção é registrada por vários anos sucessivos para a identificação de genótipos superiores.

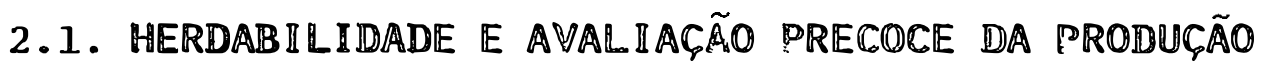

Em C. arabica., como para outras espécies, o caráter produção é altamente influenciado pelo ambiente. O efeito do arbiente sobre a produção foi avaliado por AN TUNES FILHO \& CARVALHO (1957) usanicio-se progênies de plan tas dihaplóides, duplicadas através da colchicina, linhas altamente endogâmicas e híbridos $\mathrm{F}_{1}$ entre elas. Neste es tudo, os fatores ambientais representaram de 23 a 56\% da variação observada.

O coeficiente de herdabilidade $\left(h^{2}\right)$ é um coeficiente que mede a proporção da variação fenotípica total, devida a causas genéticas ou herdáveis, o restante sendo devido a causas ambientais. Vários trabalhos foram realizados afim de estimar este coeficiente, usando diferentes materiais genéticos, em quantidades variáveis e em diversos locais. Os delineamentos experimentais e os esquemas de análise têm variado, bem como o número de re- 
petições, o número de plantas por parcela e o número de anos de colheitas empregados.

CORNIDE \& MONTES (1979), analisando os dados de um experimento de café, delineamento em blocos ao acaso, com quatro repetições e cinco plantas por parcela, co lhidas por quatro anos seguidos, estimaram os coeficientes de herdabilidade da produção no sentido amplo $\left(\mathrm{h}_{\mathrm{a}}^{2}\right)$ que foi de 0,014 para dezessete linhas de 'Caturra' e $\mathrm{h}_{\mathrm{a}}^{2}$ igual a zero para as linhas de outros cultivares.

SRINIVASAN et aliii (1979) usando dados'de cinco anos de colheitas de cultivares de $\mathbf{C}_{\text {o }}$ arabica pesquisados em três locais, com delineamento em blocos ao acaso, com cinco repetições e 30 plantas por parcela, isolaram o efeito da interação genōtipos $\mathrm{x}$ anos de colheitas, da variância genotí pica através do esquema de análise conjunta e obtiveram $\widehat{h}_{a}^{2}=0,57$ para um dos locais e $\widehat{h}_{a}^{2}=0,35$ para o outro 1o-。 cal. Eles observaram que as estimativas de $\mathrm{h}_{\mathrm{a}}^{2}$ foram mais altas em ambientes favoráveis à produção do que em ambien tes desfavoráveis à produção.

WALYARO \& VAN DER VOSSEN (1979) estimaram O . $\mathrm{h}_{\mathrm{a}}^{2}$, tanto para a média das progênies, como para as plantas individuais, em Quênia, para dezesseis cultivares avaliados por dez anos de colheitas em cinco repetições e oito plantas por parcela. Para o primeiro ano de colheita foi estimada $\mathrm{h}_{\mathrm{a}}^{2}=0,45$ ao nível de progênies e $\mathrm{h}_{\mathrm{a}}^{2}=0,17$ ao $\mathrm{n}$ íviel de plantas individuais. Quando estimadas para os biênios, cumulativamente, a $\hbar_{a}^{2}$ variou de 0,72 para 0 primeiro 
biênio a 0,81 para os cinco primeiros biênios ao nível de progênies. $O \mathrm{~h}_{\mathrm{a}}^{2}$ aumenta com $\mathrm{O}$ aumento do número de anos de colheitas, pois diminuem progressivamente os efeitos ambientais provocados pelos anos.

Usando-se 100 progênies de seis cultivares colhidas por seis anos em Campinas, em delineamento de blocos ao acaso com nove repetições e uma cova de quatro plantas por parcela, SERA (1980) estimou os coeficientes de determinação genotípica bienal $\left(\hat{b}_{\mathrm{p} 2}\right)$ semelhante $\bar{a} \hat{h}_{a}^{2}$. Foi isolado o efeito da interação de genótipos $\mathrm{x}$ biênios de colheitas do efeito genotípico através do esquema de análise em parcelas subdivididas no tempo em que se considera as produções bienais sobre a mesma parcela como subparcela. Foram obticos $\hat{\mathrm{b}}_{\mathrm{p} 2}=0,24$ para as quinze progênies de 'Mundo Novo', $\hat{\mathrm{b}}_{\mathrm{F}^{2}}=0,47$ para as treze progênies de 'Bourbon Amarelo', $\hat{b}_{\mathrm{p} 2}=0,60$ para as 51 progênies de 'Bourbon Vermelho', $\hat{b}_{\mathrm{p} 2}=0,38$ para as seis progênies de 'Caturra Amarelo' e 'Caturra Vermelho' e $\hat{b}_{p 2}$ nula para as quatro progênies de 'Arábica'. A proporção da influência genética sobre o fenótipo da progênie varia de acordo com a variabilidade genética presente no material, de 40\% para as progênies de 'Bourbon Vermelho' até Áfo\% para as progênies de 'Arábica'. A ausência de variabịlidade genética em 'Arábica' pode ser explicada pela sua origem restrita, conforme a história da migração de café pelo mundo, descrito por WELLMAN (1961). 
fase na seleção deve ser dada para a seleção tanto entre como dentro das progênies. CASTILHO-ZAPATA \& MORENO-RUIZ (1981) utilizando vinte progênies $\mathrm{F}_{3}$ do cruzamento 'Caturra' x 'Híbrido de Timor' no 1343, observadas na Colômbia durante quatro anos de colheitas, em duas repetições e parcelas de oito plantas estimaram $\mathrm{h}_{\mathrm{a}}^{2}=0,21$ quando se pratica a seleção entre as progênies e $\hat{\mathrm{h}}_{\mathrm{a}}^{2}=0,67$ quando se pratica a seleção entre e dentro das progênies.

Numa análise dialélica usando onze cultiva res nos cruzamentos, WALYARO (1983), estimou, para o primeiro ano de colheita, $\mathrm{h}_{\mathrm{a}}^{2}=0,10$, quando baseado em plantas individuais e $\mathrm{h}_{\mathrm{a}}^{2}=0,2 \mathrm{~g}$, quando baseado em média da parcela de quatro plantas.

Do que foi exposto, verifica-se que o valor da estimativa do coeficiente de herdabilidade depende do material genẹtico, dos locais, dos anos de colheitas, do número de repetições e do número de plantas por parcela, entre outros fatores. Em resumo, $\hat{\mathrm{h}}^{2}$ depende da variabilidade do material genético e da diminuição dos efeitos dos fatores ambientais, isto é, são específicos do material genético e do experimento. De um modo geral, verifica-se que dependendo destes fatores, pode-se chegar a $\mathrm{h}_{\mathrm{a}}^{2}$ tão altas como 0,81 para dez anos de colheitas ao nível de progênies e $\hat{\mathrm{h}}_{\mathrm{a}}^{2}=0,00$ para cicterminacos materiais, também ao nível de progênies. 
As flutuações anuais de produção que ocorrem em cada planta de café, especialmente em plantações brasileiras estabelecidas sem sombra e sem podas programadas são conhecidas de longa data e os seus efeitos dificultam a seleção. Segundo FAZUOLI (1977) e CARVALHO et alii (1984), as seleções de plantas individuais devem ser feitas em anos de altas produções porque neste caso, o potencial produtivo destas plantas superiores podem ser completamente realizados e, com j.sso, estas plantas podem ser mais facilmente identificadas no campo.

Segundo MEDINA et alii (1984), as primeiras floradas do cafeeiro arábico ocorrem durante o terceiro ano, mas produções máximas são atingidas somente entre o 119 e 149 ano de produção. Desde que a vida econômica da cultura transpõe vinte ou mais anos, este aspecto tem de ser levado em conta quando as seleções são feitas. Um cultivar bem sucedido deve começar a produzir cedo e manter produções altas nos anos subsequentes. Embora uma avaliação segura do comportamento produtivo possa ser obtida somente após muitos anos, um programa de melhoramento dinâmico não pode adotar tal procedimento altamente consumidor de tempo. Estudos de correlações entre anos cumulativos de produção (até dezenove anos) realizados por CARVALHO (1952), FAZUOLI (1977) e CARVALHO et alii (1985) têm indicado que as melhores progênies após mais de dezessete anos de colheitas poderiam ter sido escolhidas com base nas seis primeiras produ- 
ções consecutivas. Segundo MEDINA et alii (1984) durante os primeiros quatro anos, $29 \%$ das melhores plantas individuais e 52\% das melhores progênies seriam identificadas. Estes estudos têm sido de fundamental importância na aceleração do programa de melhoramento do cafeeiro e esta estratégia vem sendo usada rotineiramente no Brasil.

Este prazo médio pode ser alcançado ou encurtado de acordo com a variabilı̀dade genética presente no material em seleção, desde que este material não apresente o problema de senescência precoce (como ocorre com o 'Caturra') e nem manifestação tardia da produção (como ocorre com o 'Mundo Novo' no Brasil). WALYARO \& VAN DER VOSSEN (1979) estimaram,para a média de oito plantas por parcela, de dezesseis varieäades em Quênia, $\hat{h}_{a}^{2}=0,45$ para o primeiro ano de colheita, $\hat{\mathrm{h}}_{\mathrm{a}}^{2}=0,72$ para $\mathrm{O}$ primeiro biênio de colheitas e $\hat{\mathrm{h}}_{\mathrm{a}}^{2}=0,81$ para dez anos de colheitas; obtiveram um coeficiente de correlação de 0,82** entre o primeiro biênio e o total de dez anos de colheitas e concluiram que apenas dois anos (um biênio) seriam suficientes para avaliar o valor das variedades. SERA (1980) estimou os coeficientes de determinação genotípica bienal ( $\left.b_{p 2}\right)$ para um, dois, três e dez biênios ou dois, quatro, seıs e vinte anos de colheitas, respectivamente, em: 0,$13 ; 0,20 ; 0,24$ e 0,34 para as quinze progênies de 'Mundo Novo', 0,34; 0,42; 0,47 e 0,54 para as treze progênies de 'Bourbon Amarelo'; 0,43; 0,54; 0,60 e 0,70 para as 51 progênies de 'Bourbon Vermelho'. Em cultivo som- 
breado na India, SRINIVASAN (1982) avaliou por três anos de colheita quatro progênies $\mathrm{F}_{4}$ em um experimento com oito repetições; a parcela compreendeu 36 plantas para três progênies de porte alto e 119 plantas para uma única progênie de porte baixo; estimaram-se coeficientes de herdabilidade atravēs da regressão $\mathrm{F}_{3}-\mathrm{F}_{4}$ entre progênies em 0,55 para o primeiro ano, 0,64 para a média dos dois primeiros anos e 0,68 para a média dos três primeiros anos. Assim, quando se estimam as herdabilidades com base em número crescente de anos ou biênios, elas aumentam muito no começo e os incrementos diminuem progressivamente com mais anos de observações. Isto ocorre por causa da diminuição progressiva dos efeitos ambientais devidos aos anos ou biênios de colheitas na variância fenotípica. Desta maneira, para os cultivares que apresentam herdabilidades maiores já no primeiro biênio de colheitas, como é o caso de 'Bourbon Vermelho' com $\mathrm{b}_{\overline{\mathrm{p}} 2}=0,43$, seriam suficientes apenas um ou dois biênios para se praticar a seleção. Entretanto, quando as herdabilidades são baixas, como no caso do 'Mundo Novo' com $\mathrm{b}_{\bar{p} 2}=0,13$ seriam necessáriós três ou mesmo quatro biênios para se praticar a seleção entre as progênies.

\subsection{FISIOLOGIA DA PRODUÇÃO E CARACTERES CORRELACIONA- DOS COM A PRODUÇÃO}


cafeeiros são o resultado da ação dos diferentes fatores ambientais em sucessivos anos sobre a mesma planta com seus vários determinantes fisiológicos da produção. Segundo CANNELL (1975), os fatores que controlam a produção são aqueles que afetam (a) o tamanho da área foliar disponível para absorção da luz e $\mathrm{CO}_{2}$ (b) a taxa de aproveitamento do $\mathrm{CO}_{2}$ por unidade de área foliar e (c) a distribuição da matéria seca entre as sementes e as outras partes do arbusto. Um cafeeiro eficiente é aquele que produz folhagem extensa, bem iluminada, possui alta taxa de fotossintese líquida, produz muitas sementes e aloca grande quantidade de carbohidratos ano após ano. É vantajoso que os ramos localizados na parte superior da planta sejam mais eretos e que os arbustos tenham formas mais cônicas. Estas características produzem uma copa em que a maioria das folhas recebem sombras moderadas e permitem que as radiações do calor sejam dispersas sobre grandes áreas da folhagem. Isto é particularmente importante para plantas adaptadas à sombra como o cafeeiro, porque as suas folhas fotossintetizam mais rapidamente em sombra moderada do que em pleno sol. CANNELL (1985), também relata que a produção de café pode ser decomposta pro gressivamente da seguinte maneira:

Produção/ha = No de cafeeiros/ha $\times$ Produção de grãos/cafeeiro

Produção de grãos/cafeeiro = No de frutos/cafeeiro $\mathrm{x}$ peso dos grãos/fruto 
No de frutos/cafeeiro = No de nós frutíferos/cafeeiro $\mathrm{x}$ No de frutos/nó

Peso de grãos/fruto = Peso do fruto $x$ (peso dos grãos/ peso do fruto)

o aumento do número de cafeeiros/ha diminui a produção de grãos/cafeeiro porque aumenta o sombreamento mútuo e diminui a porcentagem de nós com flores, o número de inflorescência/nó e o número de flores/ inflorescência. A taxa de pegamento de frutos varia de 20 a $80 \%$, de acordo com diversos fatores ambientais e com o tamanho da florada. Assim mesmo, o cafeeiro é capaz de viabilizar muito mais frutus do que é possível sustentar pelo aparato fotossintético, levando à superprodução: Esta superprodução provoca o depauperamento nutricional das folhas, ramos e raỉzes e,em consequência, a produção do ano seguinte é reduzida. Assim, tem origem uma acentuada oscilação anual de produção e o ciclo bienal de produção de café. O conhecimento do processo fisiológico da produção ajuda a compreender e selecionar melhor para este carāter.

Neste aspecto, a identificação de caracteres correlacionados com a produção, bem como a estimação do grau de correlação existente pode auxiliar muito na seleção mais eficiente, atravēs da seleção indireta para o caráter principal. Vários trabalhos têm indicacio e/ou estimado correlações entre diversos caracteres e a produ- 
ção.

As relações entre a produção e os caracteres do sistema radicular têm sido relatadas nos trabalhos de MONACO et alii (1973), RAMOS (1980) e RAMOS et alii (1982). Os cultivares mais produtivos apresentam sistema radicular mais desenvolvido e com valores superio res da relação sistema radicular/parte aérea.

Estabeleceram-se relações entre caracteres de sementes (e frutos) e a produção (MONACO, 1952; CARVALHO et alii, 1961; CARVALHO et alii, 1964; CARVALHO \& MONACO, 1967; FAZUOLI, 1977). As progênies selecionadas para maior produção têm menor porcentual de sementes moca e concha (frutos mono e poliembriônicos), maior porcentual de sementes de tipo chato, maior tamanho de sementes do tipo chato, maior rendimento ('produção beneficiada/cereja), maior peso de 1000 sementes e maior densidade das sementes. Foi estimada uma correlaçao de 0,64* entre o peso de 1000 sementes e a densidade e $r=0,79 *$ entre o tamanho e o peso de 1000 sementes. Contudo, segundo FAZUOLI (1977), a correlação entre a produção e o tamanho das sementes tem sido variável, de acordo com o material genético e o ano de produção, pois existem correlações negativas e significativas em alguns anos e em alguns materiais e correlações não significativas em outros anos e em outros materiais; por isso as correlações devem ser avaliadas sobre as médias de vários 
anos. FAZUOLI (1977) verificoụ que vărias das plantas mais produtivas tem, também, elevado peso das sementes, apesar de $r=0,37$ não ser significativo. Entre 0 peso e o tamanho das sementes foi encontrada uma correlação de $r=0,62^{* *}$. Entre a densidade real e o tamanho da semente estimou-se $r=0,14$ n.s.; entre a densidade real e o peso de 1.000 sementes, $r=0,19$ n.s. MONACO (1952) e CARVALHO \& MONACO (1967) observaram que as plantas que apresentam maiores porcentagens de frutos chochos (frutos com uma ou duas lojas vazias) e que têm rendimento menor, em consequência disto, produzem menos café beneficiado. Notaram, também, uma porcentagem um pouco mais elevada de grãos concha nas populações que encerram maior porcentagem de frutos chochos. ROCHA et alii (1980) conjecturaram que o rendimento menor, pode ser fator indicativo de que a planta apresenta elevada quantidade de sementes moca, pericarpo espesso e peso reduzido de sementes, além de certa quantidade de frutos cho'chos.

O vigor vegetativo é uma das características mais importantes relacionadas com a produção. Em experimento com cultivares e seus híbridos, CARVALHO et aliili (1959) observaram que várias progênies mais produtivas também mostraram-se mais vigorosas, reforçando o acerto da prática de seleção de plantas matrizes de alta produção aliada a um bom aspecto vegetativo. O aspecto vegetativo de um ano reflete o índice de produção do ano se- 
guinte. Esta observação foi confirmada por outros trabalhos de CARVALHO et alii (1961), CARVALHO et alii (1964), CARVALHO \& MONACO (1967), FAZUOLI (1977), CARVALHO et alii ( 1979) e CARVALHO et alii (1984). Os coeficientes de correlação estimados entre o vigor vegetativo e a produção foram de $r=0,97 * *$ para as progênies de 'Mundo Novo' (FAZUOLI, 1977) e $\dot{x}=0,49 *$ para as progênies de 'Catuaí' (CARVALHO et alii 1979).

Outra característica vegetativa que frequentemente apresenta associação com a produção é o porte da planta, expresso pela altura e diâmetro da copa. Isto foi observado por CARVALHO et alii (1959), CARVALHO et alii (1961), CARVALHO et alii (1964), CARVALHO \& MONACO (1967), DHALIWAL (1968), ROCHA et alii (1980), SRINIVASAN \& VISHVESHWARA (1981) e VAN DER VOSSEN (1985). OS coeficientes de correlação estimados para a altura da copa foram de $r=0,22$ ns a $0,42 *$ em amostras de vários cul tivares (DHALIVAL, 1968) e $r=0,58 * *$ (ROCHA et alii, 1980); para o diâmetro da copa foram obtidos valores de $r$ $=0,04 \mathrm{~ns}$ a $0,67 \%$ em amostras de vários cultivares (DHALI WAL, 1968) $r=0,51 * *$ (ROCHA et alii, 1980) e $r=0,73 * *$ (SRINIVASAN \& VISHVESHWARA, 1981).

Diversas outras características vegetativas têm sido estudadas, relativas à relação existente entre elas e a produçao. DHALIWAL (1968) encontrou correlações entre a produção e diversos caracteres em amostras de várias cultivares: $r=$ $0,26^{*}$ a $0,71^{* *}$ para 0 diâmetro do tronco; $r=0,16 \mathrm{~ns}$ a $0,52^{* *}$ para o com 
primento do ramo plagiotrópico mais comprido e $r=0,08$ n.s. a 0,50** para o número de nós por ramo plagiotrópico primário mais longo. VALENCIA A. (1973) verificou valores altos e positivos de coeficientes de correlação entre a produção e os caracteres área foliar e indice de área foliar (IAF). Através da equação de regressão quadrática estimou que o melhor IAF, entre zero e dez, para atingir a melhor produtividade/ha seria oito, alcançado na Colômbia com o cultivar Caturra, aos três anos de semeadura,com uma densidade de 10.000 plantas/ha e, aos quatro anos com 5.000 plantas/ha. SRINIVASAN (1980) estimou os seguintes respectivos coeficientes de correlação entre diversos caracteres e a produção,para cultivares de porte alto e baixo e para cultivares de porte alto de $r=0,09$ n.s. a $r=0,13$ n.s. para o número de plagiotrópicos, $r=0,42 \mathrm{n} . \mathrm{s}$. e $r=0,69 * *$ para $\circ$ comprimento do plagiotrópico mais longo, $r=0,00$ n.s. e $r=0,38$ n.s. para o número de nós sobre o plagiotrópico mais longo, ' $r=0,46 *$ e $r=0,52 *$ para $\circ$ comprimento internodal sobre ○ plagiotrópico mais longo e $r=0,55 *$ e $r=0,51 *$ para o diâmetro do tronco. SRINIVASAN \& VISHESHWARA (1981), na sua pesquisa com uma coleção de 246 genótipos de C. arabica, da coleção mundial estabelecida no Central Coffee Research Institute (India), estimaram coeficientes de correlação entre diversos caracteres e a produção de $r=0,65^{* *}$ para o ângulo de inserção de ramos plagiotrópicos sobre ortotrópicos, $r=0,60 * *$ para 0 comprimento internodal e $r=$ $0,24 *$ para o tamanho da folha. Trabalhando com C. cane- 
phora, MAWARDI \& HARTOBUTOYO (1981) tem estimado correlações entre diversos caracteres e a produção de $r=0,25$ n.s. para o comprimento médio do plagiotrópico produzindo, $r=0,42 * *$ para o número médio de nós por plagiotrópico, $r=0,13$ n.s. para o comprimento internodal do plagiotrópico e $r=0,20$ n.s. para comprimento médio dos plagiotrōpicos.

Um outro grupo de características bastante relacionadas com a produção é o que se refere à quantidade de flores e frutos. MEDINA et alii (1984) indicaram que, quando se comparam cultivares de alta produtividade com o cultivar Arábica e introduções semi-selvagens da Etiópia, nota-se nos cultivares selecionados maior nūmero de flores por inflorescëncia e maior número de inflorescências por axila foliar. MAWARDI \& HARTOBUTOYO (1981) estimaran os coeficientes de correlação para híbridos de $\mathbb{C}$. canephora de $r=0,66 * *$ para o número médio de frutos/nó e a proủução e $r=0,59 *$ * para o número médio de frutos/ramo e a produção. SRINIVASAN . \& VISHVESHWARA (1981) avaliando na India 246 genótipos de c. arabica da coleção mundial, encontraram $r=0,40 * *$ para flores por inflorescência e a produção.

Um período longo entre o florescimento e a maturação dos frutos é uma importante característica para seleções mais produtivas, pois a planta tem um período maior de tempo para suprir os frutos com produtos da fotossintese, podendo assim, resultar em maior produção. 
SRINIVASAN \& VISHVENSHWARA (1981) têm encontrado $r=0,32^{\text {** }}$ entre a produção e o período de amadurecimento.

Considera-se que um cultivar tem um bom nível de adaptabilidade, quando o seu comportamento em uma série de ambientes,é estável e a sua produção média é elevada. CARVALHO \& MONACO (1967) e FAZUOLI (1977) observaram que, em geral, existe em Campinas maior oscilação anual de produção, isto é, menor estabilidade anual de produção, nas plantas mais produtivas. CASTILLOZAPATA \& MORENO-RUIZ (1981), avaliando sete progênies $F_{3}$ durante três colheitas em três localidades de Colômbia, conseguiram, através do método de análise de estabilidade fenotípica de Wricke, identificar genótipos mais estáveis; estimaram o coeficiente de correlação de Spearman em $r_{\mathbf{s}}=$ 0,68**; portanto, quanto mais estável o genótipo for, em diferentes locais, maior será a produtividade. MORENORUIZ et alii (1984), estudando a estabilidade fenotípica em cinco localidades da Colômbia, sobre dados obtidos por três anos de colheitas para dezesseis progênies $F_{4}$, encontraram uma associação positiva e significativa entre a produção e o coeficiente de regressão b de estabilidade fenotípica de WRICKE de $r=0,62$, enquanto que para os parâmetros de estabilidade $\mathrm{Vg}_{i}, \mathrm{E}_{j}$ e $\mathrm{Vd}_{i}$ não encontraram nenhuma associação. SRINIVASAN \& SUBBALAKSHMI (1981) estudando 25 progênies de $\mathbf{C}$. arabica e 34 de $\mathbb{C}_{\text {o canephora }}$ altamente produtivas na India, observaram que o coeficiente de va riação sobre os anos de produção das progênies variava de 
30,6 a 95,6\%, aparentemente sem relação com a produtividade. No Brasil, MATIELLO et allii (1985) observaram que o 'Catuaí' é mais estável que 'Mundo Novo', conforme dados obtidos a partir do coeficiente de variação sobre os anos de colheitas.

Nem sempre os máximos e os mínimos para cada caráter correlacionado isoladamente resultarão em maiores produções. Assim, VALENCIA A. (1973) encontrou que apesar de O IAF (de 0 a 10 ) possuir uma correlação alta e positiva com a produção, a melhor produtividade/ha seria alcançada com IAF $=8$. Da mesma forma, SRINIVASAN \& VISHVESHWARA (1981) notaram que as plantas ou os cultivares com valores intermediários de ângulo de ramificação, comprimento de internódios, tamanho de folhas, tamanho de frutos e tamanho de sementes, também tinham, em geral, produções médias maiores para 246 genótipos de c. arabica da coleção mundial de India.

Assim, constata-se que muitos caracteres estão altamente correlacionados com a produção, restando verificar a herdabilidade destes caracteres.

\subsection{HERDABILIDADE DOS CARACTERES CORRELACIONADOS COM A PRODUÇÃO}

A magnitude da resposta indireta provocada na produção pela prática de seleção sobre um segundo ca- 
ráter é diretamente proporcional aos valores da correlação genética entre os dois caracteres e da herdabilidade do caráter.

Estimando o coeficiente de regressão da média de progênies $F_{3}$ sobre os valores das plantas $F_{2}$ parentais, VISHVESHWARA \& SRINIVASAN (1977), obtiveram herdabilidade moderada de 0,42 para o caráter número de flores por inflorescência em segregantes do cruzamento C. canephora x C. arabica.

Estudando as progênies $F_{1}, F_{2}$ e RC para C. canephora do cruzamento C. congensis x C. canephora, AHMAD et alii (1977) estimaram os coeficientes de correlação parental - descendência como uma medida de herdabilidade com $r=0,33$ para flores por nó, $r=0,24$ para inflorescência por nó e $r=0,10$ para flores por inflorescência.

Em um cruzamento dialélico $10 \times 10 \quad \mathrm{com}$ quatro blocos e cinco plantas/parcela, TOSTAIN \& LE PIERRES (1978), estimaram, na Costa do Marfim os coefi- cientes de herdabilidade para as introduções de C. arabica da Etiópia : $\hat{\mathrm{h}}^{2}=0,20$ para o diâmetro do tronco, $\hat{\mathrm{h}}^{2}=0,73$ para $\mathrm{o}$ número de nós por tronco contados a partir do ápice e $\hat{h}^{2}=0,50$ para o quociente do diâmetro basal/comprimento total do sétimo par de ramo plagiotrópico.

CORNIDE \& MONTES (1979) usando dados de produção de quatro anos, obtidos em Cuba, num delineamento 
em' blocos ao acaso com quatro repetições e cinco plantas/ parcela, estimaram coeficientes de herdabilidade no sentido amplo para o caráter altura da planta: $\hat{h}_{a}^{2}=0,20$ para dezessete linhas de 'Caturra' e $\hat{h}_{a}^{2}=0,02$ para as 25 linhas de outras cultivares.

REDDY \& SRINIVASAN (1979), avaliando dezesseis variedades exóticas na India, durante dois anos, em cinco plantas, de cada variedade, estimaram os coeficientes de herdabilidade no sentido amplo de $\hat{h}_{a}^{2}=0,91$ para $\circ$ número total de flores, $\hat{h}_{a}^{2}=0,24$ para porcentagem de nôs florescendo, $\hat{\mathrm{h}}_{\mathrm{a}}^{2}=0,53$ para número de flores/nó, $\hat{\mathrm{h}}_{\mathrm{a}}^{2}=0,00$ para o pegamento inicial dos frutos; $\hat{h}_{a}^{2}=0,16$ para pegamento final dos frutos e $\hat{h}_{a}^{2}=0,20$ para a porcentagem de queda dos frutos.

Trabalhando com onze caracteres correlacionados com a produção, aos 12 anos, sobre dezesseis cultivares de C. arabica obtidos em Quênia, em parcela de oito plantas e com cinco repetições, WALYARO \& VAN DER VOSSEN (1979) estimaram $h_{a}^{2}$ com base na média da parcela e em plantas individuais, respectivamente: 0,28 e 0,13 para a altura da planta; 0,65 e 0,35 para o diâmetro do tronco; 0,31 e 0,08 para o número de ramos plagiotrópicos primários por tronco; 0,44 e 0,20 para a porcentagem de plagiotrópicos primários produzindo; 0,48 e 0,21 para ? raio da copa (comprimento do plagiotrópico primário mais longo); 0,22 e 0,08 para o número médio de frutos por nó; 0,45 e 0,20 para a extensão do crescimento num período de 
sete meses; 0,28 e 0,10 para o nümero de inflorescências por nó; 0,28 e 0,1l para o número de flores por inflorescência; 0,54 e 0,17 para a porcentagem de pegamento dos frutos.

CASTILLO-ZAPATA \& MORENO-RUIZ (1981) utilizando dezesseis progênies $F_{3}$ do cruzamento 'Caturra' $\mathrm{x}$ 'Hỉbrido de Timor' em um experimento com duas repetições e oito plantas/parcela, aos 40 meses de idade, estimaram $\mathrm{h}_{\mathrm{a}}^{2}$, respectivamente, ao nivel de progênies e ao nivel de plantas individuais: 0,65 e 0,31 para o número de pares de plagiotrópicos; 0,42 e 0,21 para a altura das plantas; 0,58 e 0,28 para o diâmetro das plantas; 0,30 e 0,10 para o vigor vegetativo. Para os caracteres de sementes, obtiveram estimativas ao nivel de progênies de 0,51 para a porcentagem de frutos chochos, $\hat{\mathrm{h}}_{\mathrm{a}}^{2}=0,47$ para sementes moca e $\hbar_{a}^{2}=0,39$ para sementes maiores que a peneira de malha 17/64 polegadas; a tendência de valores relativamen te altos de herdabilidade foi confirmada pela correlação entre as progênies $\mathrm{F}_{3}$ e respectivas plantas-mães para por centagem de frutos chochos $(r=0,89 * *)$ e para sementes

tipo moca $(r=0,69 * *)$.

$$
\text { SRINIVASAN (1982) estimou } \mathrm{h}_{\mathrm{a}}^{2} \text { de quatro }
$$
progênies $\mathrm{F}_{4}$ em experimento com oito repetições, 36 plantas/parcela para três progênies de porte alto e 119 plantas para a progênie de porte baixo, durante três colheitas. Ao nível de médias de parcelas, os coeficientes estimados foram: $\hat{h}_{a}^{2}=0,43$ para o diâmetro do tronco; $\hat{h}_{a}^{2}=$ 
0,85 para o número de ramos plagiotrópicos primários; $\hat{\mathrm{h}}_{\mathrm{a}}^{2}=0,90$ para o comprimento do ramo plagiotrópico mais longo; $\hat{h}_{a}^{2}=0,30$ para o número de nós sobre o ramo plagiotrópico primário mais longo e $\hat{h}_{a}^{2}=0,90$ para o comprimento internodal sobre o plagiotrópico mais longo.

WALYARO (1983), trabalhando com onze culti vares de C. arabica num cruzamento dialélico estimou $\mathrm{h}_{\mathrm{a}}^{2}$ para vários caracteres. Estimou as $\mathrm{h}_{\mathrm{a}}^{2}$ 's ao nivel de médias de parcelas de quatro plantas e para plantas individuais, respectivamente; 0,64 e 0,31 para o diâmetro do tronco; 0,70 e 0,37 para a altura das plantas; 0,65 e 0,31 para o diâmetro da copa; 0,74 e 0,42 para o comprimento internodal; 0,68 e 0,28 para o ângulo do ramo plagiotrópico primário sobre o ortotrópico; 0,39 e 0,14 para a porcentagem de plagiotrópicos primärios em fase de produção; 0,23 e 0,07 para a porcentagem de nós produtivos; 0,10 e 0,03 para o número de flores por nó; 0,22 e 0,06 para número de frutos por nó; 0,74 e 0,41 para o peso de 100 sementes; 0,64 e 0,35 para a porcentagem de sementes moca; 0,70 e 0,36 para a porcentagem de sementes pesadas retidas na peneira dezoito; 0,64 e 0,31 para a porcentagem de sementes pesadas retidas na peneira quinze; 0,25 e 0,08 para a porcentagem de sementes leves; 0,73 e 0,40 para a porcentagem de sementes reticas na peneira com malha $2,90 \mathrm{~mm}$. 
CASTILLO-ZAPATA (1984), analisando seis

progênies $F_{2}$, quatorze $F_{3}$ e dezoito $F_{4}$ avaliadas em três locais e durante cinco anos de colheitas (em oito, nove ou dez plantas/local) estimou $\hat{\mathrm{h}}^{2}=0,30$ para a porcentagem de grãos moca e $\hat{\mathrm{h}}^{2}=0,50$ para a porcentagem de frutos chochos, através da correlação progenitor-progênie.

Assim, verifica-se que diversos caracteres altamente correlacionados com a produção, como vigor vegetativo, diâmetro do tronco, altura da copa, diâmetro da copa, número de flores/nó, número de nós, números de plagiotrópicos primários, etc, podem ter também, herdabilidades relativamente altas, podendo ser usados na seleção indireta para a produção.

\section{4. ÍNDICE DE SELEÇÃO PARA PRODUÇÃO}

Na prática de seleção para produção, geralmente os melhoristas usam um critério subjetivo pelo mérito global da planta, incluindo-se os caracteres relacionados com a procução e a produção inicial obtidas; tais caracteres recebem índices ou pontos atribuidos subjetivamente. Outras alternativas incluem a seleção em tandem (seleção de um cạ ráter por. vez) e o índice de seleção. Embora seja a metodologia estatisticamente mais trabalhosa, o indice de seleção tem sido o procedimento mais eficiente de seleção (TORRES, 1985). Para os melhoristas experientes talvez não haja necessidade de indice estatístico de seleção, 
pois eles podem ter ínảices empíricos, mas para principiantes é de grande utilidade. Além disso, ela pode auxiliar na identificação antecipada de genótipos superiores com maior precisão.

Trabalhando com dezesseis amostras dos cultiva res Puerto Rican e Columnalis de C.arabica estudadas em três locais com 50\% de sombreamento, DHALIWAL (1968) realizou anālise de correlação múltipla para medir o efeito combinado dos caracteres das árvores para explicar a variação na produção. Para o cultivar Puerto Rican, os caracteres 1 (diâmetro do tronco), 4 (diâmetro da copa), 5 (comprimento do plagiotrópico mais longo), 7 (número de nós no plagiotrópico) e 2 (número de plagiotrópicos) explicam significativamente de 39,53 a 54,56\% da variação na produção; os caracteres 1, 4, 5, 7 e 3 (altura da planta) explicam significativamente de 35,86 a 58,63\% da variação na produção.. Para o cultivar Columnalis, os caracteres 1, 3, 4 e 6 (número de ramos plagiotrópicos secundários) e 5 explicam,significativamente, de 34,48 a 60,23\% da variação na produção; os caracteres 1, 3, 4, 6 e 7 explicam de 34,43 a 60,01\% da variação na produção. Estes caracteres são úteis na seleção de plantas individuais de cafeeiros de plantios suficientemente adultos em plena produção e em ambiente uniforme. Nos dois cultivares, as plantas individuais altamente produtivas caracterizam-se pelo maior diâmetro do tronco e da copa. 
rimento, sem sombreamento, com quatro repetições e oito plantas por parcela, durante dez anos de colheitas, em Quênia, WALYARO \& VAN DER VOSSEN (1979) estimaram os indices de seleção e avanço genético esperado na seleção, usando as primeiras produções e caracteristicas correlacionadas com a produção. Eles estimaram a eficiência relativa entre a seleção praticada com base em dez anos de produção (100\%) e a seleção praticada usando-se as primeiras produções e caracteres altamente correlacionados, altamente herdáveis e fáceis de avaliar. Selecionadas isoladamente, as eficiências relativas seriam de $64 \%$ para o diâmetro do tronco, 64\% para a porcentagem de ramos plagiotrópicos primários produtivos, 50\% para o comprimento médio do plagiotrópico primário mais longo e 89\% para as duas primeiras produções (10 biênio). Selecionando-se conjuntamente, a melhor eficiência alcançada foi de 97\% para a combinação dos caracteres diâmetro do tronco, porcentagem de plagiotrópicos primários produtivos e a produção do primeiro biênio. Os caracteres correlacionados com a produção foram tomados no ano da $11^{\mathrm{a}}$ e $12^{\mathrm{a}}$. produção. Assim, a seleção poderia ter sido praticada com eficiência semelhante a dez anos de colheitas, utilizando-se apenas as duas primeiras produções mais alguns caracteres correlacionados, economizando-se oito anos de observações.

Na India, SRINIVASAN (1980) estimou os pesos relativos dos caracteres correlacionados com a primeira produção através da análise de caminhamento. Os 
caracteres número de plagiotrópicos primários, comprimento do plagiotrópico primário maior, nós sobre plagiotrópico primário maior, comprimento internodal sobre plagiotrópico primário maior e o diâmetro do tronco:responderam por cerca de $74 \%$ da variação da primeira produção; os restantes $26 \%$ da variação não foram explicados pelos fatores considerados na pesquisa.

Através do uso da análise de caminhamento sobre uma população $F_{1}$ de $\mathbb{C}$. canephora, conduzido na Indonésia,por cinco anos, MAWARDI \& HARTOBUTOYO (1981) estimaram os valores diretos e indiretos dos caracteres correlacionados com a produção total de cinco anos. A primeira produção dā um efeito direto de 61\%. Os efeitos indiretos mais importantes encontrados foram de $88 \%$ para o número de nós por plagiotrópicos primário, 68\% para o número de frutos por plagiotrópico, 41\% para o comprimento do plagiotrópico, 9\% para peso de 100 frutos e 8\% para comprimento internodal.

SRINIVASAN (1982), usando três anos de produção em experimento com três cultivares altos e um baixo, oito repetições e 34 plantas por parcela, estimou a eficiência relativa de seleções efetuadas com base em caracteres morfológicos em relação à seleção efetuada apenas baseada na produção (100\%). Os caracteres correlacionados incluídos nos indices foram: 1 (número de plagiotrópicos primários), 2 (comprimento do primário maior), 3 (número de nós no primário maior), 4 (comprimento in- 
ternodal) e 5 (diâmetro do tronco). Eficiências maiores do que a seleção baseada somente sobre a produção foram obtidas consistentemente, para os indices baseados sobre os cinco caracteres (116\% para o primeiro ano, 119\% para a média dos dois primeiros anos e 117\% para a média de três produções), bem como para quatro caracteres (116\%, $118 \%$ e 117\%, respectivamente) e para três caracteres (115\%, 117\% e 115\%, respectivamente). Também se mostraram, eficientes os índices baseados: em dois caracteres na primeira produção (103\%); na média de três produções (104\%); e índice de apenas um caráter pela média de três anos com 98\% (número de plagiotrópicos primários). o melhor Indice do ponto de vista prático para realizar uma pré-seleção para produção (sem medir a produção) é aquela baseada em número de ramos primários plagiotrópicos, comprimento do primário mais longo e número de nós sobre o primário mais longo que podem ser usados para classificar parcelas de plantas jovens de cafeeiro por seu crescimento relativo.

Usando-se critērios subjetivos de vigor vegetativo e carga pendente (produção esperada) conjuntamente, resultando em notas, ARAUJO NETTO (1979) realizou pré-seleção das melhores plantas quanto a este aspecto e observou uma concordância geral entre notas altas e produções elevadas; obteve correlações de até 80\% para combinações de: notas altas e produções elevadas, vigor vegetativo e produção. 
Assim, constata-se que o uso de indice de seleção em café é eficiente na seleção e seleção antecipada para produção.

\subsection{ORIGEM DO CULTIVAR ACAIÁ}

Na língua Tupi-Guarani o nome Acaiá significa frutos com sementes grandes, o que o caracteriza. A origem do cultivar Acaiá de Co arabịca tem íntima relação com a cultivar Mundo Novo, por terem origens comuns.Segun do CARVALHO et aliii (1952), FAZUOLI et aliii (1977), ROCHA et alii (1980) e IAC (1980), foi encontrada em 1943, no antigo município de Mundo Novo, hoje Urupês, uma população de cafeeiros de grande rusticidade e produtividade,co nhecida como Sumatra de Mundo Novo. As primeiras plantações deste material provinham de Mineiros do Tietê (Região de Jaú). Estes plantios haviam sido formados a partir de sementes de uma única planta, provavelmente, de uma hibridação natural entre o cultivar Bourbon Vermelho e o cultivar Sumatra de C. arabica.

As primeiras seleções, embora evidenciassem que se tratava de um dos melhores cultivares já selecionados, mostravam também que havia muita variabilidade dentro e entre progênies, o que iria permitir um progresso marcante no sentido de melhorar a produção. Assim, verificou-se a ocorrência de cafeeiros extremamente rústicos e produtivos, apresentando, porém, elevada quanti- 
dade de frutos com uma ou duas lojas sem sementes (frutos chochos) ou a segregação para plantas de altura elevada, pouco produtivas e semelhantes ao parental 'sumatra'. Esses e outros defeitos puderam ser contornados pela seleção de plantas na segunda geração, conseguindo-se acréscimos consideráveis de cerca de $80 \%$ de melhoria no rendimento e produção. Vārias seleções de 'Mundo Novo' já se tornaram conhecidas e são amplamente cultivadas nas regiões agrícolas do Brasil. Uma variação do 'Mundo Novo' com sementes um pouco maiores, recebeu a denominação de 'Acaiá'. E provável que esta característica de sementes maiores, tenha provindo de 'Sumatra'.

\section{Segundo FAZUOLI (1977), CARVALHO et alii} (1978) ROCHA et alii (1980), J.AC (1980) e CARVALHO (1985) foram notadas nas progênies P474, P466 e P452 de 'Mundo Novo', plantas com sementes maiores, com peneira média um ponto a mais do que a das outras seleções de 'Mundo Novo'. Notou-se, também, que as suas progênies $\mathrm{S}_{2}$ apresentaram sementes maiores do que as do 'Mundo Novo'. Os descendentes, principalmente de cafeeiros de prefixo P474, constituem o 'Acaiá'.

As plantas matrizes D474, P466 e D452 foram selecionadas pelo pesquisador Alcides Carvalho, na região de Urupês, em covas de três, quatro e cinulutro plantas, respectivamente. Segundo informações pessoais fornecidas por CARVA」HO *, quando se têm vārias plantas por co- 
va, usualmente selecionam-se sementes apenas da melhor planta.

A partir de sementes coletadas em Urupês, com os prefixos $\mathrm{P}\left(\mathrm{S}_{\mathrm{O}}\right)$ experimentos foram instalados em Campinas, Ribeirão Preto, Mococa, Jaū e Pindorama juntamente com outras progênies de 'Iundo Novo' anteriormente selecionadas com cerca de 20 plantas em cada local ' $\left(\mathrm{S}_{1}\right)$; estas plantas receberam os prefixos C, RP, M, J e P, de acordo com as iniciais dos nomes do local onde os experimentos foram instalados. Selecionaram-se as melhores plantas para constituirem novas progênies $\left(\mathrm{S}_{2}\right)$ avaliadas em novos experimentos nos mesmos locais, os quais fornece ram as informações necessárias para a recomendação das li nhagens atuais do cultivar.

As caracteristicas principais das linhagens do cultivar Acaiá (IAC, 1980) são a boa produção de café, a rusticidade e as sementes maiores do que as do 'Mundo Novo'. A altura média das plantas adultas é de 4,2 m (4,2 a 4,4 m), sendo, portanto, maiores do que as plantas de 'Mundo Novo' $(3,0 \mathrm{~m})$. O diâmetro médio da copa é de $1,8 \mathrm{~m}(1,6$ e 2,0 m), menores que a do 'Mundo № vo' $(2,0 \mathrm{~m})$. A cor das folhas novas são geralmente bronze e os ramos secundários são menos abundantes do que na maioria das linhagens de 'Mundo Novo'. O valor da peneira média varia de 18,0 a 19,0 , sendo maiores do que as de 'Mụdo Novo' $(16,1$ a 18,1$)$. O rendimento, isto é, a rela ção entre os pesos de café maduro e café beneficiado é de 
6,5, com variação de 6,4 a 6,9, maior que o de 'Mundo Novo'. A porcentagem média de sementes normais do tipo cha to é de $80,6(77,8$ a $84,5 \%)$, menor do que a de 'Mundo Novo' $(84,9 \%)$. A produção média de 'Acaiā', em distribuição, pode alcançar $1800 \mathrm{~kg} / \mathrm{ha}$ de café beneficiado, podendo variar de 1500 a $2100 \mathrm{~kg} / \mathrm{ha}$ e a produção máxima alcançada em experimento corresponde a $6000 \mathrm{~kg} / \mathrm{ha}$, estes niveis de produção são semelhantes aos de 'Mundo Novo'. As linhagens LCP 474-4, LCP 474-7, MP 474-6, MP 474-10, MP 47414, MP 474-20, RPP 474-6, RPP 474-8 e RPP 474-9 estão sen do distribuidas aos agricultores. 


\section{MATERIAL E MÉTODOS}

O material pesquisado compreende 72 progênies do cultivar de café 'Acaiá'. Todas as progênies descendem de uma mesma progênie P474, derivada das sementes de uma única planta selecionada pelo pesquisador $\mathrm{Dr}$. Alcides Carvalho em uma cova constituida de três plantas em uma plantação comercial localizada em Urupês (SP), na propriedade do Sr. A. Bergo denominada Sitio Bacuri (FAzUOLI, 1977). Esta plantação comercial era constituida por uma população segregante, provavelmente na geração $F_{3}$, que também deu origem ao cultivar Mundo Novo.

As 72 progênies pesquisadas estão relacionadas na Tabela 1. As letras que antecedem a sigla P474 correspondem às iniciais das Estações Experimentais onde os primeiros descendentes $\left(\mathrm{F}_{4}\right)$ de P474 foram pesquisados: Campinas (CP474), Mococa (MP474), Ribeirão Preto (RPP474) e Jaú (JP474). A letra P foi preservada em Pindorama pelo fato de Urupês ficar na região Araraquarence onde está a ES tação Experimental de Pindorama. Os nưmeros que se seguem à sigla P474 identificam novas progēnies $\left(F_{5}\right)$ obtidas das melhores plantas selecionadas nas estações experimentais mencionadas e vieram a 
constituir as 72 progênies de café 'Acaiā' que formam o material desta pesquisa. Informações adicionais sobre a origem destas progênies são fornecidas na revisão da literatura (item 2.5) e na Figura 1.

As 72 progênies foram testadas na Estação Experimental de Mococa-SP. O plantio foi feito em janeiro de 1970. O delineamento experimental foi em látice (lattice) retangular $8 \times 9$ com três repetições ( $\mathrm{x}$, Y, Y') e parcelas constituidas por quatro covas. Cada cova possuia uma única planta. Utilizou-se o espaçamento de três metros entre fileiras e dois metros entre as covas dentro das fileiras.

O ambiente onde o experimento foi instalado e conduzido corresponde a um solo Latossolo Vermelho Escuro, álico A moderado textura argilosa com temperatura média anual de $21,4^{\circ} \mathrm{C}$ e com precipitação pluviométrica mé dia anual de $1442 \mathrm{~mm}$. O local acha-se situado a latitude de $21^{\circ} 28^{\prime} \mathrm{s}$, longitude de $47^{\circ} 1^{\prime} \mathrm{w}$ e altitude de $665 \mathrm{~m}$. As temperaturas minimas absolutas e as precipitações pluviométricas ocorridas no período de 1969-1979 estão apresentadas no Apêndice 1.

Os seguintes caracteres foram avaliados (Tabela 3) e são incluidos nesta pesquisa:

- produção cereja (produção de frutos sem secagem), avaliada em oito anos (1972 a 1979) em guilogramas/plan ta ; 
- rendimento $=$ peso café cereja/peso café beneficiado (ca fé em grão, seco e descascado); média dos anos 1974 e 1979;

- tamanho dos grãos, avaliado em 1974 através da peneira média dos grãos normais:

- altura da copa em metros, avaliada em 1979;

- diâmetro da copa, em metros, avaliada em 1979;

- porcentagens de grãos normais, moca e concha; observações feitas em 1974.

Toda a parte experimental foi planejada e conduzida pela Seção de Genética do Instituto Agronômico de Campinas, que muito gentilmente cedeu os dados experimentais para a realização desta pesquisa.

\subsection{Análises como latice retangular $8 \times 9$}

Inicialmente, os dados experimentais foram analisados de acordo com o delineamento original de látice retangular $8 \times 9$. Para cada caráter foram realizadas duas análises, cada análise utilizando duas repetições (planos XY e XY') conforme COCHRAN \& COX (1957). A repetição correspondente ao plano $\mathrm{x}$ foi empregado nas duas análises.

A seguir, foram estimadas as eficiências 
do delineamento em látice em relação ao delineamento em blocos ao acaso. Com isto, pode-se decidir sobre a conveniência de se continuar a pesquisa no delineamento em látice ou de se proceder sua reorganização para o delineamento em blocos ao acaso.

\subsection{Variabilidade, coeficiente de determinação geno- típica e progresso genético esperado na seleção para o caráter produção cereja}

Inicialmente, estimou-se o coeficiente de correlação fenotípica entre as produções cereja e beneficiada ao nível de médias de progênies, para verificar a possibilidade de se usar a primeira em sủbstituição à segunda. Os dados originais de produção cereja têm a vantagem de não conter as variações de rendimento que ocorrem de ano a ano nos dados de produção beneficiada.

Realizaram-se as seguintes análises de va-

riância:

1. como blocos ao acaso da produção total (STEEL \& TORRIE, 1960);

2. como parcelas sub-sub-divididas no tempo de dados de produção bienais (Tabela 42), considerando-se os biênios de colheitas como subparcelas no. tempo (SERA, 1980) e as plantas individuais dentro de progēnies e repetições como sub-sub-parcelas (VELLO, 1975); 
3. como parcelas sub-divididas no tempo, de dados anuais de produção (T'abela 4l), considerando-se os anos de co lheitas como sub-parcelas no tempo (STEEL \& TORRIE, 1960 e SERA, 1980).

Os esquemas de análise e as esperanças dos quadrados médios são os apresentados na Tabela 7 para blocos ao acaso, na Tabela 2 para parcelas sub-sub-divididas no tempo bienal e, na Tabela 11 para parcelas sub-divididas no tempo anual. As esperanças dos quadrados médios foram obtidas considerando-se os efeitos de progênies (p) como fixos, e os efeitos de anos ou biênios de colheitas (a ou b), de plantas individuais dentro de progênies e repetições (i) e de repetições ( $r$ ) como aleatórios, sendo que $p$ $=1,2,3, \ldots, 72, a=1,2,3, \ldots, 8 ; b=1,2, \ldots, 4$; $i=1,2, \ldots, 4$ e $r=1,2$ e 3 。

Os testes $\mathrm{F}$ foram aplicados de acordo com as esperanças dos quadrados médios [E(QM)], apresentados nas Tabelas 5,7 e 11 .

$\mathrm{Na}$ aplicação do teste $\mathrm{F}$ para a fonte de variação progênies, houve necessidade de se combinar três quadrados médios para se obter o resíduo adequado. Neste caso, os novos números de grau de liberdade foram calculados pela fórmula de Satterthwaite*, citado por GOMES (1970), da seguinte forma:

\footnotetext{
*SATTERTHWAITE, F。E. An approximate distribution of estimates of variance componentes. Biometrics, Baltimore, 2:110-4, 1946 .
} 


$$
\text { G.L. } \cong \frac{\left(\mathrm{QM}_{\mathrm{Ea}}+\left(\mathrm{QM}_{\mathrm{PXA}} \text { ou } \mathrm{QM}_{\mathrm{PxB}}\right)-\mathrm{QM}_{\mathrm{Eb}}\right)^{2}}{\frac{\left(\mathrm{QM}_{\mathrm{Ea}}\right)^{2}}{142}+\left(\frac{\left(\mathrm{QM}_{\mathrm{PxA}}\right)^{2}}{497} \text { ou } \frac{\left(\mathrm{QM}_{\mathrm{PxB}}\right)^{2}}{213}\right)+\frac{\left(\mathrm{QM}_{\mathrm{Eb}}\right)^{2}}{426}}
$$

As estimativas de coeficiente de determinação genotípica $\left(\hat{b}_{p}\right)$ para os diferentes esquemas de análise foram obtidas a partir das seguintes expressões:

10) $b_{p}: v_{p} /\left(v_{p}+\sigma_{e}^{2} / r\right)$ para blocos ao acaso;

20) $b_{p}: v_{p} /\left(V_{p}+\sigma_{e}^{2} / r+\sigma_{p b}^{2} / b+\sigma_{s}^{2} / r b+\sigma_{i}^{2} / r b i\right)$ para parcelas sub-sub-divididas no tempo bienal;

30) $b_{p}: v_{p} /\left(v_{p}+\sigma_{e}^{2} / r+\sigma_{p a}^{2} / a+\sigma_{s}^{2} / r a\right)$ para parcelas sub -divididas no tempo anual. Sendo que:

$\mathrm{V}_{\mathrm{p}}$ : variância devido ao efeito fixo das progênies $\sigma_{e}^{2}:$ variância ambiental que ocorre entre as parcelas $\sigma_{\mathrm{pb}}^{2}$ : variância de interação entre o efeito de progênies e biênios de colheitas

$\sigma_{\text {pa }}^{2}$ : variância de interação entre o efeito de progênies e anos de colheitas

$\sigma_{S}^{2}$ : variância ambiental que ocorre entre as sub-parcelas

$\sigma^{2}$ : variância ambiental que ocorre entre as sub-sub-parcelas.

Após estimação de $b_{p}$ atravēs de diferentes esquemas de análise obtiveram-se as porcentagens relati- 
vas de cada $b_{p}$ ao nivel de parcelas, fazendo-se o segundo esquema como $100 \%$ por ser o valor majs próximo do real (SERA, 1980) .

A partir da análise de variância como parcelas sub-sub-divididas no tempo bienal obteve-se também a estimativa de coeficiente de determinação genotípica ao nỉvel de indivíduo $\left(\bar{b}_{i}\right)$ dentro de progênies e repetições. A $\sigma_{i}$ foi obtida através da expressão $\sigma_{i}=\sigma_{i}^{2} /\left(\sigma_{i}^{2}+\sigma^{2}\right)$, onde $\sigma_{i}^{2}=$ variância devido ao efeito dos indivíduos dentro de progênies e repetições.

Estimou-se o progresso genético esperado na seleção (Gs) ao nível de frarcelas ou progênies através da expressão $\mathrm{Gs}=\mathrm{ds} \cdot \mathrm{b}_{\mathrm{p}}$, onde $\mathrm{ds}=$ diferencial de seleção obtido a partir da média das dezoito progênies mais produtivas $(\mathrm{p}=0,25)$ e da média geral de todas as progênies.

Com o objetivo de se conhecer o reflexo em $\mathrm{b}_{\mathrm{p}}$ obtido a partir da análise como parcelas sub-sub-divididas no tempo bienal obtiveram-se os valores preditos de $b_{p}$ variando-se os valores de $r, b$ e $i$

Foi estimada a variância média dentro de cada progênie a partir das variâncias entre plantas dentro de repetições. Aplicou-se o teste $\mathrm{F}$ máximo/mínimo para testar a hipótese de nulidade de diferença entre duas variân cias com (i-1)r graus de liberdade tanto para o numerador como para o denominador. Também, foi aplicado o teste de Dun- 
can a 5\% para comparação das médias de progênies, usando- se como residuo $\sqrt{2 \mathrm{E}_{\mathrm{a}} / \mathrm{rb}}$ da análise como parcelas sub-sub-divididas no tempo bienal (STEEL \& TORRIE, 1980);com isto, as progênies puderam ser classificadas.

\subsection{Estabilidade fenotípica da produção anual}

$$
\text { Inicialmente, realizaram-se análises de }
$$

variāncia individualmente para cada ano de colheita, segundo esquema de análise em blocos ao acaso. A seguir, analisou-se, conjuntamente, a produção cereja anual como parcelas sub-divididas no tempo para verificar se os anos de colheita podem ser considerados ambientes diferentes e para se obter o resíduo médio a ser usado no esquema de análise de estabilidade fenotípica. o resíduo médio é obtido da divisão do erro b da análise conjunta pelo númmero de repetições, segundo SINGH \& CHAUDARY (1979)。

Realizou-se a análise de estabilidade fenotípica pelo método de EBERHART \& RUSSEL (1966), tomando-se os anos de colheitas como ambientes. A hipótese de valor 1,0 para o coeficiente de regressão das progênies sobre os ambientes foram testados pelo teste $t$ (STEEL \& TORRIE, 1980), através da expressão $t=(b-1) / \bar{\sigma}_{b}$.

Foram estimadas as correlações entre os parâmetros de estabilidade fenotípica: coeficiente de regressão (b), variância média dos desvios da regressão 
$\left(S_{d}^{2}\right)$ e produção cereja $\left(Y^{\prime}\right)$.

Também visando verificar a relação existente entre $\mathrm{b}$ e coeficiente de regressão das produções anuais sobre os anos subsequentes que mede o incremento anual médio da produção e entre $s_{d}^{2}$ e a oscilação anual da produção, obtiveram-se as estimativas de correlação simples entre eles.

\subsection{Variabilidade, coeficiente de determinação geno- tipica e progresso genético esperado na seleção para outras caracteres agronômicos}

Além dos caracteres agronômicos originalmente avaliados, derivaram-se novos caracteres a partir da produção cereja (Tabela 3) : produção beneficiada, obti da da divisão produção cereja/rendimento (Y); precocidade de produção, obtida da soma do primeiro + segundo ano de produção $\left(\mathrm{x}_{8}\right)$; incremento anual de produção nos três primeiros anos, obtido do coeficiente de regressão das produções anuais sobre os anos de colheita $\left(\mathrm{x}_{11}\right)$; oscilação anual de produção nos três primeiros anos, obtido do coeficiente de variação das produções anuais sobre a produção média anual $\left(\mathrm{x}_{12}\right)$; produção dos melhores anos iniciais $\left(\mathrm{x}_{13}\right)$; incremento anual de produção nos oito primeiros anos $\left(\mathrm{X}_{14}\right)$ e oscilação anual de produção nos oito primeiros anos $\left(\mathrm{x}_{15}\right)$. 
blocos ao acaso e aplicaram-se teste de Duncan a 5\% às médias das progênies. Através da esperança dos quadrados médios (Tabela 7.) apresentado por STEEL \& TORRIE (1960), estimaram-se os componentes da variância fenotípica e os coeficientes de determinação genotípica ao nível de progênies para os caracteres agronômicos mencionados.

Supondo-se a realização de seleção das sete melhores progênies pela produção beneficiada $(p=0,10)$, estimaram-se os ganhos de seleção (Gs) para as características agronômicas avaliadas pela expressão $\mathrm{Gs}=\mathrm{ds} \cdot \mathrm{b}_{\mathrm{p}}$. Para a produção beneficiada usou-se a $\sigma_{\mathrm{p}}$ obtida da análise como parcelas sub-sub-divididas no tempo bienal da produção cereja.

Para verificar os efeitos indiretos nos outros caracteres agronômicos ào se selecionar as progênies apenas pelo critério de produtividade $(p=10 \%)$, reuniram-se os valores de cada caráter com respectivos grupos de médias a que pertencem pelo teste de Duncan a 5\% na Tabela 30.

\subsection{Correlaç̃ões entre a produção total e as combina- ções de anos de produção}

Com o objetivo de se conhecer o grau de associação entre a produção total de oito anos e as diferentes combinações de anos de produção, visando seleção an 
tecipada, estimaram-se os coeficientes de correlação simples entre eles.

Inicialmente, correlacionaram-se a produção cereja total com os diferentes anos, individualmente. A seguir, correlacionaram se som os anos de colheitas dois a dois e, finalmente, com os anos de colheita cumulativamente. Os coeficientes de correlação foram obtidos segundo.STEEL \& TORRIE (1980) através da expressão:

$$
r=\frac{\sum(X-\bar{X})(Y-\bar{Y})}{\sqrt{\sum(X-\bar{X})^{2} \sum(Y-\bar{Y})^{2}}}=\frac{S P_{X Y}}{\sqrt{S Q_{X} \cdot S Q_{Y}}}
$$

\subsection{Correlação entre a produção total e outros carac- teres agronômicos}

Estimaram-se os coeficientes de correlação

simples $(r)$, fenotipica $\left(r_{F}\right)$ e genotipica $\left(r_{G}\right)$ entre a produção beneficiada total de oito anos e outros caracteres agronômicos ao nível de progênies.

Os coeficientes $r$ foram estimados da mesma forma que no item anterior. Os $r_{F}$ e $r_{G}$ foram obtidos segundo STEEL \& TORRIE (1980) através das expressões:

$$
r_{F}=\frac{\operatorname{cov}_{F} X, Y}{\sqrt{\sigma_{F X}^{2} \cdot \sigma_{F Y}^{2}}} \quad \frac{\operatorname{cov}_{G} X, Y}{{ }^{2} G}
$$

onde 
$\operatorname{cov}_{F}=$ covariância fenotípica, $\operatorname{cov}_{\mathrm{G}}=$ covariância genotípica, $\sigma_{F}^{2}=$ variância fenotípica e $\sigma_{G}^{2}=$ variância genotípica.

\subsection{Seleção antecipada com base em caracteres agrôno- micos avaliáveis até o terceiro ano de colheita}

O conceito de seleção antecipada será discutido no item 5. Para verificar a possibilidade de se praticar seleção antecipada para produção beneficiada, usa ram-se combinações de caracteres agronômicos avaliáveis até o terceiro ano de produção da Tabela 3 e a produção beneficiada total (Y). Foram obtidas equações de regressão múltipla $(\hat{Y})$, e coeficientes de determinação $\left(R^{2}\right)$, através cis programa SISREG de microcomputador PC desenvolvido pelo C.H. MATIOLI (CIAGRI-ESALQ/USP). A seguir, escolheram-se variáveis indepenđentes da Tabela 3, que apre sentaram correlações simples estatisticamente significati vas com a produção beneficiada total (Tabela 32).

Identificaram-se as melhores equações de regressão múltipla pelo $\mathrm{R}^{2}$ anoós uma, duas e três colheitas e também usando-se apenas os caracteres altura e diâmetro da copa sem incluir produção. Feito isto, estimaram-se as produções por planta e por progênie para estas melhores equações de regressão múltipla após uma, duas e três colheitas.

A seguir classificaram-se as progênies pelos valores de $\hat{Y}, Y$ e $X_{8}$ para se conhecer $O$ número de pro- 
gênies que devem ser selecionados com base em $\hat{Y}$ e $X_{8}$, de maneira a se incluir as progênies $10 \%$ melhores por $Y$.

$$
\text { Finalmente, verificaram-se a porcentagem }
$$

de inclusão das trẽs melhores plantas individuais dentro das melhores progênies pela $\hat{Y}$, usando-se dados disponíveis aos três e dois anos de colheita com $p=0,25$. 


\title{
4. RESULTADOS
}

\subsection{Análises como látice retangular $8 \times 9$}

\author{
As eficiēncias médias do delineamento em \\ látice,em relação ao delineamento em blocos ao acaso, pa- \\ ra os caracteres originalmente avaliados, acham-se apre- \\ sentados na Tabela 4 . \\ Obtiveram-se os valores ảe $109 \%$ para a \\ produção cereja, $94 \%$ para $\circ$ tamanho dos grãos, $94 \%$ para $\circ$ \\ rendimento, $110 \%$ para a altura da copa, 102\% para o diâme \\ tro da copa, 107\% para a porcentagem de grãos normais, \\ 109\% para a porcentagem de grãos moca e 102\% para a por- \\ centagem de grãos concha.
}

4.2. Variabilidade, coeficiente de determinação genotỉpica e progresso genético esperado na seleção para o caráter produção

Como a correlação obtida entre a produção cereja e a beneficiada foi estatisticamente significativa e alta, de 0,934 e, por ser o dado original menos influen- 
ciado pelas variações do rendimento que ocorrem ano ano, resolveu-se utilizar os dados de produção cereja para o estudo da variabilidade de produção nos oito anos de colheitas.

Os resultados das análises de variância como blocos ao acaso da produção total, como parcelas sub-sub-divididas no tempo das produções bienais e como parcelas sub-divididas no tempo das produções anuais acham-se apresentados nas Tabelas 7, 5 e 11. De acordo com o teste $\mathrm{F}$, as probabilidades de se encontrarem diferenças significativas ao nível de médias de progênies foram superiores a 0,99, 0,99 e 0,86, respectivamente, para cada esquema de análise de variância. Os coeficientes de variação obtidos foram iguais a $11,1 \%$ nos três esquemas de análise.

Os coeficientes de determinação genotípica ao nível de progênies $\left(b_{p}\right)$ para o caráter procução com oito anos de colheitas foram estimados em 0,396 para blocos ao acaso, 0,273 para parcelas sub-sub-divididas no tempo bienal e 0,179 para parcelas sub-divididas no tempo anual. Fazendo-se $\sigma_{p}=0,273$ como $100 \%, \sigma_{p}=0,396$ corresponde a $145 \%$ e $5_{p}=0,179$ corresponde a $66 \%$

Para a análise como parcelas sub-sub-divididas no tempo bienal, obteve-se a estimativa do coeficiente de determinação genotípica ao nível de plantas individuais $\left(\bar{b}_{i}\right)$ de 0,489 . O teste $F$ para a fonte de variação 
plantas individuais dentro de progênies e de repetições acusou diferenças significativas ao nível de 1\% de probabilidade e o coeficiente de variação (erro c) foi 65,3\%.

Ao nível de progênies com a média geral de $45,988 \mathrm{~kg}$, amplitude de variação de 53,550 a $31,290 \mathrm{~kg}$ e $\mathrm{b}_{\mathrm{p}}=0,273, \mathrm{O}$ Gs ao se selecionar as $10 \%$ mais produtivas foi $3,35 \%$

Obtiveram-se estimativas de coeficiente de determinação genotípica (Tabela 6) iguais a $0,152,0,216$, $0,251,0,273$, e 0,326 , respectivamente para $1,2,3$, 4. e 10 biênios de colheitas. Fixando-se quatro biênios e variando-se o número de repetições obtiveram-se $\widehat{b}_{\mathrm{p}}$ de $0,203,0,272,0,321,0,359,0,390,0,455$ e 0,491 , respectivamente para $2,3,4,5,6,9$, e 12 repetições. Fixando-se quatro biênios de colheitas e nove repetições obtiveram-se $\sigma_{p}$ de $0,455,0,462$ e 0,466 , respectivamente paira 4, 6 e 8 indivíduos.

Os valores de variâncias médias, dentro de progênies,foram significativos a 1\% de probabilidade para nove progênies (1๕,5\% do total) e 5\% de probabilidade para 19 progênies $(26,4 \%$ do total), conforme resultados apresentados na Tabela 8. Para as progênies 25\% mais produtivas todas pertencentes ao mesmo grupo de médias, a aplicação do teste de Duncan a 5\% mostrou que: quatro delas (as de número 62, 30, 39 e 24) apresentaram variâncias significativas a 1 \% de probabilidade; oito delas (as de 
no $40,2,3,66,25,54,12$ e 22) apresentaram variâncias significativas a 5 ㅇ de probabilidade e seis delas (as de no $13,71,43,53,10$ e 46) não apresentaram variāncias significativas.

\subsection{Estabilidade fenotîpica da produção anual}

Os valores da média geral, coeficientes de variação experimental, probabilidadesde não existirem diferenças significativas entre as progênies das análises de variâncias individuais de anos (ou ambientes, de 1 a 8) acham-se apresentados na Tabela 10. As probabilidades de não existirem diferenças estatisticamente significativas pelo teste $F$ foram de $0,26,0,00,0,12,0,00,0,45,0,00$, 0,53 e 0,00, respectivamente, para as análises dos anos $1,2,3,4,5,6,7$ e 8 . Ainda, os respectivos coeficientes de variação experimental foram de $14,5 \%, 29,9 \%, 16,4 \%$, $80,1 \%, 39,2 \%, 15,9 \%, 74,7 \%$ e $15,4 \%$. As produções médias anuais foram menores para os anos $2,4,5$ e 7 .

O resultado da análise de variância conjunta dos anos de colheitas, como parcelas sub-divididas no tempo está apresentado na Tabela 11 . Obtiveram-se os coeficientes de variação de $11,1 \%$ ao nível de parcelas e 19,7\% ao nível de sub-parcelas. As probabilidades de se encontrarem diferenças significativas pelo teste $F$ foram maiores que 0,86 para progênies e 0,99 para anos de colheitas e para a interação progênies $x$ anos de colheitas. 
Na Tabela 12 estão apresentados os resultados da análise de estabilidade fenotípica. O teste $\mathrm{F}$ acusou diferenças significativas aos desvios de regressão e à interação progênies $x$ ambientes (linear) ao nível de 1\% de probabilidade e o ambiente (linear) não apresentou diferenças significativas. Aplicando-se o teste $F$ aos desvios da regressão para cada progênie, identificaram - se 14 progênies estatisticamente significativas a 5 e $1 \%$ de probabilidade.

As produções cereja, os coeficientes de regressão e as variâncias médias dos desvios da regressão para cada progênie estão apresentados na Tabela 13 . Os resultados do teste de hipótese de igualdade a valor 1,0 do coeficiente de regressão pelo teste $t$, indicaram que apenas dez progênies diferem estatisticamente. As progênies incluidas entre as mais produtivas ( $p=25 \%$ apresentaram os seguintes valores de coeficiente de regressão e da variância média dos desvios da regressão, respectivamente: 1,00 ns e $2,59 *$ (progênie no 13); 0,96 ns e 2,56 * $(\mathrm{n} O 62) ; 1,26 *$ e $0,37 \mathrm{~ns}(\mathrm{n} 040) ; 1,21 *$ e $0,40 \mathrm{~ns}$ (no 71); $1,09 \mathrm{~ns}$ e $-0,16 \mathrm{~ns}(\mathrm{n} \circ 2) ; 1,02 \mathrm{~ns}$ e $-0,09 \mathrm{~ns}$ (no 3); 0,98ns e $1,04 *$ (no 66); $1,04 \mathrm{~ns}$ e $1,09 *$ (no 25); $1,18^{*}$ e $0,73 *$ (no 30); $1,04 \mathrm{~ns}$ e $-0,32 \mathrm{~ns}$ (no 43); 1,19** e $-0,09 \mathrm{~ns}$ (no $39) ; 0,98 \mathrm{~ns}$ e $0,32 \mathrm{~ns}$ (no 54); 0,90ns e 0,36ns (no 53); $1,12 \mathrm{~ns}$ e $U, 24 \mathrm{~ns}$ (no 12); $1,10 \mathrm{~ns}$ e $-0,26 \mathrm{~ns}$ (no 22); 1,21 ** e $0,33 \mathrm{~ns}(\mathrm{n} 0$ 68); 1,17 * e $0,31 \mathrm{~ns}$ (no 24); 0,97ns e $1,07 *$ * (no 46). 
Os coeficientes de correlação simples entre o coeficiente de regressão e a produção foi de 0,582** e, entre a variância média dos desvios da regressão e a produção, foi de $0,123 \mathrm{~ns}$.

Os coeficientes de correlação simples entre o coeficiente de regressão da estabilidade e o coeficiente de regressão do incremento médio anual da produção, (Tabela 15) foi de $0,661 * *$ e entre a variância média dos desvios da regressão e a oscilação anual da produção, foi de $-0,231 \mathrm{~ns}$.

\subsection{Variabilidade, coeficiente de determinação geno- tỉpica e progresso genético esperado na seleção para outros caracteres agronômicos}

Os resultados da análise de variância como blocos ao acaso e da aplicação do teste de Duncan a 5\% ao nivel de progênies para os caracteres agronômicos avaliados, acham-se apresentados nas Tabelas 16 a 28 .

Obtiveram-se os seguintes resultados do teste $\mathrm{F}$ e do coeficiente de variação, respectivamente: $1,71 *$ e $11,1 \%$ (produção beneficiada $\mathrm{Y}$ ), 1,41* e 2,1\% (tamanho dos grãos), 3,32** e 2,6\% (rendimento), 2,40** e $2,5 \%$ (altura da copa), $1,28 \mathrm{~ns}(\mathrm{p}=0,89)$ e $6,1 \%$ (diâmetro da copa), 2,63** e 2,6\% (porcentagem de grãos nor-

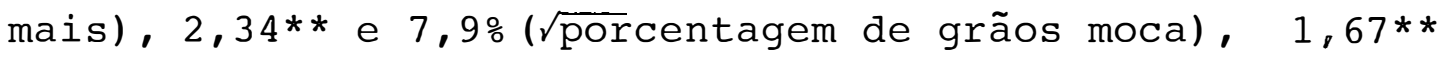




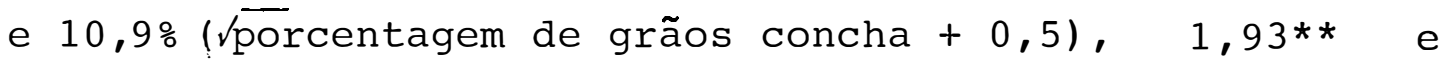
12,7\% (produção do primeiro biênio ou precocidade de produção), 1,53** e 61,2\% (incremento anual de produção nas três primeiras colheitas), 1,69** e 24,5\% (oscilação anual da produção nas três primeiras colheitas), 2,61** e 147,7\% (incremento anual da produção nas oito primeiras colheitas) e $1,65 *$ e $0,71 \%$ (oscilação anual da produção nas oito primeiras colheitas).

Para o caráter principal, produção beneficiada (Y), quando se aplicou o teste Duncan a 5\% (Tabela 16) observou-se que as sete progênies ( $\mathrm{p}=10 \%)$ mais produtivas, as de número $62,13,3,53,25,54$ e 40, por ordem, pertencem todas ao mesmo grupo de médias.

Os valores de $E_{p}$ obtidos a partir das análises de variância como blocos ao acaso para os outros ca racteres agronōmicos (Tabela 29), foram de 0,290 para o tamanho dos grãos, 0,699 para o rendimento, 0,584 para a altura da copa, 0,386 para diâmetro da copa, 0,620 para a porcentagem de grãos normais, 0,572 para a produção de grãos moca, 0,677 para a porcentagem de grãos concha, 0,482 para a precocidade de produção, 0,346 para incremento anual de produção nas três primeiras colheitas, 0,409 para a oscilação anual da produção nas três primeiras colheitas, 0,617 para o incremento anual da produção nas oito primeiras colheitas e 0,394 para a oscilação anual da produção nas oito primeiras colheitas. 
Selecionando-se apenas as sete progênies melhores pela produção beneficiada, o ganho indireto esperado seria de $0,24 \%$ para o tamanho dos grãos, $0,88 \%$ para o rendimento, 2,65\% para a altura da copa, 1,65 para o diâmetro da copa, $-0,04 \%$ para a porcentagem de grãos normais, $-0,65 \%$ para a porcentagem de grãos moca, 5,22\% para a porcentagem de grãos concha, 3,39\% para a precocidade de produção, $0,56 \%$ para 0 incremento anual da produção nas três primeiras colheitas, 7,40\% para a oscilação anual de produção nas três primeiras colheitas, $12,58 \%$ para $\circ$ incremento anual da produção nas oito primeiras colheitas e $2,10 \%$ para a oscilação anual de produção nas oito primeiras colheitas.

Na Tabela 30 estão apresentadas as classificações (Duncan, 5\%) em letras, para as médias dos caraç teres agronômicos estudados apenas para as sete progênies mais produtivas.

Algumas das progênies selecionadas para produção não mostraram superioridade em parte dos demais caracteres. Tais progênies são relatadas a seguir, juntamente com os caracteres em que não foi detectada superioridade relativa: progênie no 13 e caracteres porcentagem de grãos normais e incremento anual da produção nas três primeiras colheitas; progênie no 3 e caracteres incremento anual da produção nas três primeiras colheitas e e incremento anual da produção nas oito primeiras colheitas: progênie no 53 e caracteres incremento anual da pro- 
dução nas três primeiras colheitas, porcentagem de grãos concha e incremento anual da produção nas oito primeiras colheitas; progênie no 25 e caracteres porcentagem de grãos normais, porcentagem de grãos moca e oscilação anual da produção nas oito primeiras colheitas; progênie no 40 e caracteres rendimento, porcentagem de grãos normais,por centagem de grãos moca, precocidade de produção, oscilação anual da produção nas três primeiras colheitas e oscilação anual da produção nas oito primeiras colheitas. A progênie no 54 foi a única dentre as sete mais produtivas que mostrou o mesmo grau de superioridade para todos os caracteres avaliados.

\subsection{Correlações entre a produção total e as combina- ções de anos de produção}

Todos os coeficientes de correlação entre a produção total e as combinações de anos de produção foram estatisticamente significativas pelo teste $t$ (Tabela 31). As correlações foram estimadas em 0,262, 0,516, $0,541,0,250,0,512,0,795,0,217$ e 0,818 , respectivamente para $\circ 10,20,30,40,50,60,70$ e 80 ano de colheita. As suas respectivas médias de produção, em quilogramas de fruto maduro foram 7,291, 4,323,9,726, 1,040, 2,056, $10,295,0,496$ e 10,919 .

Para os anos de colheitas agrupados dois a dois (biênios), as correlações foram estimadas em 0,666, 
$0,739,0,858$ e 0,837 , respectivamente para o $10,20,30$ e 4 o biênio de colheitas. As respectivas médias de produção,em quilogramas, foram de $11,614,10,766,12,351$ e 11,414 .

Ao se correlacionar a produção total com os anos de produção cumulativos, do 10 ano até $10+20$ + $3 \underline{0}+4 \underline{0}+5 \underline{0}+7 \underline{0}$ ano, obtiveram-se correlações de 0,262, $0,666,0,794,0,833,0,869,0,961$ e 0,961 . As suas respectivas produções médias em quilogramas foram de 7,291, $11,614,21,340,22,380,24,436,34,731$ e 35,227 .

\subsection{Correlações entre produção total e outros carac- teres agronômicos}

Os valores obtiäos de correlações fenotípica e genotípica entre a produção beneficiada e outros caracteres agronômicos, estão apresentados na Tabela 32 .As correlações fenotípicas variaram de $0,766 * *$ a $-0,474 *$; as correlações genotípicas variaram de 0,870 a $-0,772$.

\subsection{Seleção antecipada com base em caracteres agronō- micos aváliaveis até o terceiro ano de colheita}

As 55 equações da regressão múltipla obtidas estão apresentadas na Tabela 33. A melhor predição da produção total $\left(\mathrm{R}^{2}=0,793\right)$ ocorreu quando se utilizaram 
dados de produção e outros caracteres agronōmicos, avaliados até o terceiro ano de colheita; com menor tempo de avaliação ocorreram prejuízos na predição da produção total, indicados pelos valores menores de $\mathrm{R}^{2}=0,718$ (para dois anos iniciais de colheita), $\mathrm{R}^{2}=0,571$ (para o primeiro ano de colheita), $\mathrm{R}^{2}=0,454$ (para altura e diâmetro da copa, antes da primeira colheita). A predição da produção total também foi prejudicada quanco não se usou os demais caracteres, ou seja, quando a seleção antecipada baseou-se apenas na produção observada nas colheitas iniciais: $\mathrm{R}^{2}=0,615$, combinando 20 e 30 anos; $\mathrm{R}^{2}=0,489$ combinando 10 e 20 anos; $\mathrm{R}^{2}=0,070$, com base unicamente no 10 ano de produção.

As estimativas da produção total loito anos) com base nas melhores equações de regressão múltipla e as classificações relativas das progênies, são apresentadas nas Tabelas 34 a 38 .

As plantas individuais que seriam selecionadas dentro das progênies superiores $(p=25 \%$, correspondente às três plantas superiores dentre as 12 plantas avaliadas em cada progênie) foram classificadas nas Tabelas 39 e 40 , respectivamente para as melhores equações de regressão múltipla combinada com outros caracteres agronômicos nos três e nos dois anos de produção. 


\section{DISCUSSÃO}

Um dos objetivos principais desta pesquisa è a verificação da possibilidade de se praticar seleção antecipada para produtividade em cafeeiro. O termo seleção antecipada é utilizado para designar a prática de seleção nos primeiros anos de vida da planta, incluindo-se os três anos de crescimento vegetativo e os três anos iniciais de colheitas. A principio, este procedimento pode ser empregado em plantas de qualquer geração, ou seja, com qualquer grau de endogamia. Portanto, a seleção antecipada difere da seleção precoce, que tem sido tradicionalmente empregada em melhoramento para designar a prática de seleção em gerações iniciais ( $\mathrm{p} \cdot \mathrm{ex}, \mathrm{F}_{2}$ e $\mathrm{F}_{3}$ ), nas quais as plantas ainda não alcançaram um grau significativo de endogamia.

\subsection{Análise como látice retangular $8 \times 9$}

As eficiências médias alcançadas das análises em delineamento látice retangular em relação ao delineamento em blocos ao acaso para os caracteres origi- 
nalmente avaliados, inferiores a $110 \%$, indicam que as futuras análises poderão ser realizadas como se o delineamento experimental empregado fosse em blocos ao acaso.

\subsection{Variabilidade coeficiente de determinação geno- típica e progresso genético esperado na seleção para 0 caráter produção}

Segundo ALLARD (1971), as estimativas de variâncias que são úteis para os melhoristas de plantas apresentam grande variabilidade. Estas estimativas dependem muito da unidade ambiental. Se os materiais forem pesquisados em apenas um local e num só ano, a soma variância genética $\left(\sigma_{g}^{2}\right)$ + variância de interação genótipos por locais $\left(\sigma_{g l}^{2}\right)+$ variância de interação genótipos por anos $\left(\sigma_{g a}^{2}\right)+$ variância de interação genótipos por locais e por anos $(\underset{g l a}{2})$ é estimada, conjuntamente, como sendo a variância genética. Fazendo-se comparações em anos diferentes, mas num só local as quantidades estimáveis serão $\left(\sigma_{g}^{2}+\sigma_{g l}^{2}\right)$ e $\left(\sigma_{g a}^{2}+\sigma_{g l a}^{2}\right)$ : portanto, a variância genética fica confundida com a variância da interação entre genótipos e local. Considerando-se, porém, amostras gradativamente maiores de locais e anos, torna-se possivel identificar e remover quantidades crescentes de variâncias devidas às interações, obtendo-se, assim, estimativas melhores da variância genética. O mesmo ocorre com as estimativas da herdabilidade ou do coeficiente de determi- 
nação genotípica que é definida como o quociente entre a variância genotípica e a fenotípica.

$A b_{p}=0,396$ obtida da análise em blocos ao acaso da produção total de oito anos não considera os anos de colheita. Assim, a $b_{p}$ na realidade foi , obtida usando-se a soma $\sigma_{g}^{2}+\sigma_{g a}^{2}+\sigma_{g l}^{2}+\sigma_{g l a}^{2}$ como sendo $\sigma_{g}^{2}$ e, por isso está bastante superestimada. Isto é agravado pe la já conhecida acentuada oscilação anual de produção de café em plantações brasileiras estabelecidas a pleno sol e sem pođas programadas (MEDINA et alii, 1984), que aumenta a magnitude de $\sigma_{g a}^{2}$ e de $\sigma_{g l a}^{2}$

Usando-se dados de produções anuais analisadas como parcelas sub-divididas no tempo consegue-se iso lar a componente $\sigma_{\text {ga }}^{2}$ da variāncia genotípica de progênies (STEEL \& TORRIE, 1960; SERA, 1980). Mesmo assim, a compo nente $\sigma_{g}^{2}+\sigma_{g l}^{2}$ é estimada como sendo variância genotípica. Como este matërial genético possue ampla adaptação a várias regiões cafeeiras (IBC-GERCA, 1979) esta superestimativa deve ser de pequena monta e a $b_{p}=0,179$ obtida está mais próximo do valor real.

Entretanto, segundo STEVENS (1949), a quan tidade primária que interessa na análise estatística é a colheita total ou a colheita média de um número par de anos para minimizar o efeito do ciclo bienal de produção de café que ocorre no Brasil. CARVALHO \& MONACO (1969) recomendam realizar a seleção após um número par de anos de colheitas para contornar o problema do ciclo bienal de 
produção de café na seleção. Assim, a análise como parcelas sub-divididas no tempo usando-se dados de produções bienais é mais apropriado como foi demonstrado por SERA (1980) para as progênies de diversos cultivares de café em Campinas, SP.

O esquema de análise de variância apresentado na Tabela 5 permite a obtenção de estimativas de coe ficientes de determinação genotípica livres das interações com biênios de colheita, tanto entre como dentro de progênies. Este esquema da Tabela 5 tem o objetivo de juntar às fontes de variação o respectivo resíduo; na rea lidade, biênios de colheita e indivíduos (plantas) parecem ter a mesma grandeza estatística, de maneira que ambos poderiam ser considerados como subparcelas.

O $b_{p}=0,273$ apresentada na Tabela 6 é uma estimativa melhor do que a $b_{p}=0,179$ obtida de análise como parcelas sub-divididas no tempo de dados anuais. Es ta $\widehat{b}_{\mathrm{p}}$ para as 72 progênies de 'Acaiá' em Mococa está próxima da $b_{p}=0,244$ obtida em Campinas para as 15 progênies de 'Mundo Novo' por SERA (1980). Esta semelhança de resul tados já era esperada, com base na origem comum dos cultí vares Acaiá e Mundo Novo (FAZUOLI, 1977; CARVALHO et aliini, 1978; ROCHA et aliii, 1980 e CARVALHO, 1985).

$$
\text { Fazendo-se } b_{p}=0,273 \text { obtida da análise }
$$

como parcelas sub-divididas no tempo bienal como sendo 100\%, verifica-se que a $\widehat{b}_{\mathrm{p}}=0,396$, obtida da análise em blocos ao acaso, superestime $\circ b_{p}$ em 45,3\%. Por outro lado, a $\widehat{b}_{\mathrm{p}}=0,179$ obtida da análise como parcelas sub-di 
vividas no tempo anual é apenas $65,9 \%$ da $5_{\mathrm{p}}$ obtida da análise bienal.

A estimativa do coeficiente de determinação genotípica, semelhantemente à herdabilidade no sentido amplo $\left(\mathrm{h}_{\mathrm{a}}^{2}\right)$ é uma estimativa específica para cada material genético e para cada ambiente. Assim, a $\sigma_{p}$ obtida nesta pesquisa apesar de bem diferente de $b_{p}=0,24$ para 'Mundo Novo', $b_{p}=0,47$ para 'Bourbon Amarelo', $b_{p}=0,60$ para 'Bourbon Vermelho', $\sigma_{p}=0,38$ para 'Caturra' e $\sigma_{p}=$ 0,00 para 'Arabica' obtidas por SERA (1980) em Campinas e $h_{\mathrm{a}}^{2}=0,57$ e $h_{\mathrm{a}}^{2}=0,35$ para dois locais obtidos por SRINIVASAN et alii (1979) na India, considerando-se apenas as estimativas de herdabilidade obtidas a partir de mais de cinco anos de produção e isolando-se os componentes origi nários da oscilação anual de produção, está dentro do esperado.

O coeficiente de determinação genotípica ao nivel de plantas individuais $\left(\widehat{\sigma}_{i}=0,489\right)$ mostrou-se supe rior ao mesmo coeficiente entre progênies $\left(\sigma_{p}=0,273\right)$. Este resultado indica que a variabilidade genética dentro de progênies é maior que a variabilidade existente entre progênies. De fato, altos niveis de variabilidade foram detectados ém pelo menos 28 das 72 progênies avaliadas (Tabela 8). Tal fato não era esperado, pois progênies na geração $F_{5}$ tem grau elevado de endogamia e devem ser homo zigóticas para a maioria dos genes. Algumas hipóteses podem ser levantadas para explicar a maior variabilidade:, dentro das progênies, relativamente à variabilidade entre progênies: 
(a) cruzamentos naturais ocasionais nas gerações anteriores; (b) heterozigosidade integrada; (c) subestimação de $b_{p} ;$ (d) superestimação de $b_{i} ;$ (e) maior endogamia.

A taxa de cruzamento natural de cerca de $10 \%$ que ocorre comumente em Campinas (MONACO et alii, $1963)$ poderia explicar, em parte, estes resultados. Realmente, esta hipótese já foi antes levantada por FAZUOLI (1977) no caso de progênies de 'Mundo Novo' Só em Campinas, provavelmente na geração $\mathrm{F}_{3}$, para explicar uma varia bilidade dentro da progênie,maior do que a esperada, para o caráter frutos com lojas sem sementes e para o caráter cor bronze dos brotos. No histórico da origem e seleção deste conjunto de progênies àe 'Acaiá', é bem possível que o fator cruzamento natural tenha contribuido, decisivamen te, para manter a variabilidade dentro das progênies. E provável que isto tenha ocorrido em pelo menos três ocasiões. A primeira suposição é a de que a planta que forneceu as sementes para a formação da progênie P474 fosse uma planta $F_{1}$, fato que é pouco provável mas não desprezí vel. A segunda ocasião em que, com maior certeza, ocorreu uma taxa de cruzamento natural de cerca de 10\%, foi na cova de três plantas no Sítio Bacuri onde se obtiveram de uma única planta as sementes que deram origem à progênie P474. A terceira ocasião em que podem ter ocorrido cruzamentos naturais foi quando se pesquisou, regionalmen te a progênie P474, juntamente com a maioria das outras progênies de 'Mundo Novo' (que se caracterizam pela semente e altura de p?anta menores e outras diferenças), num 
delineamento com cerca de vinte repetições e uma única planta por parcela (FAZUOLI, 1977) . Assim, as 72 progênies estudadas neste experimento poderiam ser uma mistura de progênies na geração $\mathrm{F}_{1}, \mathrm{~F}_{2}, \mathrm{~F}_{3}, \mathrm{~F}_{4}$ e $\mathrm{F}_{5}$.

Para explicar a manutenção de heterozigosi dade em linhagens de espécies autógamas, PANDEY (1974) le vantou a hipótese de heterozigosidade integrada. Por esta hipótese, um certo nivel de heterozigosidade poderia ser mantido no sistema poligênico, que modifica os genes prin cipais e tal heterozigosidade seria responsável por segre gações em gerações mais avançadas de endogamia. A magnitude deste evento poderia ser ainda amplificada pela ocor rência de cruzamentos naturais ocasionais e/ou taxas rela tivamente altas de permutas genéticas.

Uma outra explicação para $\widehat{b}_{i}$ maior do que $\mathrm{b}_{\mathrm{p}}$ é que $\mathrm{o} \mathrm{b}_{\mathrm{p}}$ poderia estar subestimado. Isto pode ser constatado pela magnitude das estimativas de componentes $\sigma_{e}^{2}, \sigma_{S}^{2}$ e $\sigma^{2}$ (Tabela 6) que ao serem divididos por um núme ro maior de repetições, diminuem as suas participações na variância fenotípica, aumentando consequentemente, a $\widehat{b}_{\mathrm{p}}$. Assim, a $b_{p}=0,273$ com três repetições, deveria ser igual a 0,321,com quatro repetições; igual a 0,359,com cinco re petições; igual a 0,390 , com seis repetições e igual a 0,455, com nove repetições. Esta hipótese é pouco provável, pois mesmo com um número tão grande quanto nove repe tições, o valor de $\widehat{b}_{\mathrm{p}}=0,455$ seria no máximo semelhante ao valor estimato de $\mathrm{b}_{i}=0,489$. 
Outra possivel explicação é a de que o $\mathrm{b}_{i}$ foi superestimado. A estimativa da variância genotípica dos individuos $\left(\sigma_{i}^{2}\right)$ estimada neste estudo, na realidade é a somatória da $\sigma_{i}^{2}+$ variância ambiental de natureza perma nente $\left(\sigma_{C}^{2}\right)$, os quais são inseparáveis quando os dados de produção são obtidos sobre a mesma planta, ano após ano, de maneira semelhante ao que ocorre com animais (BRIQUET JUNIOR, 1967). Neste caso, as diferenças como aquelas de vida ao tamanho das mudas, às dificuldades na ocasião do plantio das mudas, aos efeitos da seca, às geadas, às pra gas e às doenças atuando em níveis de produções anuais di ferentes e às diferenças de solo, entre outras, acumulariam progressivamente mais efeitos ambientais permanentes sobre diferentes plantas com o passar dos anos. Este efeito deve ser de grande magnitude pois em outros estudos tem sido constatado baixa relação entre a produção de planta matriz e a sua progênie (CARVALHO \& MONACO, 1969).

A grande variabilidade detectada dentro de progênies também pode ser explicada pelo próprio processo de endogamia natural que leva ao aparecimento de plantas homozigóticas mas geneticamente heterogêneas. o grau de homozigosidade provavelmente varia de uma progênie para outra, de maneira que é possível supor-se que as progênies mais homozigóticas também são as mais heterogêneas e deve haver maior variabilidade entre as suas plantas. 
Assim, apesar da existência de variabilidạ de dentro das progênies, a $b_{i}$ neste experimento deve ser bem inferior a 0,27. Uma estimativa de $b_{i}$ mais próxima da realidade deve ser obtida através de outros métodos, co mo a regressão progenitor-descendente.

O progresso genético esperado na seleção $(p=10 \%)$ ao nível de médias de progênies foi de $3,35 \%$, Este progresso, de razoável magnitude, poderia ser superior; caso também fosse considerada a possibilidade de se praticar seleção das melhores plantas dentro das 'progênies superiores, principalmente se tais progênies tivessem apresentado variância significativa entre suas plantas como as progềnies no 62 e 3 .

O trabalho refere-se a um experimento de seleções regionais de café Acaiá. As 72 progênies são de rivadas dos melhores cafeeiros da progênie P474, plantadas em Campinas, Ribeirão Preto, Pindorama, Mococa e Jaú. Seria de se esperar uma predominância de progênies, selecionadas em Mococa. Esta expectativa confirmou-se entre as progênies 25\% melhores (18) do experimento. As progênies estudadas originárias de Mococa contribuiram com $40 \%$ das 18 melhores, vindo em seguida progênies originárias de Ribeirão Preto com $30 \%$ e de Campinas, com 19\%. 


\subsection{Estabilidade fenotípica da produção anual}

Dos resultados das análises de variância individuais, como blocos ao acaso,das produções anuais de café cereja,verificou-se que os coeficientes de variação experimental foram altos nos anos de baixas produções e baixos nos anos de altas produções. Isto era esperado, porque nos anos de altas produções o potencial produtivo dos genótipos são plenamente realizados (FAzUOLI, 1977 e CARVALHO et alii, 1984) e é nestes anos que se realizam as seleções com maior sucesso.

Os resultados do teste $\mathrm{F}$ significativos a $1 \%$ de probabilidade para os anos $2,4,6$ e 8 e não significativos para os anos 1, 3, 5 e 7 indicam a possibilidade de uso destes dados para o estudo da estabilidade fenotípica, prosseguindo com a realização da análise conjunta。

A análise conjunta como parcelas sub-divididas no tempo das produções anuais com o coeficiente de variação de $11,1 \%$ para as parcelas constituídas de progênies e 19,7\% para as sub-parcelas constituidas de anos de colheitas indicam precisão satisfatória dos dados analisados. Os testes $\mathrm{F}$ acusaram probabilidades maiores do que 0,85 e 0,99 de se encontrarem diferenças significativas entre as progênies e entre os anos de produção, confirmando a validade do uso destes dados para a análise da estabilidade fenotípica. 
A análise de estabilidade fenotípica de EBERHART \& RUSSEL (1966) mostrou, através do teste $F$, que existem diferenças significativas a $1 \%$ de probabilidade para as progênies, ambientes, interação progênies x ambientes (linear), e desvios da regressão.

Um cultivar estável é definido por EBERHART \& RUSSEL (1966) como sendo aquele que apresenta b = 1,0 e $s_{d}^{2}=0$. Um genótipo com $b=1,0$ deve ter resposta diretamente proporcional à melhoria ambiental, enquanto que $\mathrm{b}<1,0$ indica pouca exigência ambiental e b $>1,0$ indịca muita exigência em ambiente. O så significativamente diferente de zero indica um genótipo de comportamento imprevisivel enquanto cque $\mathrm{s}_{\mathrm{d}}^{2}=0$ indica um genótipo de comportamento previsivel ou estável. Assim, uma linhager. desejável seria aquela que tivesse uma produção média alta, resposta diretamente proporcional à melhoria ambiental e comportamento previsivel em ambientes semelhantes (BONATO, 1978 e SANTOS, 1980).

Dentre as progênies 25\% melhores pela produção cereja, todas pertencentes ao mesmo grupo de médias (Tabela 9) as melhores progênies pelos parâmetros de estabilidade, são as de número $2,3,43,54,53,12$ e 22 (Tabela 13)。Destas, as progênies no 3, 53 e 54 também se incluem entre as progênies $10 \%$ superiores pela produÇão beneficiada (Tabela 16) e, também, entre as com menor oscilação anual de produção (Tabela 15 e 28). Isto torna as progênies no 3, 53 e 54 de muito interesse. Além disso, a 
constatação da existência de variabilidade para os parâmetros de estabilidade fenotípica neste estudo confirmam os resultados obtidos por SRINIVASAN \& VISHVESHWARA (1978) que encontraram variabilidade para estabilidade fenotipica usando-se anos de produção, como ambientes, na India.

A correlação $r=0,582 *$ entre a produção e o coeficiente b de estabilidade obtida, indica que as progênies mais produtivas respondem bem à melhoria ambien tal do ano ou são exigentes em ambientes do ano; este fato é reforçado pela inexistência de progênies com b $<1,0$ (com baixa exigência ambiental) dentre as progênies 25\% mais produtivas.

Por outro lado, a inexistência de correlação entre a variância média dos desvios da regressão $\left(\mathbf{s}_{d}^{2}\right)$ e a produção indica que é possĩvel selecionar tanto progênies de comportamento previsivel como as de comportamento imprevisivel com alta produtividade.

A estimativa da correlação entre os valores de $s_{d}^{2}$ e os valores de coeficiente de variação das pro‘ duções anuais relativamente à produção média, foi igual a -0,231, quase atingindo a significância ao nivel de 5\% Uma tendência de correlação negativa como esta indica ser possivel encontrar progênies de comportamento não-previsí vel ( $s_{d}^{2}$ significativo) mas com menor oscilação anual de produção, como as progênies no 62 e no 13 (Tabela 14). 
A estimativa da correlação entre os valores de b da análise de estabilidade fenotípica e os valores de incremento médio das produções anuais de frutos ce reja foi igual a 0,661 , correlação esta significativa a 1\% de probabilidade. Correlação positiva, alta e signifi cativa como esta indica que as progênies que apresentam resposta diretamente proporcional à melhoria do ambiente, também tendem a mostrar produções crescentes com o decorrer dos anos de produção.

\subsection{Variabilidade coeficiente de determinação geno- típica e progresso genético esperado na seleção para outros caracteres agronômicos}

Os testes $\mathrm{F}$ das análises de variância como blocos ao acaso para os caracteres agronômicos estudados (Tabelas 16 a 28) mostram que são altas as probabilidades de se encontrarem diferenças significativas entre as progênies (maiores do que 0,95), exceto para o caráter diâmetro da copa com $\mathrm{p}=0,89$.

Os coeficientes de variação experimental

obtidos (Tabelas 16 a 28) inferiores a 12,7\%, exceto para os caracteres oscilação anual de produção nas três primeiras colheitas $(24,5 \%)$, incremento anual da produção nas três primeiras colheitas $(61,2 \%)$ e incremento anual da produção nas oito primeiras colheitas $(147,7 \%)$, mostram, de um modo geral, uma precisão experimental satisfa- 
tória. O coeficiente de variação experimental da oscilação anual de produção nas três primeiras colheitas,apesar do elevado valor, ainda é aceitável. Os altos coeficientes de variação do incremento anual de produção nas três e nas oito primeiras colheitas, devem-se ao cancelamento de valores negativos e positivos que torna muito baixa a média geral do caráter que entra no denominados da fórmula do cálculo de coeficiente de variação, tornando-o sem significado, para indicar a precisão experimental.

As $\sigma_{p}$ e os Gs obtidos para os caracteres agronômicos, apresentados na Tabela 29, podem não ter validade prática para algumas delas. Estas são caracteres que sofrem influência da produtividade do ano em que o ca ráter foi avaliado. As variâncias genotípicas dos caracteres tamanho dos grãos, rendimento e porcentagem de:grãos normais, moca e concha, provavelmente seriam estimativas irreais, que podem ter resultado em $\sigma_{p}$ e Gs também irreais, pois foram avaliadas apenas em um ou dois anos de produção devendo conter variância devido a interações na variância genotípica .

As $5_{\mathrm{p}}$ obtidas de 0,584 para a altura da copa, 0,386 para o diâmetro da copa, 0,482 para a precocidade de produção (primeiro biênio), 0,346 para incremento anual de produção nas três primeiras colheitas, 0,409 para a oscilação anual da produção nas três primeiras colheitas, 0,617 para incremento anual da produção nas oito primeiras colheitas e 0,394, para a oscilação anual de produção nas oito primeiras colheitas, provavelmente são 
estimativas próximas do valor real. A $b_{p}$ obtida nesta pesquisa para os caracteres altura e diâmetro da copa estão compatíveis com as respectivas $\hbar_{a}^{2}$ obtidas por WALYARO \& VAN DER VOSSEN (1979) de 0,28 e 0,21, em Quênia e por CARTILLO-ZAPATA \& MORENO-RUIZ (1981), de 0,42 a 0,58 em Colômbia。

Constata-se que, ao se selecionar para a produção beneficiada ocorre uma melhoria indireta de 2,65\% para a altura da copa, 1,65\% para o diâmetro da copa, 3,39\% para a precocidade de produção, 0,56\% para incremento anual da produção nas três primeiras colheitas, 7,40\% para oscilação anual de produção nas três primeiras colheitas, $12,58 \%$ para incremento anual de produção nas oito primeiras colheitas e 2,10\% para oscilação anual de produção nas oito primeiras colheitas. Estes resultados são também consequências de correlações genéticas de razoável magnitude que existem entre a produção beneficiada e estes caracteres (Tabela 29).

As sete progênies mais produtivas, todas elas pertencentes ao mesmo grupo de médias pelo teste de Duncan a 5\%, possuem como características comuns, sementes grandes e altura e diâmetro da copa maiores (Tabela 30). As seis melhores progênies apresentam também como caracte risticas comuns, altos rendimentos, maior precocidade de produção e uma menor oscilação anual da produção nas três e nas oito primeiras produções; exceção ocorreu apenas na progênie no 25, para o caráter oscilação anual da produ- 
ção. Quanto ao tipo de sementes, com maior porcentagem de grãos normais e menor porcentagem de grãos concha, destacam-se as progênies no 13,3 e 54. Quanto ao incremento anual da produção nas três primeiras produções, as progênies no 25, 54 e 40 são as melhores. E, quanto ao incremento anual da produção nas oito primeiras produções, as progênies no 13, 25, 54 e 40 são as melhores.

\subsection{Correlações entre a produção total e as combina- ções de anos de produção}

O exame da Tabela 31 revelou que os anos de maiores produções médias tiveram tendência de apresentar maiores correlações com a produção total, excetuando- se a primeira produção. Isto está de acordo com as conclusões de CARVALHO (1952) para o cultivar Bourbon Vermetho e com as conclusões de FAZUOLI (1977) para o cultivar Mundo Novo. Desta forma, confirmou-se a recomendação de se selecionar no ano de elevada produção.

O mesmo ocorreu quando se agrupou os anos de produção dois a dois, formando biênios. As melhores correlações ocorreram nos biênios mais produtivos, excetuando-se o primeiro. Desde que se disponha de produções bienais seria melhor selecionar com base em biênio do que somente em anos isolados; isto é confirmado pelas maiores correlações obtidas, concordando com as recomendações de STEVENS (1949) e CARVALHO \& MONACO (1969). 
A alta correlação existente entre a produção total e altas produções anuais ou bienais , não se aplica ao primeiro ano e nem ao primeiro biēnio. Isto, provavelmente, tem explicação na variabilidade para o caráter precocidade de produção ou produção do primeiro biênio (Tabela 24), que existe neste material genético.

Quando se correlacionou a produção total com as produções cumulativas da primeira à sétima produção, verificou-se que o total de três ou quatro produções apresenta uma correlação razoávelmente alta $(0,79)$, fato que permitiria realizar uma seleção mais branda. Porém, o mais seguro seria esperar seis produções com $r=0,96$ para se praticar a seleção final,concordando com as recomendações de MEDINA et alii (1984).

\subsection{Correlação entre a produção total e outros ca- racteres agronômicos}

Os valores de coeficientes $r, r_{F}$ e $r_{G}$ entre as outras caracteristicas e a produção beneficiada to tal, apresentados na Tabela 32, de uma maneira geral, apresentaram concordância satisfatória entre si, quantificados pelas correlações de $0,788 * *$ entre $r_{G}$ e $r$, de $0,835 * *$ entre $r_{G}$ e $r_{F}, 0,967 * *$ entre $r_{F}$ e $r$.

$\mathrm{Na}$ seleção indireta para a produção o que interessa é uma alta correlação entre os outros caracte- 
res agronômicos e a produção beneficiada. Assim, a discussão girará somente sobre o coeficiente $r_{G}$ entre a produção e os demais caracteres.

O coeficiente $r_{G}$ de 0,643 entre 0 tamanho dos grãos e a produção é bastante elevada. Isto contrasta com o resultado obtido por FAZUOLI (1977) para as progênies de 'Mundo Novo', incluindo-se aî uma progênie CP 474, onde as correlações obtidas variaram de acordo com o ano de produção e com o material genético, apresentando ora correlações negativas e significativas e ora correlações não significativas. Como neste trabalho os dados fo ram obtidos, em um ano de alta produção, a $r_{G}$ possivelmen te é uma estimativa próxima da real. As correlações entre a produção total e os caracteres rendimento $(-0,0909)$, porcentagem de grãos normais $(0,0000)$, porcentagem de grãos moca $(0,0000)$ e porcentagem de grãos concha $(-0,1515)$ mostraram-se negativos e baixos ou nulos. Apesar dos baixos valores, as correlações negativas com a produção total para os caracteres rendimento e porcentagem de grãos concha indicam que estes caracteres devem ser os menores ‘ possíveis, para não prejudicar a produtividade. A $r_{G}=$ 0,426 obtida entre a altura da planta e a produção total, está de acordo com $r=0,22$ ns a $0,42 *$ obtidos por DHALIWAL (1968) em amostras de vários cultivares e com $r=0,58 * *$ obtido por ROCHA et alii (1980). A correlação genética entre o diāmetro da copa e a produção beneficiada $(0,285)$, mostrou-se concordante com os valores antes 
obtidos por DHALIWAL $(1968, r=0,04$ ns a $0,67 * *)$, ROCHA et $\mathbb{a} \mathbb{1} i \mathrm{i}(1980, r=0,51 * *)$, SRINIVASAN \& VISHVESHWARA $(1981, r=0,73 * *)$ 。

A correlação genética negativa de $-0,772$ encontrada entre a produção total e a primeira produção, indica que as progênies mais produtivas no primeiro ano resultaram em progênies menos produtivas no total de oito anos de colheitas. Isto pode ser explicado pela existência de progênies que iniciaram a produção mais cedo e outras progênies que iniciaram a produção mais tardiamente, como foi revelado pelos resultados apresentados na Tabela 24 . Dentre as produções anuais e as diferentes combinações de produções anuais nas três primeiras produções, a melhor $r_{G}$ obtida com a produção beneficiada total foi 0,870 , combinando-se a segunda e a terceira produção.

O incremento anual de produção nas três e nas oito primeiras produções, apresentaram, respectivamente, $r_{G}$ de 0,376 e 0,294 com a produção beneficiada. FAzUOLI (1977) mostrou que em Campinas, as linhagens selecionadas dos cultivares Bourbon Vermelho, Bourbon Amarelo e Mundo Novo têm a tendência de crescer com menos oscilação anual de produção, até o 50 ano e,após isto,entram no período de acentuada oscilação anual de produção, apresentando o máximo de produção por planta entre o 11 o e o 14o. ano de produção; a partir daí, o cafeeiro entra num período de declínio, ainda com a acentuada oscilação anual de produção. Desta forma, as progênies desejáveis são 
aquelas que apresentam um incremento anual de produção maior por um prazo maior. As progênies com menor incremento anual são aquelas que começam a produzir cedo, mas o seu aparato fotossintético não consegue sustentar a produção (SERA, 1984 e CANNEL, 1985) e o incremento anual de produção é menor ou negativo. Por outro lado, as progênies com maior incremento anual podem ser aquelas que começam a produzir tarde e a capacidade produtora é manifestada mais tarde (produção tardia) o que não è desejável. Apesar da correlação positiva, o desejável seria um incremento anual da produção intermediário, nem baixo e nem alto. Pode ser que as progênies que apresentam pro duções crescentes nestes oito anos sejam aquelas que continuarão produzindo com elevadas produções por mais anos.

Os cafeeiros nas condições brasileiras de cultivo sem sombra e sem podas programadas, apresentam menores oscilações anuais de produção até o quinto ano e, a partir daí,entram num período de oscilações acentuadas (F $\underline{A}$ ZUOLI, 1977). Os resultados obtidos nesta pesquisa de $r_{G}=-0,657$ e $r_{G}=-0,239$, respectivamente, para a oscilação anual de produção nas três e oito primeiras colheitas com a produção beneficiada, contrariam as observações de CARVALHO et alii (1952), CARVALHO \& MONACO (1967),CARVALHO et alii (1973) e FAZUOLI (1977), que afirmaram existir uma oscilação anual de produção maior nas plantas mais produtivas. No entanto, o resultado desta pesquisa concorda com o ponto de vista de STEVENS (1949) que acha que 
a seleção de uma variedade altamente produtiva não aumenta a amplitude da oscilação anual de produção. Também, CASTILLO-ZAPATA \& QUICENO (1968) não encontraram uma relação clara entre os cultivares mais produtivos e uma maior oscilação anual de produção. Os resultados do presente trabalho indicaram ser possível selecionar progênies ao mesmo tempo produtiva e com menor oscilação anual de produção.

\subsection{Seleção antecipada com base em caracteres agronô- micos avaliáveis até o terceiro ano de colheita}

A identificação antecipada de genótipos mais produtivos com maior precisão do que a alcançada usando-se apenas a produção dos anos iniciais, é altamente desejável no melhoramento genético do cafeeiro. Segundo MEDINA et alii (1984) a vida econômica do cafeeiro transpõe vinte anos de produção e, assim, um cultivar bem sucedido, deve começar a produzir cedo e manter produções al tas por mais anos. As melhores progênies podem ser escolhidas com base nas seis primeiras produções consecutivas (CARVALHO, 1952; FAZUOLI, 1977 e CARVALHO et alii, 1985). Entretanto, a obtenção de produções num tal período de tempo, para uma cultura perene arbustiva que começa a produzir somente após très anos de período vegetativo ainda é consumidora de tempo, além de ser consumidora de espaço e recursos. 
o coeficiente de determinação $\left(R^{2}\right)$ indica o porcentual em que a produção estimada pela equação de regressão múltipla explica a produção real (SNEDECOR \& COCHRAN, 1974). As melhores equações de regressão múltipla, usando-se apenas as produções iniciais de três, duas e uma colheita, apresentaram coeficientes de determinação respectivamente iguais a $0,615,0,489$ e 0,070 (Tabela 33).

A melhor de todas as equações para a seleção antecipada baseando-se em caracteres agronômicos avaliáveis nos três primeiros anos de produção com $R^{2}=0,791$ è

$$
\begin{aligned}
\vartheta_{2} & =-5,8503+0,1888 x_{1}-0,6041 x_{2}+1,6447 x_{3}+ \\
& +1,7935 x_{4}+0,4019 x_{8}+0,3939 x_{11}+0,4019 x_{12}
\end{aligned}
$$

Uma outra equação interessante é a $\mathbb{\Upsilon}_{1.1} \mathrm{com}$ $R^{2}=0,7718$.

A melhor equação para a estimação da produção beneficiada total usando-se caracteres, agronômicos avaliáveis nas duas primeiras produções com $R^{2}=0,717$ é

$$
\begin{aligned}
\nabla_{7} & =-9,7458+0,2631 x_{1}-0,2071 x_{2}+2,3135 x_{3}+ \\
& +2,1474 x_{4}+0,3209 x_{8}
\end{aligned}
$$

Usando-se apenas os caracteres agronômicos avaliáveis até o primeiro ano de produção, a melhor equação de regressão múltipla para estimar a produção beneficiada total com $R^{2}=0,571$ é 


$$
\begin{aligned}
\hat{P}_{6} & =-14,8174+0,6908 x_{1}-0,7514 x_{2}+2,7622 x_{3}+ \\
& +2,7744 x_{4}+0,2872 x_{5}
\end{aligned}
$$

Observa-se que os caracteres $x_{1}$ (tamanho de grãos, $x_{2}$ (rendimento), $x_{3}$ (altura da copa) e $x_{4}$ (diâmetro da copal estão presentes nas três equações mencionadas $\left(\hat{Y}_{2}, \hat{Y}_{6}\right.$ e $\left.\hat{Y}_{7}\right)$. Alguns autores (ARAÚJO NETO, 1979; SRINIVASAN, 1982), tëm preconizado a realização de seleção antecipada nos anos iniciais em que as plantas ainda não iniciaram a produção de grãos. Estes tipo de seleção antecipada deve ser baseada em caracteres morfológicos,tais como altura ediâmetro da copa, vigor vegetativo, número de ramos produtivos e número de nós com produtividade. Quạndo a produção foi excluída, a melhor equação de regressão múltipla obtida com $\mathrm{R}^{2}=0,454$ foi

$$
P_{41}=-7,3116+3,3537 x_{3}+2,9482 x_{4}
$$

Por esta equação, a produção total seria estimada com base apenas nos caracteres altura $\left(\mathrm{X}_{3}\right)$ e diâmetro $\left(\mathrm{x}_{4}\right)$ da copa.

Verifica-se que todas as equações estimadas com o uso da produção e de outros caracteres apresentaram $\mathrm{R}^{2}$ maiores que os $\mathrm{R}^{2}$ obtidos usando-se apenas produção. A equạ̧ão $\hat{Y}_{41}$ obtida apenas com os caracteres altura e diâmetro da copa, apresentou um $\mathrm{R}^{2}$ próximo do $\mathrm{R}^{2}$ obtido quando se usou apenas as duas primeiras produções. 
Os caracteres altura e diâmetro da copa foram avaliados no oitavo ano de produção: Embora não tenham sido avaliados nos anos iniciais, são características que se manifestam cedo, desde o segundo ou primeiro ano do período vegetativo, como já tem sido pesquisado por SRINIVASAN (1982) e também nos anos iniciais de produção (WALYARO, 1983). Portanto, a utilização destes caracteres representam uma inferência que pode ser válida nos anos iniciais de desenvolvimento das plantas. As condições em que tais caracteres foram avaliados devem ter sido diferentes das condições iniciais de desenvolvimento e podem haver diferenças importantes. Vejamos qual seria a melhor equação, caso de excluissem os caracteres altura e diâmetro da copa. Neste caso, a melhor equação $\operatorname{com} \mathrm{R}^{2}=$ 0,692 seria

$$
\begin{aligned}
\Omega_{8} & =-0,8010+0,4093 x_{1}-0,5122 x_{2}+0,4873 x_{8}+ \\
& +0,5557 x_{11}+0,0119 x_{12}
\end{aligned}
$$

Em relação à melhor equação estimada nas duas e três colheitas iniciais $\left(\hat{\nabla}_{2}\right)$ houve uma perda de representatividade de $9,9 \%(79,1 \%-69,2)$ da produção to tal.

Comparando-se as classificações obtidas pelas progênies, com base nas produções totais observadas e estimadas pelas melhores equações de regressão múltipla (Tabela 34 a 37), verificou-se que para incluir as 
sete progênies $(p=10 \%)$ mais produtivas pela produção estimada, seria necessário selecionar as 13 melhores pela equação n! 2, 20 progênies melhores pela equação n? 7 , as 24 progênies melhores pela equação no 8 ou as 50 melhores pela equação no 6. Caso se realizasse a seleção com base apenas na produção do primeiro biênio $\left(\mathrm{R}^{2}=0,488\right)$ ha veria necessidade de se selecionar as 54 melhores progênies, para poder incluir as sete progênies superiores em produção total; este procedimento tornar-se-ia inviável.

Quando a predição não envolve nenhuma colheita, verificou-se que haveria necessidade de se selecionar as 37 progênies melhores pela produção estimada (equação no 41, Tabela 38) para se incluir as sete melhores progênies $(p=10 \%)$. Como as medidas de altura e diâmetro da copa não foram obtidas antes de se iniciar a produção, este resultado deve ser tomado com reserva.

Em resumo, conclui-se que existe viabilida de para a realização de seleção antecipada baseada na produção estimada através da equação de regressão múltipla para as duas ou as três primeiras colheitas, dependendo de $\mathrm{o}$ ano de grande produção ocorrer na segunda ou na terceira produção. No caso de ocorrer uma produção baixa na segunda colheita, deve-se esperar a terceira colheita para então selecionar, pois os anos de grande produção são melhores para se praticar seleção, conforme FAZUOLI (1977) e CARVALHO et alii (1984). A seleção anteci pada para produção é bastante útil para o melhorista,pois 
não haveria motivo para continuar colhendo planta a planta as progênies que se mostram, desde o início não possuir potencial produtivo.

A utilização das equações no 4 e 7 (três e duas colheitas iniciais) para prática de seleção dentro de progênies, mostrou que uma intensidade de seleção de 25\% (seleção das três plantas superiores dentre as 12 plantas pesquisadas de cada progêniel foi suficiente para manter respectivamente $77 \%$ e $70 \%$ das plantas individuais em produção total. Desta forma, a seleção antecipada usando-se as produções e outros caracteres das colheitas iniciais (conforma apresentado por WALYARO \& VAN DER VOSSEN, 1979) e a seleção antecipada para antes do início da produção (sugerida por ARAÚJO NETO et aliii, 1979 e por SRINIVASAN, 1982), tiveram a sua viabilidade confirmada por esta pesquisa.

Assim, nas condições ambientais em que 0 experimento foi conduzido e com o germoplasma pesquisado, foi possivel verificar que existem possibilidades satisfatórias para praticar seleção antecipada com base nas observações experimentais de dois ou três anos iniciais de colheita. Para garantir que as progênies antecipadamente selecionadas incluam as progênies realmente superio res em produção total, é aconselhável utilizar intensidades de seleção mais brandas, tanto entre como dentro de progênies. 
Esta pesquisa apresenta a limitação de ter empregado oito anos iniciais de colheita para avaliação da produção total. Torna-se recomendāvel a continuidade desta pesquisa no sentido de que mais colheitas sejam acumuladas, de maneira a se permitir a observação de uma produção total em um período de tempo mais próximo daquele correspondente à longevidade do cafeeiro. Com isto, seria possível verificar se as equações obtidas continuariam a ter o mesmo poder de predição. 


\section{CONCLUSÕES}

As seguintes conclusões puderam ser obtidas dos resultados desta pesquisa:

(a) Confirmou-se a adequação do esquema de análise em par celas sub-divididas no tempo, de dados bienais de pro dução para neutralizar o efeito de ciclos bienais de produção para estudos de herdabilidade.

(b) A variabilidade genética existente entre progênies (provavelmente na geração $F_{5}$ ) foi inferior à variabilidade dentro de progênies, mas ambas: mostraram-se passiveis de serem exploradas por seleção.

(c) Três progênies destacaram-se por apresentarem altos níveis de produtividade, respostas diretamente proporcionais à variação ambiental, comportamento previsível (estável) das produções anuais e grau satisfạ tório de oscilação anual de produção.

(d) As progênies com respostas diretamente proporcionais à variação ambiental também mostraram tendências de proảuções crescentes nos anos sucessivos de colheitas. A oscilação anual ce produção mostrou-se melhor guve 
o parâmetro de previsibilidade de comportamento para fins de seleção.

(e) O nivel de variabilidade genética dos caracteres mostrou a seguinte ordem decrescente de magnitude: incremento anual da produção nos oito anoṣ iniciais de colheita, altura da copa, precocidade de produção, os cilação anual da produção nas três colheitas iniciais, oscilação anual da produção nas oito colheitas iniciais, diâmetro da copa, incremento anual da produção nas três primeiras colheitas.

(f) A seleção das progênies superiores em produção relacionou-se com outros caracteres agronômicos, de manei ra que as progênies mais produtivas também exibiram sementes graúdas, rilaior altura e diâmetro da copa,bai xa relação produção cereja/produção beneficiada, precocidade de produção e menores oscilações anuais de produção, nas três e nas oito colheitas iniciais.

(g) A oscilação anual da produção mostrou tendência de correlação negativa com a produção. Os demais caracteres correlacionaram-se, positivamente, com produção, na seguinte ordem decrescente de magnitude: tamanho dos grãos, precocidade de produção, altura da copa, in cremento anual da produção nas três colheitas iniciais, incremento anual da produção nas oito colheitas iniciais, e diâmetro da copa.

(h) Existem possibilidades de se praticar seleção anteci- 
pada, pois a produção e demais caracteres avaliados nos três anos iniciais de colheita foram suficientes para predizer $79 \%$ da variação da produção total das progênies. A diminuição dos caracteres e/ou do número de anos de colheitas envolvidos, prejudicou, sensi velmente a predição da produção total.

(i) Para incluir todas as sete progênies selecionadas com base na produção total $(p=10 \%)$, foi necessário rela xar as seleções antecipadas para intensidade de seleção iguais a $18 \%$ (três anos de colheitas) e 28\% (dois anos de colheita). A seleção antecipada também mostrou-se viável de ser praticada dentro de progênies.

(j) Os caracteres auxiliares que poderiam ser empregados na seleção antecipada para a produção até a terceira colheita, são: produção, cscilação anual da produção, tamanho dos grãos, altura da copa, incremento anual da produção e diâmetro da copa por satisfazerem os re quisitos de correlação genética com a produção total e herdabilidade de razoável magnitude aliado à facili dade de avaliação. 


\section{REFERENCIAS BIBLIOGRAFICAS}

AHMAD, J.; VISHVESHWARA, S.; SRINIVASAN, C.S. Variability in coffee; III. Inheritance of flower number in Cofbea congensis $\mathrm{x}$ Coffea canephora. Journar of Coffee Research, Karnataka, ㄱ(4): 105-8, 1977.

ALLARD, R.W. Principios de me thoramento genético das plan tas. São Paulo, Edgard Bücher, 1971. 381 p.

ANTUNES FILHO, H. \& CARVALHO, A. Melhoramento do cafeeiro; XII. Variabilidade em linhas puras de café. Bragantia, Campinas, 16: 197-213, 1957.

ARAÚJO NETO; K. de. Avaliação preliminar de progênies de Cofbea arabica pela estimativa simultânea de vigor vege tativo e carga pendente. In: CONGRESSO BRASILEIRO DE PESQUISAS CAFEEIRAS, 6. Ribeirão Preto, 1978. Resumos. Rio de Janeiro, Ministério da Indústria e Comércio-IBC, 1978. p. 110-3.

BONATO, E.R. Estabilidade fenotípica da produção de grãos de dez cultivares de soja [Glycine max (L.) Merril)] nas condições do Rio Grande do Sul. Piracicaba, 1978. 75 p. (Mestrado - Escola Superior de Agricultura "Luiz de Queiroz"/USP. 
BRIQUET JÚNIOR, R. Melhoramento genético animal. São Pau 1o, Editôra da Universidade de São Paulo, 1967. 268 p.

CANNELL, M.G.R. Crop physiological aspects of coffee bean yield. Journal of Coffee Research, Karnataka, ㅍ(1/2): $7-20,1975$.

CANNELL, M.G.R. Physiology of the coffee crop. In: CLIFFORD, M.D. \& WILLSON, K.C., ed. Coffee; botany, biochemistry and production of beans and beverage. Westport, AVI, 1985. p. 251-83.

CARVALHO, A. Melhoramento do cafeeiro; VI. Estudo e interpretação para fins de seleção de produções individuais na variedade Bourbon. Bragantia, Campinas, 12(6): 179-200, abr., jun., 1952.

CARVAlHo, A. Evolução nos cultivos de café. o agronômico, Campinas, $37(1): 7-11,1985$.

CARVALHO, A.; KRUG, C.A.; MENDES, J.E.T.; ANTUNES FILHO, H.; MORAIS, H. de; ALOISI SOBRINHO, J.; MORAIS, M.V. de; ROCHA, T.R. da. Melhoramento do cafeeiro; IV. Café Mun do Novo. Bragantia, Campinas, 12'4-6); 07-129, 1952.

CARVALHO, A. \& MONACO, L.C. Melhoramento do cafeeiro; XXXI. Ensaio de populações $\mathrm{F}_{2}$ de híbridos entre cultivares de Cobbea arabica. Bragantia, Campinas 26(5): 79-92, 1967.

CARVALHO, A. \& MONACO, L.C. The breeding of arabica coffee. In: FERWERDA, F.P., ed. Outlines of perennial Crop breeding in the tropic. Wageningen, Veenman, 1969, p. $189-241$. 
CARVALHO, A.; MONACO, L.C.; ANTUNES FILHO, H。 Melhoramento do cafeeiro; XV. Variabilidade observada em progênies de café. Bragantia, Campinas, 18(26): 374-86, 1959 .

CARVALHO, A.; MONACO, L.C. CAMPANA, M.P. Melhoramento do cafeeiro; XXVII. Ensaio de seleções regionais de Jaí. Bragantia, Campinas, 233(13): 129-42, 1964 .

CARVALHO, A.; MONACO, L.C.; FAZUOLI, L.C. Melhoramento do cafeeiro; XXXIX. Produtividade e características de pro gênies $\mathrm{S}_{2}$ e $\mathrm{S}_{3}$ de 'Mundo Novo' e 'Bourbon Amarelo' e de híbridos entre estes cultivares. Bragantia, Campinas, $37(15): 129-38,1978$.

CARVALHO, A.; MONACO, L.C.; FAZUOLI, L.C. Melhoramento do cafeeiro; XL。 Estudos de progênies e híbridos de café 'Catuaí'. Bragantia, Campiras, 38 (22): 202-16, 1979.

CARVALHO, A.; MONACO, L.C.; FAZUOLI, L.C。; COSTA, W.M. da ; MEDINA, H.P. Variabilidade na produção em progêries de cafeeiro 'Mundo Novo'. Bragantia, Campinas, 4 (32): 50917,1984 .

$\therefore$ CARVAlHO, A.; SCARANARI, H.J.; ANTUNES FILHO, H.; MONACO, L.C. Melhoramento do cafeeiro; XXII. Resultados obtidos no ensaio de seleções regionais de Campinas. Bragan tia, Campinas, 20 $(30): 711-40,1961$.

CASTILLO-ZAPATA, J. Evaluacion agronomica de hibridos : de cafe introducidos a Colombia. Cenicafé, Chinchinā, : 9-25, jàn/mar。 1984 . 
CASTILLO-ZAPATA, J. \& MORENO-RUIZ, G. Selection de cruzamientos derivados del "Híbrido de Timor" en la obtencion de variedades mejoradas de cafe para Colombia. Cenicafé, Chinchiná,:37-53, abr/jan. 1981 .

CATILLO-ZAPATA, J. \& QUICENO, G. Estudio de la producción de seis variedades comerciales de café. Cenicafé, Chinchiná, 19 (1): 18-39, 1968.

CORNIDE; M.T. \& MONTES, S. Analisis de la interaccion genotipo-ambiente: componentes de la varianza y estabilidad de la cosecha en lineas de cafe seleccionadas em $\mathrm{Cu}-$ ba. Cultivo Tropicales, San José de las Lajas, 111:131$41,1979$.

COXRAN, W.G.\& COX, G.M.Experimental designs. 2. ed. New York, John Wiley \& Sons, 1957. $611 \mathrm{p}$.

DHALIWAL, T.S. Correlation between yield and morphological characters in Puerto Rican and Columnaris varieties of Cobfea arabica L. Journal of the Agricultural University of Puerto Rico, 52: 29-37, 1968 .

EBERHART, S.A.\& RUSSEL, W.A. Stability parameters for comparing varieties. Crop Science, Madison, 6: 36-40, jan./fev. 1966 .

FAZUOLI, L.C. Avaliação de progênies de café 'Mundo Novo' (Cobfea arabica L.). Piracicaba, 1977. 146 p. (Mestra do - Escola Superior de Agricultura "Luiz de Queiroz/USP) 
FONSECA, M.A.S. da; ARAUJO, P.F.C. de; PEDROSO, I॰A. Retor no social aos investimentos em pesquisa na cultura do ca fë. São Paulo, BADESP, 1978。 14 p.

GOMES, F.P. Curso de estatistica experimental. 4ạ ed. Piracicaba, Nobel, 1970. 480 p.

IAC, Campinas, Café (Cofbea arabica L. 'Acaica'). O Agronömico, Campinas, 32: 66-7, 1980 .

IBC-GERCA, Rio de Janeiro. Cultura de café no Brasil - Manual de Recomendações, 3ạ ed. Rio de Janeiro, IBC-GERCA/ Ministério da Indústria e Comércio, 1979。 503 p.

MATIELLO, J.B.; SOUZA, D.D。 de; ASSUMPÇÃO, J.M.; ĀVILES, D。 P. Análise do ciclo bienal de produção. In: CONGRESSO BRASILEIRO DE PESQUISAS CAFEEIRAS, 12。, Caxambu, 1985. Resumos. Rio de Janeiro, Ministério da Indústria e Comér cio - IBC, 1985. p. 217-9.

MAWARDI, S。 \& HARTOBUTOYO, S. Correlation study of yield and branch characteristics of robusta coffee lcoffea canephora Pierre var. robusta Cheval.) on $\mathrm{F}_{1}$ hybrid population. Menara Perkebunan, Jember, $\underline{49}(5): 115-20$, 1981 .

MAWARDI, S.; ISWANTO, A.; HARTOBUTOYO, S. Selection of the $\mathrm{F}_{2}$ population of arabica coffee; II. A preliminary study for individual selection by applying selection indexes. Menara Perkebunan, Jember, 51(5), 128-32, 1983. 
MEDINA, H.P॰; CARVALHO, A.; SONDAHL, M.R॰; FAZUOLI, L.C.; COsTA, H.M. da. Coffee breeding and related evolutionary aspects. In: JANICK, J., ed. Plant breeding reviews. Westport, AVI, 1984. p. 157-94.

MONACO, L.C. Efeito das lojas vazias sobre o rendimento de café 'Mundo Novo', Bragantia, Campinas, 12: 179-200, 1952 。

MONACO, L.C.; CARVALHO, A.; ANTUNES FILHO, H. Cruzamento natural dentro da "cova" do cafeeiro. Bragantia, Campinas, 22 (nota n: 4): XI-XV, maio 1963.

MONACO, L.C.; SCALI, M.H.; CARVALHO, A.; FAZUOLI, L.C. Variabilidade no sistema radicular de genótipos de café. In: REUNIÃO ANUAL DA SBPC, 25., Ilha do Fundão/GUANABARA, 1973. Resumos. Ilha do Fundão, SBPC, 1973. p. 247.

MORENO-RUIZ, G.; CASTILLO-ZAPATTA, J.; OROZCO-GALLEGO, L. Estabilidad de la produccion de progenies de cruzamientos de 'Caturra' por 'Híbrido de Timor'. Cenicafé, Chin chiná, :79-90, out./dez.1984.

PANDEY, K.K. Elimination of heterozigosity and efficiency of genetic systems. Theoretical and Applied Genetics, Berlin, 44 : 199-205, 1974 .

RAMOS, L.C. da S. Desenvolvimento de plântulas de quatro cultivares de café. Bragantia, Campinas, 39: 2158,1980 。 
RAMOS, L.C. das S.; LIMA, M.M.A. de; CARVALHO, A. Crescimento do sistema radicular e da parte aérea em plantas jovens de cafeeiro. Bragantia, Campinas, 41: $93-9$, 1982 .

REDDY, G.S.T. \& SRINIVASAN, C.S. Variability for flower production, fruit set and fruit drop in some varieties of Coffea arabica L. Journal of Coffee Research, Karna taka, $\underline{9}(2): 27-34,1979$.

ROCHA, T.R.; CARVALHO, A.; FAZUOLI, L.C. Melhoramento do cafeeiro; XXXVIII. Observações sobre progênies do cultị var Mundo Novo de Cobjea arabica na Estação Experimental de Mococa. Bragantia, Campinas, 39(15): 148-60, 1980 .

SANTOS, J.B. dos. Estabilidade fenotípica de cultivares de feijão (Phaseolus vulgaris $\mathrm{L}$. ) nas condições do sul de Minas Gerais. Piracicaba, 1980。110 p. (Mestrado - Es cola Superior de Agricultura "Luiz de Queiroz"/USP) •

SERA, T. Estimação cios componentes da variāncia e do coeficiente de determinação genotípica da produção de grãos de café (Cobfea arabica L。) . Piracicaba, 1980. 62 p. (Mestrado - Escola Superior de Agricultura "Luiz de Quei roz"/USP) .

SERA, T. Seleção precoce para produção no melhoramento genético de plantas perenes. Piracicaba, 1984. 115 p. (Monografia - Escola Superior de Agricultura "Luiz de Queiroz"/USP) . 
SINGH, R.K. \& CHAUDARY, B.D. Biometrical methods in quantitative genetic analysis. 2 ed. Ludhiana, Kalya$\mathrm{ni}, 1979.304 \mathrm{p}$.

SNEDECOR, G.W. \& COCHRAN, W.G. Statistical methods. 6 . ed. Ames, Iowa State University, 1974. 593 p.

SRINIVASAN, C.S. Association of some vegetative characters with initial fruit yield in coffee (Cofbea arabica L.). Journal of Coffee Research, Karnataka, 10(2): $21-7,1980$

SRINIVASAN, C.S. Pre-selection for yield in coffee. Indian Journal of Genetics, New Delhi, 42(1): 15-9, 1982.

SRINIVASAN, C.S. \& SUBBALAKSHMI, V。 A biometrical study of yield variation in some coffee progenies. Journal of Coffee Research, Karnataka, 11(2): 26-34, 1981.

SRINIVASAN, C.S. \& VISHVESHWARA, S. Variability and breeding value of some characters related to yield in a world collection of arabica coffee. Indian Coffee, Bangalore, 15 (5): 119-28, 1981 .

SRINIVASAN, C.S.; VISAVECHViARA, S。; SUBRAMANYA, H. Genotype-environmental interaction and heritability of yield in Coffea arabica L. Journal of Coffea Research, Karnataka, 9 (3): 69-73, 1979. 
STEVENS, W.L. Análise estatística do ensaio de variedades de café. Bragantia, Campinas, 9 (5-8): 103-123, 1949.

STILL, R.G.D.\& TORRIE; J.H. Principles and procedues of statistics. 1å ed. New York, McGraw-Hill, 1960. 481 p.

STILL, R.G.D. \& TORRIE, J.H. Principles and procedures of statistics. 2. ed. New York, McGraw-Hill, 1980. 633 p.

TORRES, R. Indice de Seleção. Piracicaba, 1985. 77 p. (Mㅡㅡ nografia - Escola Superior de Agricultura "Luiz de Queiroz"/USP) .

TOSTAIN, S. \& PIERRES, D. le. Etude de croissements contrólés entre differentes oriçines de coffea arabica. In: INSTITUT FRANÇAIS DU CAFE ET DU CACAO. Etude de la structure et de la variabilite genetique des cafeirs: Resultats des études et des expërimentations réalisées au Cameroun, et Côte d'Ivoire et à Madaguscar sur lẻspèce Coffea arabica L. Collectée en Ethiopie par une mission ORSTOM en 1966. Paris, IFCC, 1978. p. 79-88 (Bulletin. 14)。

VALENCIA A.,G. Relation entre el indice de area foliar y la productividad del cafeto. Cenicafẻ, Chinchiná, :79-89, out./dez. 1973.

VELLO, N.A. Comportamento e variabilidade em populações de capim gordura (Melinis minutiflora Beauv.). Piraci caba, 1975. 100 p. (Mestrado - Escola Superior de Agricultura "Luiz de Queiroz"). 
VISHVESHWARA, S. \& SRINIVASAV, C.S. Studies on quantitative inheritance in coffee 1. Flower number per inflo rescence in Coffea canephora x C. arabica. Turrialba, Turrialba, $27(4): 405-9,1977$.

VAN DER VOSSEN, H.A.M. Coffee selection and breeding.In: CLIFFORD, M.N. \& WILLSON, K.C. ed. Coffee; Botany, biochemistry and production of beans and beverage. Westport, AVI, 1985. p. 48-96.

WALYARO, D.J. Considerations in breeding for improved yield and quality in arabica coffee l cofbea arabica L.) . Wageningen, 1983. 119 p. (Doutorado - Agricultural University).

WALYARO, D.J. \& VOSSEN, H.A.M。 Van Der。 Early determination of yield potential in arabica coffee by applying index selection. Euphytica, Wageningen, 28: $465-72,1979$.

WELLMAN, F.L. Details of origin and dispersion of arabica coffee. In: Polunin, N., ed. Coffee; Botany, cultivation, and utilization, London, Leonard Hill, 1961. cap. 3, p. 27-40 
.98 .

\section{FIGURA E TABELAS}




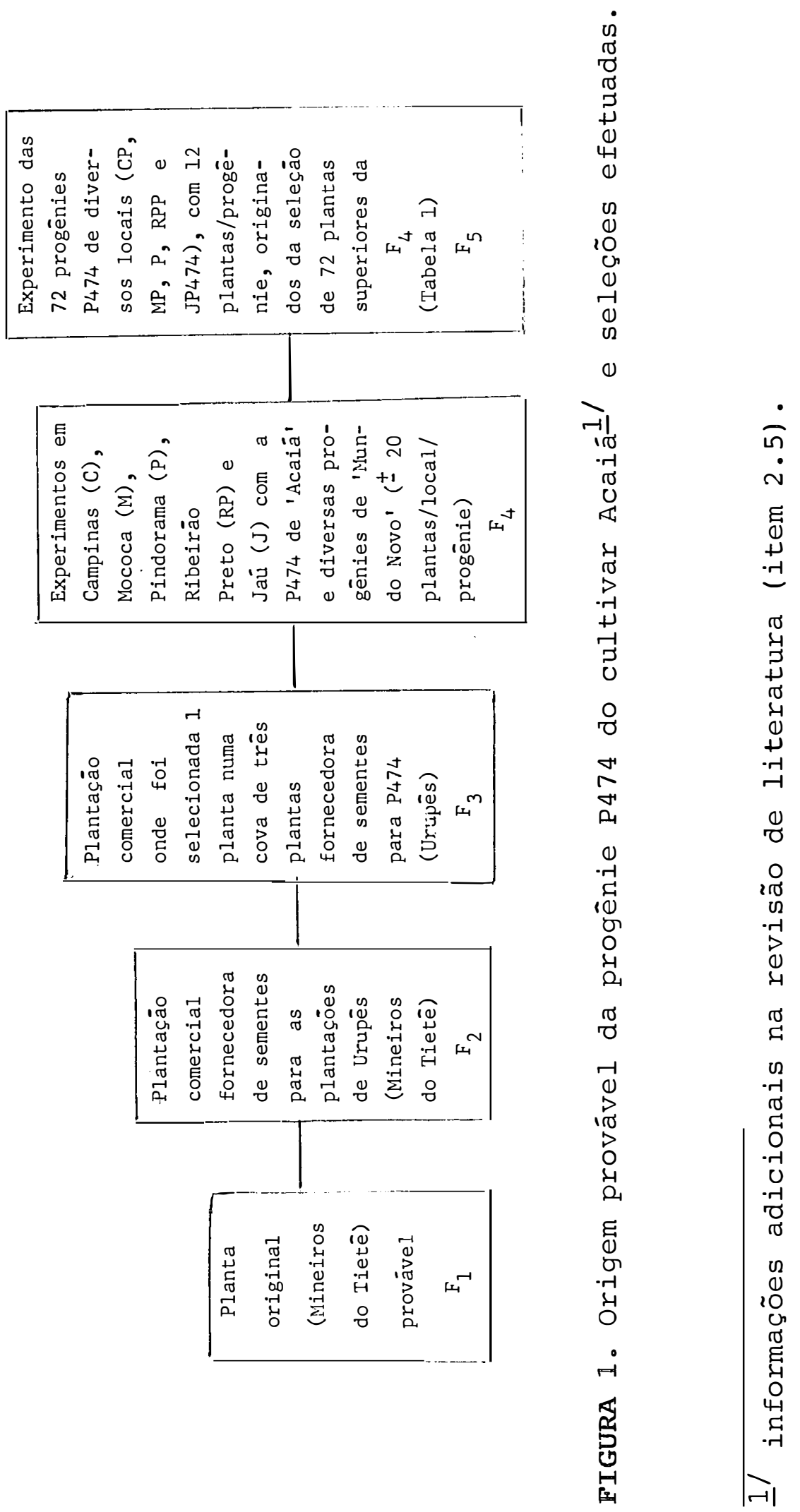


TABELA 1 - Relação de progênies da cultivar Acaiá de c. arabica L. estudadas na Estação Experimental de Mococa do Instituto Agronômico de Campinas.

\begin{tabular}{|c|c|c|c|c|}
\hline \multirow[b]{2}{*}{$\begin{array}{c}\text { No da } \\
\text { progênie }\end{array}$} & \multirow[b]{2}{*}{ 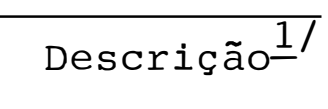 } & \multirow[b]{2}{*}{$\begin{array}{c}\text { No da } \\
\text { progênie }\end{array}$} & \multicolumn{2}{|c|}{11} \\
\hline & & & Des & scrição-1/ \\
\hline 1 & CP 474-3 & 37 & $\mathrm{CP}$ & $474-21$ \\
\hline 2 & MP $\quad 474-19$ & 38 & $\mathrm{P}$ & $474-7$ \\
\hline 3 & MP 474-7 & 39 & $\mathrm{RPP}$ & $474-8$ \\
\hline 4 & RPP $474-13$ & 40 & MP & $474-17$ \\
\hline 5 & P $474-1$ & 41 & MP & $474-13$ \\
\hline 6 & $\operatorname{RPP} \quad 474-20$ & 42 & $\mathrm{P}$ & $474-20$ \\
\hline 7 & P $474-10$ & 43 & $\mathrm{RPP}$ & $474-1$ \\
\hline 8 & CP 474-15 & 44 & $\mathrm{CP}$ & $474-7$ \\
\hline 9 & MP $\quad 474-18$ & 45 & $\mathrm{P}$ & $474-14$ \\
\hline 10 & CP 474-9 & 46 & $\mathrm{CP}$ & $474-20$ \\
\hline 11 & $\mathrm{RPP} \quad 474-6$ & 47 & $\mathrm{CP}$ & $474-28$ \\
\hline 12 & P 474-15 & 48 & $\mathrm{RPP}$ & $474-15$ \\
\hline 13 & $\mathrm{RPP} \quad 474-2$ & 49 & MP & $474-8$ \\
\hline 14 & $\mathrm{RPP} \quad 474-10$ & 50 & MP & $474-20$ \\
\hline 15 & CP $474-14$ & 51 & $\mathrm{CP}$ & $474-11$ \\
\hline 16 & CP $474-36$ & 52 & $\mathrm{RPP}$ & $474-5$ \\
\hline 17 & P 474-19 & 53 & $\mathrm{RPP}$ & $474-3$ \\
\hline 18 & MP $\quad 474-11$ & 54 & $\mathrm{CP}$ & $474-16$ \\
\hline 19 & P $474-5$ & 55 & $\mathrm{CP}$ & $474-25$ \\
\hline 20 & CP 474-6 & 56 & $\mathrm{RPP}$ & $474-7$ \\
\hline 21 & $\operatorname{RPP} \quad 474-18$ & 57 & MP & $474-6$ \\
\hline 22 & MP 474-2 & 58 & RPP & $474-9$ \\
\hline 23 & $\mathrm{P} \quad 474-13$ & 59 & $\mathrm{RPP}$ & $474-14$ \\
\hline 24 & MP 474-15 & 60 & $\mathrm{CP}$ & $474-17$ \\
\hline 25 & RPP $474-16$ & 61 & MP & $474-9$ \\
\hline 26 & CP $474-18$ & 62 & $\mathrm{CP}$ & $474-19$ \\
\hline 27 & MP $474-15$ & 63 & MP & $474-10$ \\
\hline 28 & CP 474-22 & 64 & MP & $474-12$ \\
\hline 29 & $\mathrm{RPP} \quad 474-4$ & 65 & $\mathrm{CP}$ & $474-10$ \\
\hline 30 & MP $\quad 474-4$ & 66 & $\mathrm{RPP}$ & $474-11$ \\
\hline 31 & P 474-12 & 67 & RPP & $474-17$ \\
\hline 32 & CP $474-5$ & 68 & MP & $474-16$ \\
\hline 33 & CP $474-12$ & 69 & $\mathrm{CP}$ & $474-8$ \\
\hline 34 & P 474-3 & 70 & JP & $474-7$ \\
\hline 35 & RPP $474-12$ & 71 & MP & $474-1$ \\
\hline 36 & RPP 474-19 & 72 & $\mathrm{JP}$ & $474-8$ \\
\hline
\end{tabular}

1/ Informações adicionais na revisão de literatura (item 2.5) e na Figura 1 . 


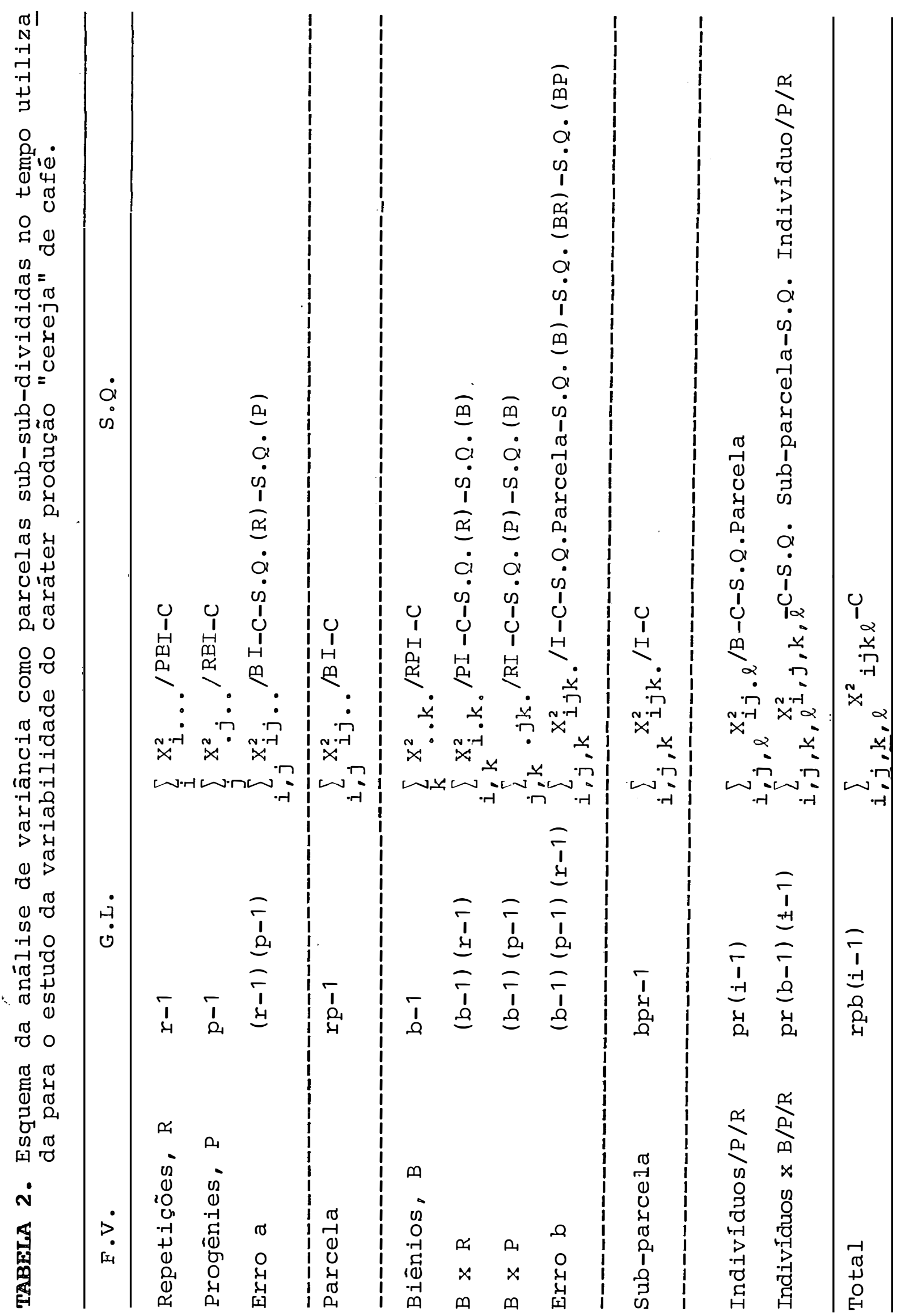


TABELA 3. Caracteres agronōmicos estudados nas progēnies de café 'Acaiā' da Estação Experimental de Mococa, SP, $1972 / 79$.

Caracteres Sỉmbolos Descriçāo

- Produção cereja tota1

- Produção beneficiada tota1

- Tamnho dos gräos

- Renda

- Altura da copa

- Diāmetro da copa

- Porcentagem de grāos normais

- Porcentagem de grãos moca

- Porcentagem de grãos concha

- Produção do primeiro ano

- Produção do segundo ano

- Produção do terceiro ano

- Produçāo do primeiro biēnio ou precocidade de produção

- Produção do segundo + terceiro ano

- Produçāo do primeiro triēnio

- Incremento anual da produção 3

- Oscilação anual de produção 3 $\because$

- Incremento anual da produção 8

- Oscilação anua1 da produção 8

- Produção dos melhos anos iniciais
$Y^{\prime}$

Peso em quilogramas da produçāo total de oito anos de frutos de café

Y Peso em quilogramas da produção total de oito anos de grãos de café (frutos sem a casca)

$\mathrm{X}_{1} \quad$ Peneira média dos grãos normais ou chatos

$\mathrm{x}_{2}$ Prod. cereja/bener. nas 3 lás. colheitas

$\mathrm{x}_{3} \quad$ Altura da planta em metros

$\mathrm{X}_{4}$ Diāmetro da planta em metros a $1,5 \mathrm{~m}$ do solo

GN \% de GN do tipo chato em relação a todos os tipos

GM \% de GM do tipo encaracolado em relação a todos os tipos

GC \% de GC do tipo poliembriōnicos em relação a todos os tipos

$\mathrm{X}_{5}$ Peso em quilogramas da produção cereja do 10 ano

$x_{6}$. Peso em quilogramas da produção cereja do $2 \underline{Q}$ ano

$\mathrm{X}_{7} \quad$ Peso em quilogramas da produção cereja do 30 ano

$\mathrm{X}_{8} \quad$ Peso em quilogramas da produção cereja do 1 o biēnio

$\mathrm{X}_{9}$ Peso em quilogramas da produçāo cereja do $2 \underline{O}+3 \underline{0}$ anos

$\mathrm{X}_{10} \quad$ Peso em quilogramas da produção cereja do 10 triēnio

$\mathrm{x}_{11}$ Incremento médio anual da produção cere ja no 1o triēnio medido pelo coeficiente de regressão das produçōes anuais so bre os anos de colheitas

$\mathrm{x}_{12}$ Estabilidade da produção anual no 10 triēnio medido pelo coeficiente de variação das produçōes cereja anuais sobre a produção média anual

$\mathrm{X}_{14} \quad$ Idem a $\mathrm{X}_{11}$ para a produçāo total de oi-

$x_{15}$ tom a $x_{12}$ para a produção total de oi-

$\mathrm{X}_{13}$ Peso em kg da produçāo cereja do 10 + 30 anos 


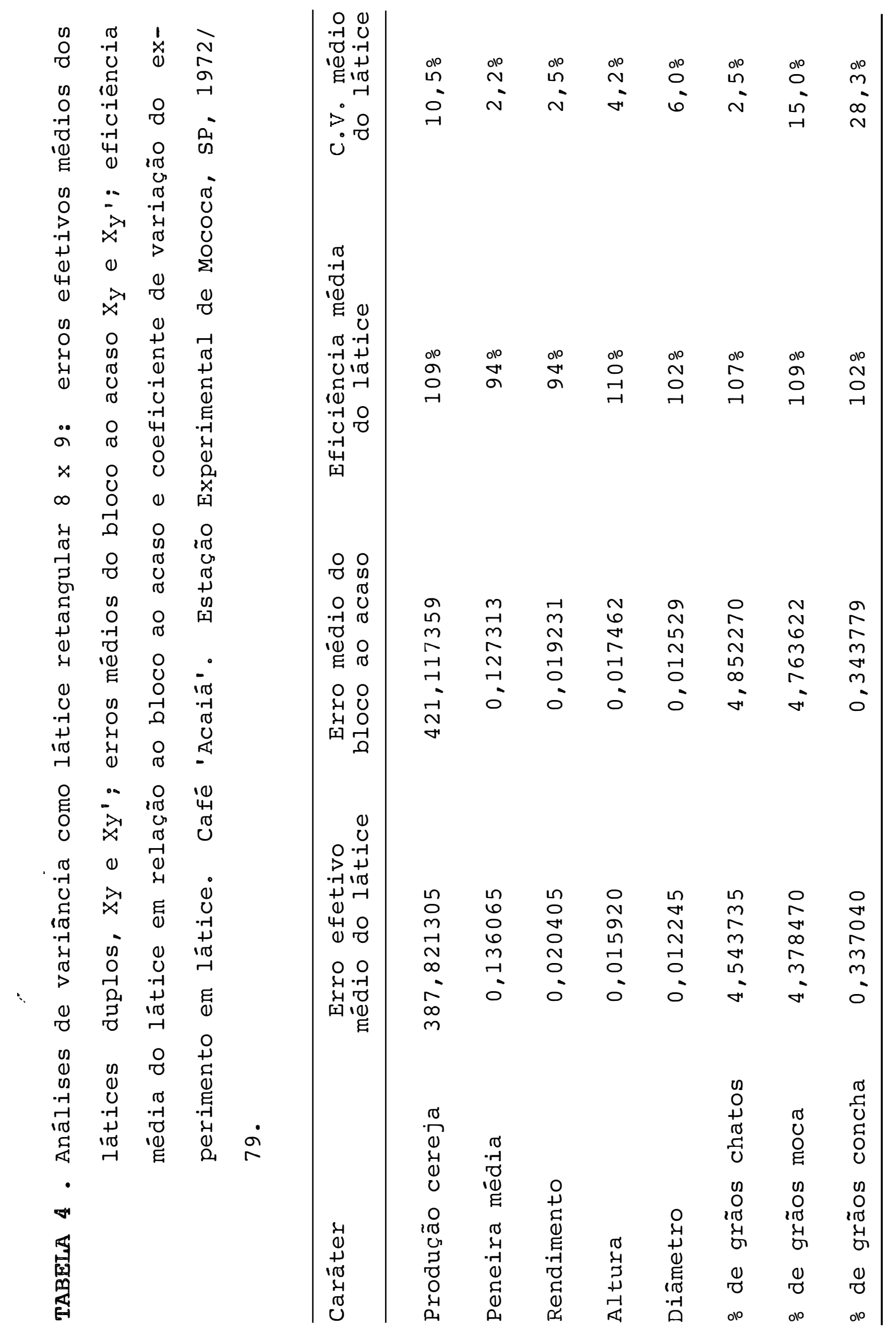




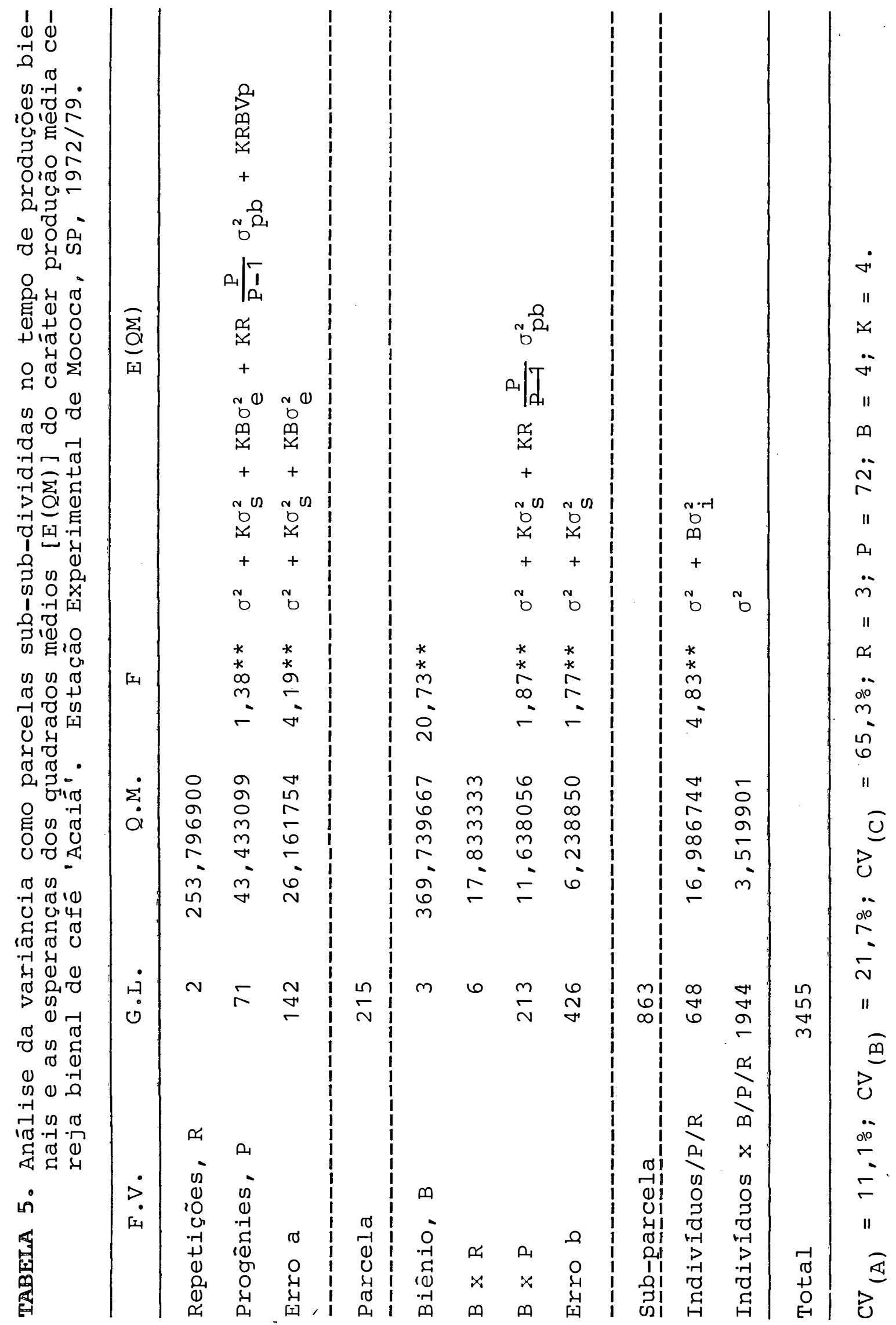


TABELA 6. Estimativas dos componentes da variância fenotípica e dos coeficientes de determinação genotipica bienal para plantas individuais $\left(\sigma_{i}\right)$ e para progênies $\left(\sigma_{p}\right)$ com diferentes números
de biênios.

\begin{tabular}{|c|c|c|c|}
\hline Progênies & individuais & & Enies \\
\hline \multirow[t]{4}{*}{$\hat{\sigma}_{i}^{2}$} & $=3,366711$ & $\hat{\mathrm{v}}_{\mathrm{p}}$ & $=0,989345$ \\
\hline & - & $\hat{\sigma}_{e}^{2}$ & $=4,980726$ \\
\hline & - & $\hat{\sigma}_{\mathrm{pb}}^{2}$ & $=1,774739$ \\
\hline & - & $\widehat{O}_{\mathrm{S}}^{2}$ & $=5,358875$ \\
\hline$\sigma^{2}$ & $=3,519901$ & $\widehat{\sigma}^{2}$ & $=3,519901$ \\
\hline$\widetilde{\sigma}_{\mathrm{F}}^{2}$ & $=6,886612$ & $\bar{\sigma}_{\mathrm{F}}^{2}$ & $=3,6194$ \\
\hline$b_{i}$ & $=0,4889$ & $\mathrm{~b}_{\mathrm{p}} 4 \mathrm{~B}, 3 \mathrm{R}$ & $=0,2728$ \\
\hline
\end{tabular}

$5_{\mathrm{p}} 3 \mathrm{~B}, 3 \mathrm{R}, 4 \mathrm{I}=0,2509$

$\mathrm{b}_{\mathrm{p}} 2 \mathrm{~B}, 3 \mathrm{R}, 4 \mathrm{I}=0,2156$

$\mathrm{b}_{\mathrm{p}} 1 \mathrm{~B}, 3 \mathrm{R}, 4 \mathrm{I}=0,1515$

$5_{\mathrm{p}} 10 \mathrm{~B}, 3 \mathrm{R}, 4 \mathrm{I}=0,3257$

$5_{p} 4 B, 9 R, 4 I=0,4624$

$\mathrm{b}_{\mathrm{p}} 4 \mathrm{~B}, 9 \mathrm{R}, 6 \mathrm{I}=0,4554$

$\sigma_{p} 4 B, 9 R, 8 I=0,4659$ $\mathrm{b}_{\mathrm{p}} 4 \mathrm{~B}, 2 \mathrm{R}, 4 \mathrm{I}=0,2029$

$5_{p} 4 B, 4 R, 4 I=0,3211$

$5_{p} 4 B, 5 R, 4 I=0,3593$

$\mathrm{b}_{\mathrm{p}} 4 \mathrm{~B}, 6 \mathrm{R}, 4 \mathrm{I}=0,3902$

$5_{p} 4 B, 7 R, 4 I=0,4157$

$5_{p} 4 B, 8 R, 4 I=0,4371$

$5_{p} 4 B, 9 R, 4 I=0,4554$

$6_{p} 4 B, 12 R, 4 I=0,4910$ 
.106 .

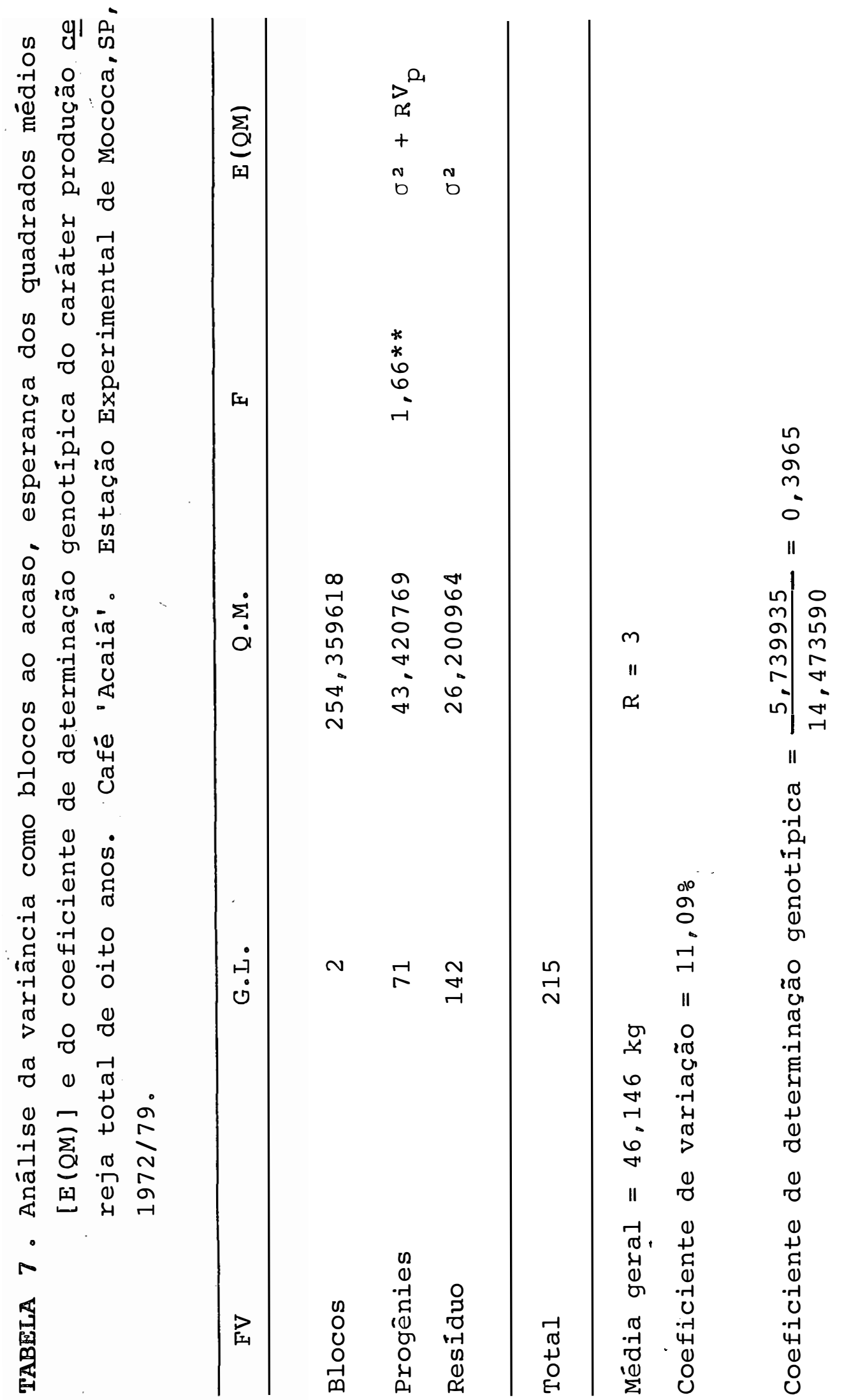


TABEl 8 . Produçōes médias de café cereja por planta obtidas de oito anos de colheitas em quilogramas, variāncias e valores extremos das progēnies de 'Acaiá'. Estação Experimental de Mococa, SP, 1972/79.

\begin{tabular}{|c|c|c|c|c|c|c|c|}
\hline Progēnies & $\overline{\mathrm{X}}$ & $s^{2}$ & Extremos & Progēnies & $\overline{\mathrm{X}}$ & $s^{2}$ & Extremos \\
\hline 1 & 45,20 & $64,43 \mathrm{~ns}$ & $32,1-58,8$ & 37 & 43,58 & $31,47 \mathrm{~ns}$ & $33,6-51,9$ \\
\hline 2 & 51,16 & $80,63 *$ & $32,7-63,2$ & 38 & 48,44 & $57,75 \mathrm{~ns}$ & $32,8-57,6$ \\
\hline 3 & 51,11 & $77,00 *$ & $36,7-66,9$ & 39 & 49,76 & $126,06 * *$ & $32,0-71,4$ \\
\hline 4 & 45,66 & $101,22 *$ & $28,3-64,7$ & 40 & 51,90 & $82,72 *$ & $40,0-76,0$ \\
\hline 5 & 37,83 & $38,77 \mathrm{~ns}$ & $27,5-49,5$ & 41 & 41,53 & $88,25 *$ & $28,1-58,4$ \\
\hline 6 & 44,00 & $46,31 \mathrm{~ns}$ & $24,4-51,8$ & 42 & 45,84 & $42,23 n s$ & $32,8-53,5$ \\
\hline 7 & 48,54 & $44,46 n s$ & $35,7-54,9$ & 43 & 49,91 & $53,61 \mathrm{~ns}$ & $36,2-56,3$ \\
\hline 8 & 47,01 & $88,40 *$ & $34,1-70,4$ & 44 & 43,82 & $33,20 \mathrm{~ns}$ & $31,3-52,9$ \\
\hline 9 & 46,81 & $42,10 n s$ & $33,9-58,2$ & 45 & 48,60 & $38,51 n s$ & $37,5-60,5$ \\
\hline 10 & 49,21 & $36,03 n s$ & $36,9-56,6$ & 46 & 48,94 & $41,75 \mathrm{~ns}$ & $38,6-62,7$ \\
\hline 11 & 45,59 & $87,21 *$ & $32,9-66,7$ & 47 & 46,51 & $49,93 n s$ & $34,9-59,5$ \\
\hline 12 & 49,21 & $93,78 *$ & $35,7-69,1$ & 48 & 47,52 & $72,12 *$ & $36,4-66,7$ \\
\hline 13 & 53,55 & $71,01 n s$ & $31,4-61,3$ & 49 & 46,44 & $33,22 \mathrm{~ns}$ & $35,7-62,4$ \\
\hline 14 & 47,90 & $24,58 \mathrm{~ns}$ & $36,3-59,5$ & 50 & 48,02 & $27,02 \mathrm{~ns}$ & $37,7-57,6$ \\
\hline 15 & 45,05 & $119,98 * *$ & $19,2-60,3$ & 51 & 48,11 & $228,98 * *$ & $27,4-82,9$ \\
\hline 16 & 44,81 & $30,34 \mathrm{~ns}$ & $38,6-52,9$ & 52 & 40,70 & $35,90 \mathrm{~ns}$ & $24,7-54,8$ \\
\hline 17 & 42,71 & $39,62 \mathrm{~ns}$ & $33,2-51,5$ & 53 & 49,29 & $27,38 \mathrm{~ns}$ & $39,5-58,8$ \\
\hline 18 & 41,91 & $49,64 \mathrm{~ns}$ & $26,5-54,7$ & 54 & 49,39 & $75,28 *$ & $39,9-65,3$ \\
\hline 19 & 47,31 & $84,90 *$ & $24,1-62,2$ & 55 & 45,55 & $40,03 n s$ & $34,0-58,6$ \\
\hline 20 & 43,31 & $38,74 \mathrm{~ns}$ & $36,0-63,9$ & 56 & 48,71 & $27,20 \mathrm{~ns}$ & $41,9-63,2$ \\
\hline 21 & 45,94 & $98,12 *$ & $16,6-61,8$ & 57 & 47,68 & $58,04 \mathrm{~ns}$ & $37,2-60,5$ \\
\hline 22 & 49,18 & $100,00 *$ & $37,3-69,5$ & 58 & 44,66 & $54,75 n s$ & $35,3-53,8$ \\
\hline 23 & 42,21 & $61,86 \mathrm{~ns}$ & $28,0-53,9$ & 59 & 44,97 & $37,08 \mathrm{~ns}$ & $35,7-53,4$ \\
\hline 24 & 48,95 & $132,86 * *$ & $26,5-64,3$ & 60 & 37,21 & $62,39 \mathrm{~ns}$ & $25,9-46,5$ \\
\hline 25 & 50,39 & $87,39 *$ & $33,0-74,2$ & 61 & 46,23 & $56,71 n s$ & $29,1-66,9$ \\
\hline 26 & 31,29 & $27,25 \mathrm{~ns}$ & $15,9-62,2$ & 62 & 52,44 & $138,57 * x$ & $21,2-68,8$ \\
\hline 27 & 44,24 & $115,08 * x$ & $15,9-62,2$ & 63 & 44,88 & $101,89 *$ & $27,9-65,3$ \\
\hline 28 & 43,60 & $67,29 \mathrm{~ns}$ & $33,2-58,4$ & 64 & 45,15 & $33,14 \mathrm{~ns}$ & $34,7-56,4$ \\
\hline 29 & 44,82 & $83,46 *$ & $28,8-60,4$ & 65 & 40,54 & $38,76 n s$ & $28,6-56,2$ \\
\hline 30 & 50,12 & $127,06 * * x$ & $34,0-75,1$ & 66 & 50,47 & $90,84 *$ & $30,3-73,8$ \\
\hline 31 & 47,76 & $70,81 n s$ & $28,1-61,2$ & 67 & 41,39 & $143,68 * x$ & $26,0-66,9$ \\
\hline 32 & 45,01 & $38,68 n s$ & $35,5-54,0$ & 68 & 48,88 & $89,34 *$ & $37,0-63,9$ \\
\hline 33 & 40,67 & $60,04 \mathrm{~ns}$ & $30,0-54,0$ & 69 & 48,78 & $44,71 \mathrm{~ns}$ & $40,1-67,5$ \\
\hline 34 & 43,27 & $59,35 n s$ & $26,9-56,7$ & 70 & 47,26 & $17,43 \mathrm{~ns}$ & $33,8-54,8$ \\
\hline 35 & 42,33 & $128,44 * *$ & $23,9-63,7$ & 71 & 51,23 & $57,53 \mathrm{~ns}$ & $32,1-68,3$ \\
\hline 36 & 44,09 & $81,04 *$ & $30,6-64,1$ & 72 & 46,11 & $53,06 \mathrm{~ns}$ & $35,5-56,6$ \\
\hline
\end{tabular}


TABELA 9. Resultados da aplicaçāo do teste Duncan a 5\% às médias das progēnies para o caráter produção cereja em quilogramas a partir da análise da variāncia como parcelas sub-sub-divididas no tempo da produção bienal. Café 'Acaiā'. Estação Experimental de Mococa, SP, 1972-74.

\begin{tabular}{|c|c|}
\hline Progēnie & $\overline{\mathrm{x}}$ \\
\hline 13 & 53,55 a \\
\hline 62 & $52,44 \mathrm{ab}$ \\
\hline 40 & $51,90 \mathrm{abc}$ \\
\hline 71 & 51,23 abcd \\
\hline 2 & 51,16 abcd \\
\hline 3 & 51,11 abcd \\
\hline 66 & 50,47 abcde \\
\hline 25 & 50,39 abcde \\
\hline 30 & 50,12 abcde \\
\hline 43 & 49,91 abcdef \\
\hline 39 & 49,76 abcdef \\
\hline 54 & 49,39 abcdefg \\
\hline 53 & 49,29 abcdefgh \\
\hline 12 & $\because \quad 49,21$ abcdefgh \\
\hline 10 & 49,21 abcdefgh \\
\hline 22 & 49,18 abcdefgh \\
\hline 24 & 48,95 abcdefgh \\
\hline 46 & 48,94 abcdefgh \\
\hline 68 & 48,88 abcdefghi \\
\hline 69 & 48,78 abcdefghij \\
\hline 56 & 48,71 abcdefghij \\
\hline 45 & 48,60 abcdefghij \\
\hline 7 & 48,53 abcdefghij \\
\hline 38 & 48,44 abcdefghij \\
\hline 51 & 48,11 abcdefghijk \\
\hline 50 & 48,02 abcdefghijk1 \\
\hline 14 & 47,90 abcdefghijk1m \\
\hline 31 & 47,76 abcdefghijklm \\
\hline 57 & 47,68 abcdefghijk1m \\
\hline 48 & 47,52 abcdefghijk1m \\
\hline 19 & 47,31 abcdefghijk1m \\
\hline 70 & 47,26 abcdefghijk1m \\
\hline 8 & 47,01 abcdefghijk1m \\
\hline 9 & 46,81 abcdefghijk1m \\
\hline 47 & 46,51 abcdefghijklm \\
\hline 49 & 46,44 abcdefghijklm \\
\hline
\end{tabular}

\begin{tabular}{|c|c|c|}
\hline Progēnie & & $\overline{\mathrm{X}}$ \\
\hline 61 & 46,23 & abcdefghijklm \\
\hline 72 & 46,11 & abcdefghijklm \\
\hline 21 & 45,94 & bcdefghijklm \\
\hline 42 & 45,84 & bcdefghijklm \\
\hline 4 & 45,66 & bcdefghijklm \\
\hline 11 & 45,59 & bcdefghijklm \\
\hline 55 & 45,55 & bcdefghijklm \\
\hline 1 & 45,20 & bcdefghijk1m \\
\hline 64 & 45,15 & bcdefghijklmn \\
\hline 15 & 45,05 & bcdefghijklmn \\
\hline 32 & 45,01 & bcdefghijk1mn \\
\hline 59 & 44,97 & cdefghijk1mn \\
\hline 63 & 44,88 & cdefghijklmn \\
\hline 29 & 44,82 & cdefghijklmn \\
\hline 16 & 44,81 & cdefghijklmn \\
\hline 58 & 44,66 & cdefghijklmn \\
\hline 27 & 44,24 & defghijklmno \\
\hline 36 & 44,09 & defghijklmno \\
\hline 6 & 44,00 & defghijklmno \\
\hline 44 & 43,82 & defghijklmno \\
\hline 28 & 43,60 & efghijklmno \\
\hline 37 & 43,58 & efghijklmno \\
\hline 20 & 43,31 & efghijklmno \\
\hline 34 & 43,27 & efghijklmno \\
\hline 17 & 42,71 & fghijklmno \\
\hline 35 & 42,33 & ghijklmno \\
\hline 23 & 42,21 & ghijklmno \\
\hline 18 & 41,91 & hijklmno \\
\hline 41 & 41,53 & ijklmno \\
\hline 67 & 41,39 & jklmno \\
\hline 52 & 40,70 & klmno \\
\hline 33 & 40,67 & $1 \mathrm{mno}$ \\
\hline 65 & 40,54 & mno \\
\hline 5 & 37,83 & no \\
\hline 60 & 37,21 & 0 \\
\hline 26 & 31,29 & $\mathrm{P}$ \\
\hline
\end{tabular}


$: 109$

TABELA 10. Médias gerais em quilogramas $(\bar{X})$, coeficientes de variação ( $C V \%$ ) e probabilidade do teste F (F) de análises de variāncias como blocos ao acaso individualmente para os oito anos de pro dução cereja. Café 'Acaiā'。 Estação Experimental de Mococa, SP, 1972-79.

\begin{tabular}{cccc}
\hline Anos & $\overline{\mathrm{X}}$ & $\mathrm{CV}$ \% & $\mathrm{F}$ \\
\hline 1 & 7,291 & 14,49 & 0,256 \\
2 & 4,323 & 29,92 & 0,000 \\
3 & 9,726 & 16,37 & 0,123 \\
4 & 1,040 & 80,07 & 0,000 \\
5 & 2,056 & 39,21 & 0,448 \\
6 & 10,295 & 15,88 & 0,002 \\
7 & 0,496 & 74,74 & 0,530 \\
\hline & 10,919 & 15,36 & 0,000 \\
\hline
\end{tabular}


.110 。

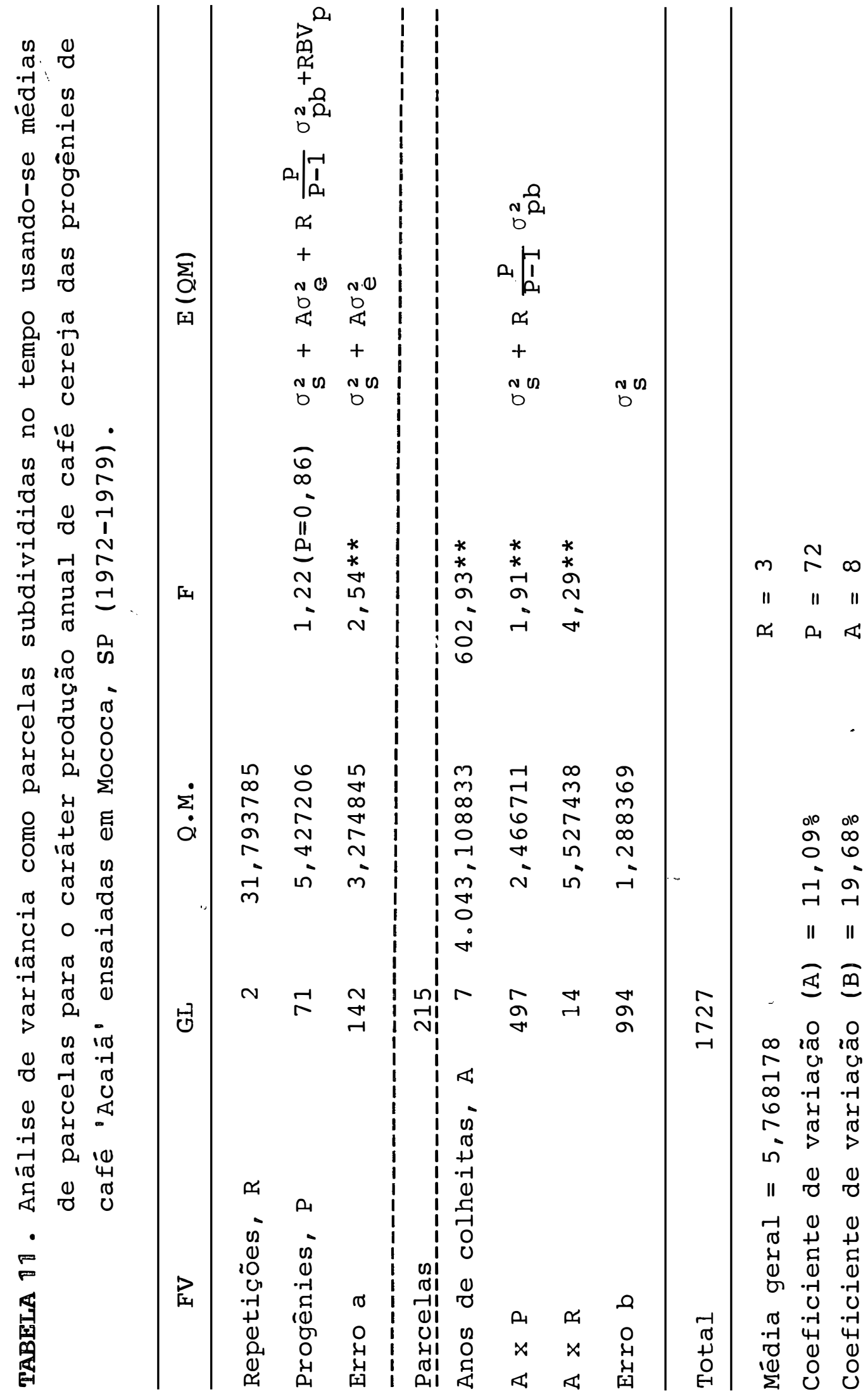


TABELA 12. Análise da variāncia da análise de estabilidade fenotípica de EBERHART \& RUSSEL (1966) aplicados a dados de oito produçōes anuais de café cereja de progênies de café 'Acaiā'.

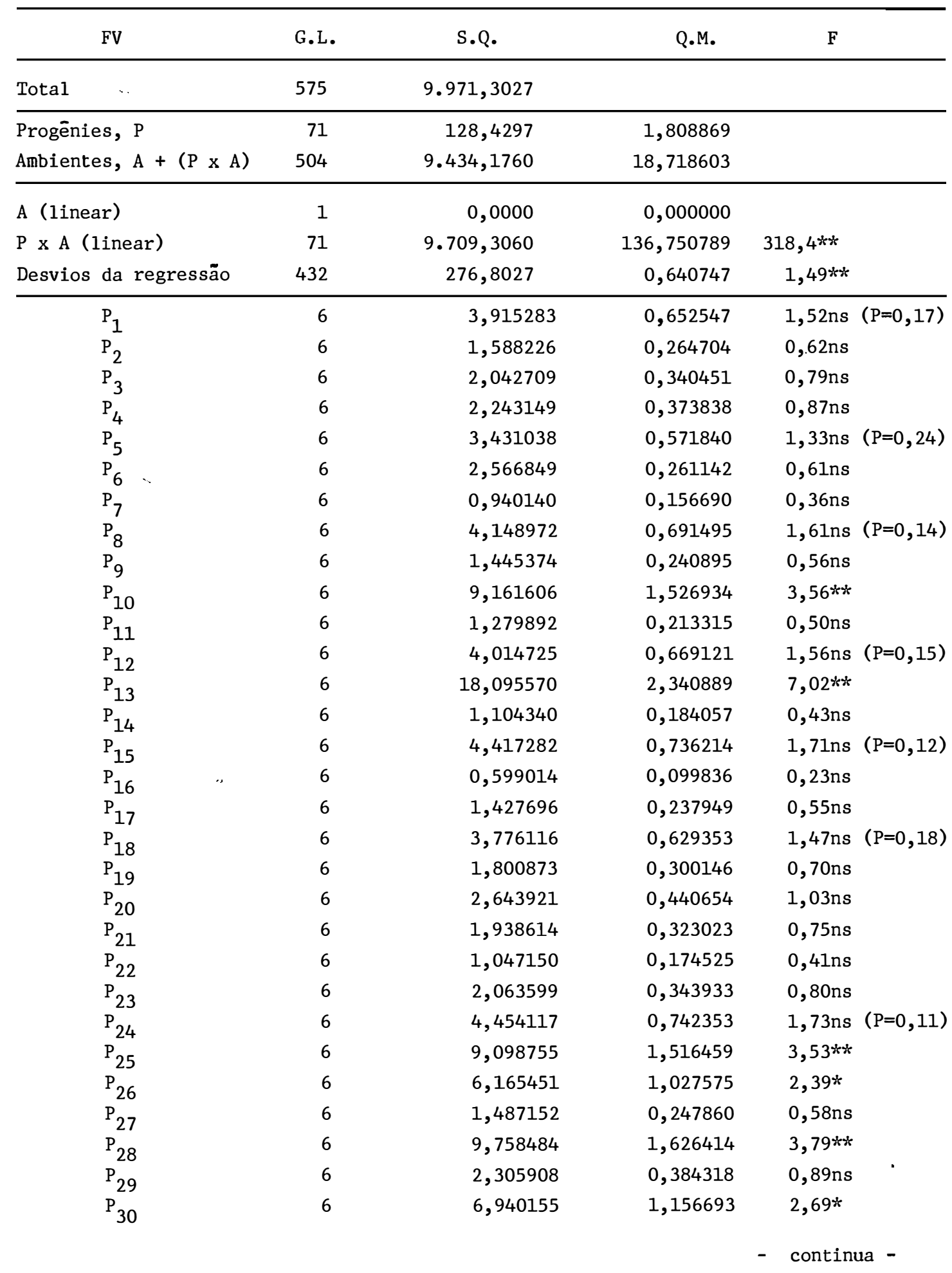


.112 .

TABELA 12. continuaçāo

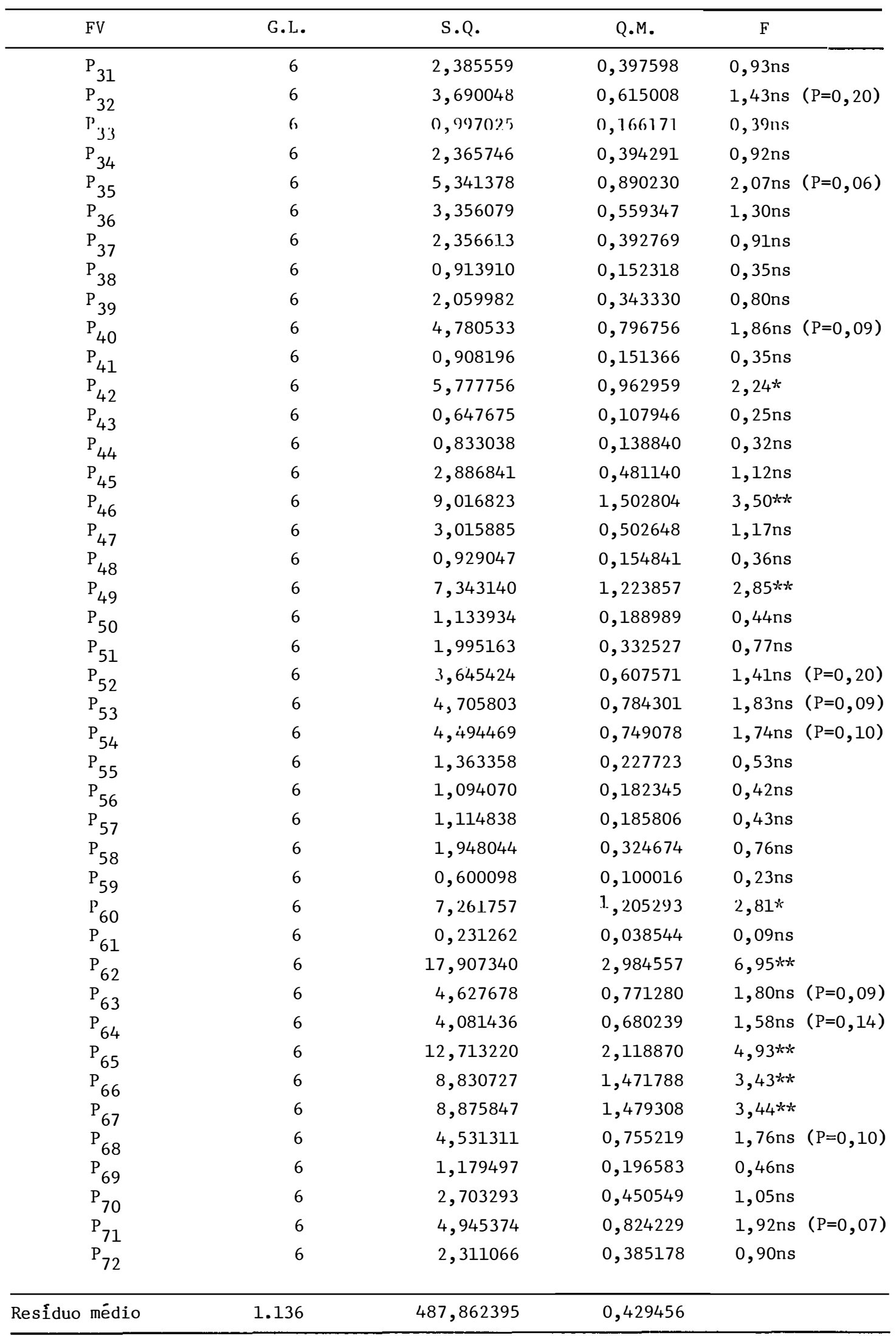




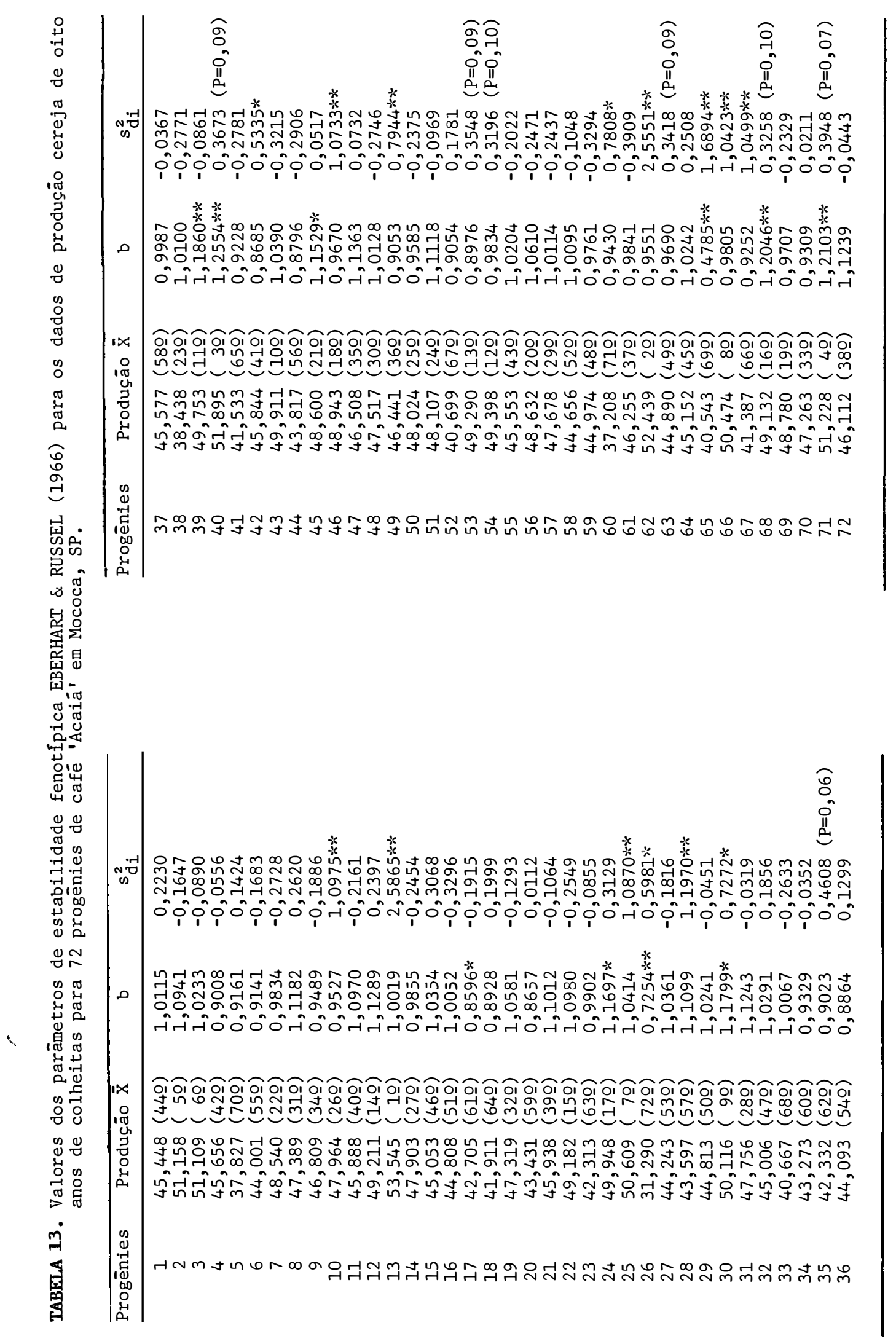




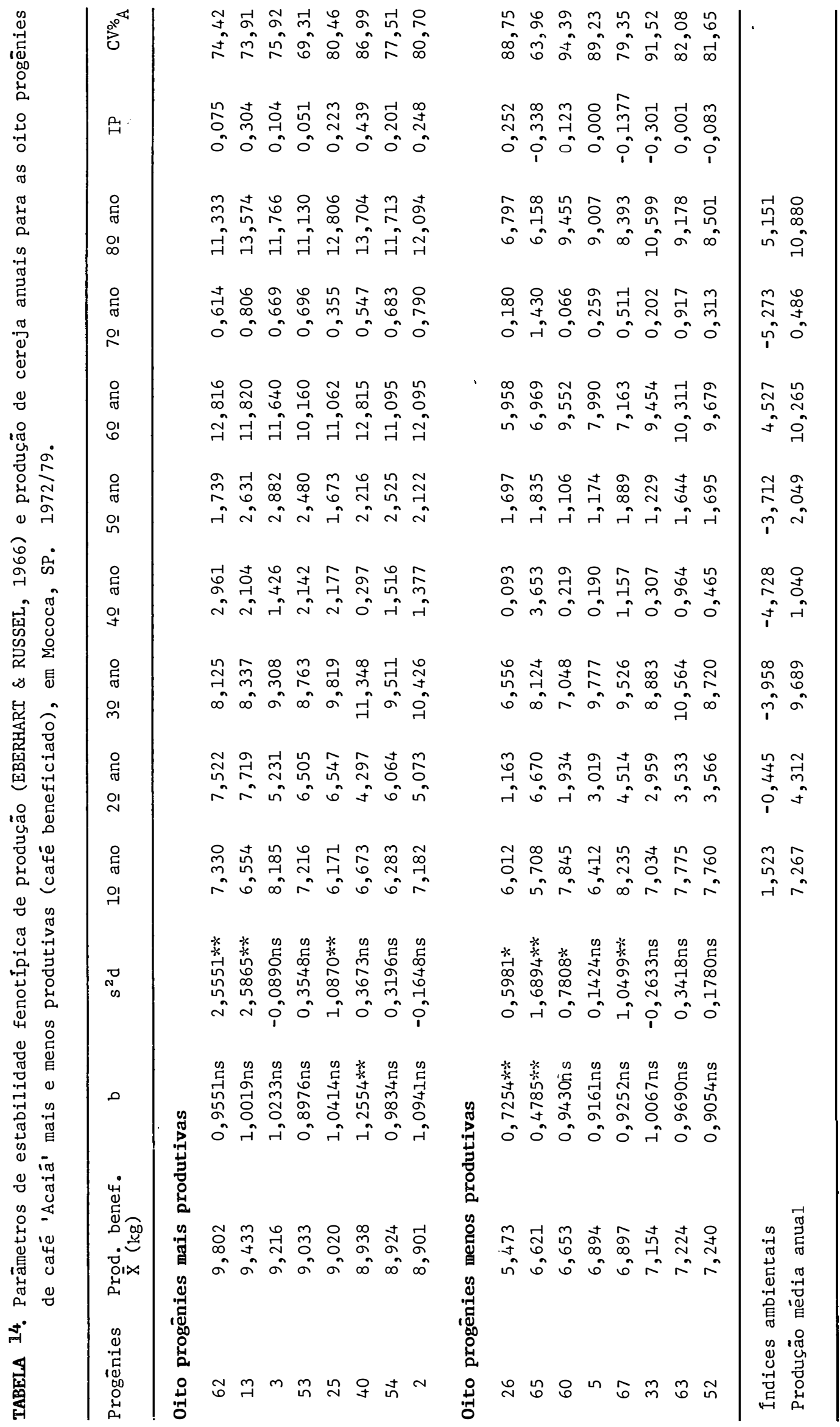


TABELA 15. Progēnies de café 'Acaiá' cm Mococa, SP. Valores médios de produção cereja/planta em quilogramas (X), de coeficientes de regressão (IP) e de coeficientes de variação sobre os oito anos de colheitas (CV\%).

\begin{tabular}{|c|c|c|c|}
\hline Progēnies & $\bar{x}$ & $1 P$ & CV\% \\
\hline 1 & 45,448 & 0,2261 & 82,45 \\
\hline 2 & 51,158 & 0,2477 & 80,70 \\
\hline 3 & 51,109 & 0,1042 & 75,92 \\
\hline 4 & 45,656 & $-0,0465$ & 75,64 \\
\hline 5 & 37,827 & $-0,0001$ & 89,23 \\
\hline 6 & 44,001 & $-0,0449$ & 77,94 \\
\hline 7 & 48,540 & 0,1673 & 74,02 \\
\hline 8 & 47,389 & 0,2671 & 90,56 \\
\hline 9 & 46,809 & 0,0318 & 74,38 \\
\hline 10 & 47,964 & 0,2127 & 77,36 \\
\hline 11 & 45,888 & 0,1704 & 90,95 \\
\hline 12 & 49,211 & 0,3344 & 83,73 \\
\hline 13 & 53,545 & 0,3043 & 73,99 \\
\hline 14 & 47,903 & 0,0371 & 76,59 \\
\hline 15 & 45,053 & $-0,1155$ & 87,32 \\
\hline 16 & 44,808 & 0,1063 & 81,95 \\
\hline 17 & 42,705 & 0,1112 & 78,39 \\
\hline 18 & 41,911 & $-0,0452$ & 82,50 \\
\hline 19 & 47,319 & 0,2840 & 82,35 \\
\hline 20 & 43,431 & $-0,0372$ & 77,06 \\
\hline 21 & 45,938 & 0,2622 & 89,16 \\
\hline 22 & 49,182 & 0,1456 & 82,59 \\
\hline 23 & 42,313 & 0,0394 & 84,55 \\
\hline 24 & 49,948 & 0,2612 & 87,48 \\
\hline 25 & 50,609 & 0,2229 & 80,46 \\
\hline 26 & 31,290 & 0,2523 & 88,75 \\
\hline 27 & 44,243 & 0,0619 & 86,52 \\
\hline 28 & 43,597 & 0,3794 & 76,34 \\
\hline 29 & 44,813 & 0,0736 & 82,34 \\
\hline 30 & 50,116 & 0,4442 & 84,53 \\
\hline 31 & 47,756 & 0,1208 & 86,33 \\
\hline 32 & 45,006 & $-0,0279$ & 82,73 \\
\hline 33 & 40,667 & 0,1642 & 91,52 \\
\hline 34 & 43,273 & 0,0680 & 79,28 \\
\hline 35 & 42,332 & $-0,1269$ & 82,91 \\
\hline 36 & 44,093 & $-0,0190$ & 76,27 \\
\hline
\end{tabular}

\begin{tabular}{ccrc}
\hline Progēnies & $\overline{\mathrm{X}}$ & \multicolumn{1}{c}{ IP } & \multicolumn{1}{c}{ CV\% } \\
\hline 37 & 45,577 & 0,0543 & 83,37 \\
38 & 48,438 & 0,0518 & 70,71 \\
39 & 49,753 & 0,1972 & 87,19 \\
40 & 51,895 & 0,4394 & 86,99 \\
41 & 41,533 & 0,1185 & 85,29 \\
42 & 45,844 & $-0,0533$ & 73,34 \\
43 & 49,911 & 0,1068 & 78,60 \\
44 & 43,817 & $-0,0245$ & 73,65 \\
45 & 48,600 & 0,3425 & 85,54 \\
46 & 48,943 & 0,2766 & 80,83 \\
47 & 46,508 & 0,1606 & 90,60 \\
48 & 47,517 & 0,2202 & 81,04 \\
49 & 46,441 & 0,0813 & 75,31 \\
50 & 48,024 & $-0,0273$ & 73,63 \\
51 & 48,107 & 0,2885 & 87,56 \\
52 & 40,699 & $-0,0830$ & 81,65 \\
53 & 49,290 & 0,0511 & 69,31 \\
54 & 49,398 & 0,2009 & 77,51 \\
55 & 45,553 & $-0,0318$ & 82,21 \\
56 & 48,632 & 0,0123 & 78,27 \\
57 & 47,678 & 0,0524 & 79,31 \\
58 & 44,656 & 0,0293 & 83,85 \\
59 & 44,974 & 0,1428 & 79,95 \\
60 & 37,208 & 0,1227 & 94,39 \\
61 & 46,255 & 0,0624 & 79,77 \\
62 & 52,439 & 0,0754 & 74,42 \\
63 & 44,890 & 0,0009 & 82,08 \\
64 & 45,152 & 0,0157 & 84,37 \\
65 & 40,543 & $-0,3379$ & 63,96 \\
66 & 50,474 & 0,1476 & 73,55 \\
67 & 41,387 & $-0,3008$ & 79,35 \\
68 & 49,132 & 0,3533 & 89,22 \\
69 & 48,780 & 0,0795 & 75,86 \\
70 & 47,262 & 0,1141 & 73,60 \\
71 & 51,228 & 0,1788 & 88,32 \\
72 & 46,112 & 0,0801 & 84,43 \\
& & & \\
\hline & & & \\
& & &
\end{tabular}


TABELA 16. Análise da variāncia como blocos ao acaso e resultados da aplicação do tes te de Duncan a $5 \%$ às médias das progēnies para o caráter produção total de oito anos de café beneficiado/planta em quilogramas. Café 'Acaiá'. Estaçào Experimental de Mococa, Sl', 1972-79.

\begin{tabular}{lrrrr}
\hline \multicolumn{1}{c}{ F.V. } & G.L. & S.Q. & Q.M. & F \\
\hline Blocos & 2 & 14,319430 & 7,149715 & \\
Progenenies & 71 & 100,622904 & 1,417224 & $1,71 * *$ \\
Resíduo & 142 & 117,769262 & 0,829361 & \\
\hline Total & 215 & 232,711590 & & \\
\hline
\end{tabular}

Média geral $=8,175 \mathrm{~kg}$

Coeficiente de variação $=11,14 \%$

Teste de Duncan a 5\%:

\begin{tabular}{|c|c|}
\hline Progēnie & $\bar{x}$ \\
\hline $\begin{array}{r}62 \\
13 \\
3 \\
53 \\
25 \\
54 \\
40 \\
2 \\
43 \\
22 \\
71 \\
66 \\
69 \\
46 \\
38 \\
7 \\
50 \\
70 \\
56 \\
30 \\
19 \\
14 \\
12 \\
10 \\
39 \\
24 \\
42 \\
61 \\
9 \\
31 \\
48 \\
45 \\
49 \\
59 \\
68 \\
11\end{array}$ & $\begin{array}{l}\text { 9,802 a } \\
\text { 9,322 ab } \\
\text { 9,216 abc } \\
\text { 9,024 abcd } \\
\text { 9,020 abcd } \\
\text { 8,964 abcd } \\
\text { 8,938 abcd } \\
\text { 8,901 abcd } \\
\text { 8,877 abcd } \\
\text { 8,871 abcd } \\
\text { 8,864 abcd } \\
\text { 8,704 abcde } \\
\text { 8,691 abcde } \\
\text { 8,648 abcde } \\
\text { 8,638 abcde } \\
\text { 8,623 abcde } \\
\text { 8,617 abcde } \\
\text { 8,608 abcde } \\
\text { 8,581 abcde } \\
\text { 8,578 abcde } \\
\text { 8,562 abcde } \\
\text { 8,534 abcde } \\
\text { 8,532 abcde } \\
\text { 8,497 abcdef } \\
\text { 8,475 abcdefg } \\
\text { 8,451 abcdefg } \\
\text { 8,434 abcdefg } \\
\text { 8,421 abcdefg } \\
\text { 8,412 abcdefg } \\
\text { 8,405 abcdefg } \\
\text { 8,399 abcdefg } \\
\text { 8,351 abcdefg } \\
\text { 8,350 abcdefg } \\
\text { 8,342 abcdefg } \\
\text { 8,327 abcdefg } \\
\text { 8,283 abcdefg }\end{array}$ \\
\hline
\end{tabular}

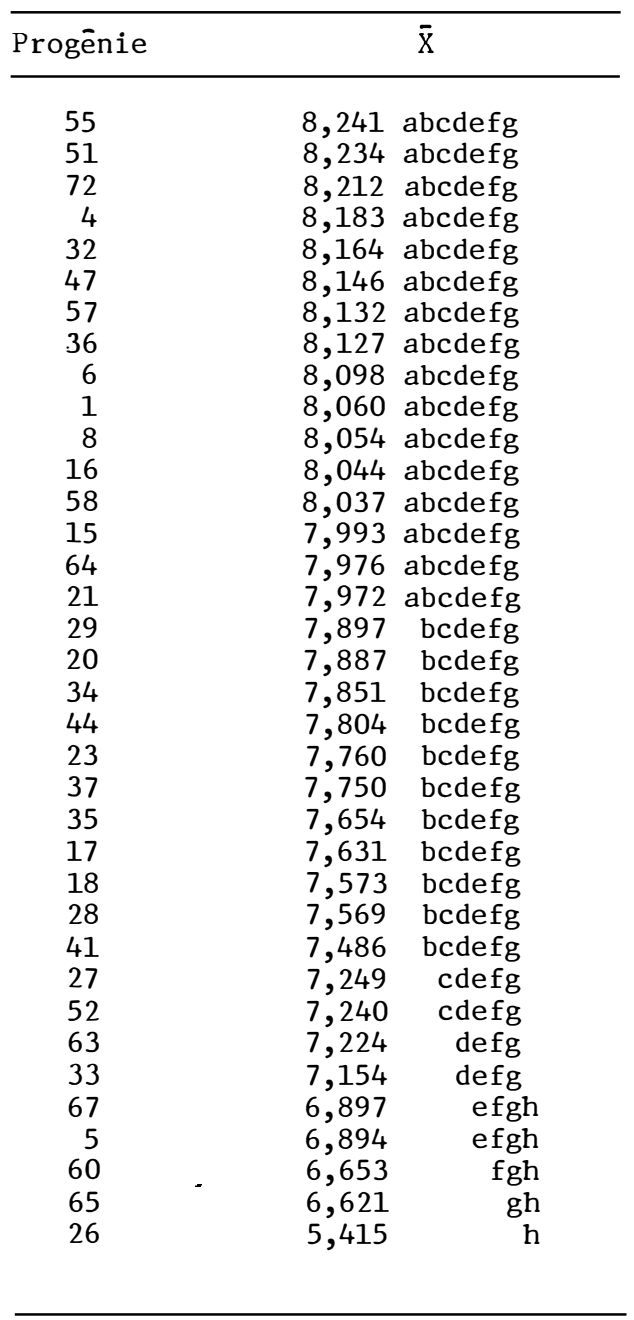




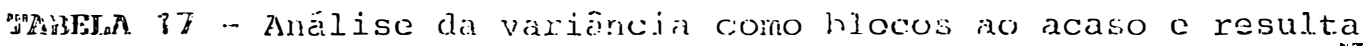
dos da aplicaçäo do toste àe Duncan a $5 \frac{\text { à }}{a}$ do médias das proyenties para o caräter tiananho dos grãos chatos dado pela peneira média. Cáfé 'Acaiá'. Estação Experimental de Mococá, SP, 1973.

\begin{tabular}{lrrrr}
\hline \multicolumn{1}{c}{ F.V. } & G.l. & S.Q. & O.M. & F \\
\hline Blocos & 2 & 1,945708 & 0,972854 & \\
Progenies & 71 & 12,179494 & 0,171542 & $1,41 *$ \\
Residuo & 142 & 17,319482 & 0,121968 & \\
\hline & TOTAL 215 & 31,444684 & &
\end{tabular}

Média geral $=16,95$

Coeficiente de variação $=2,06 \%$

'reste de Duncan a $5 \mathrm{~g}:$

\begin{tabular}{|c|c|c|c|c|}
\hline Progênie & $\overline{\mathrm{x}}$ & Progênie & $\overline{\mathrm{x}}$ & $\overline{\mathrm{x}}$ \\
\hline 25 & 17,47 a & 50 & 16,90 & abcde \\
\hline 66 & 17,47 a & 1 & 15,89 & abedo \\
\hline 2 & $17,47 \mathrm{a}$ & 69 & 16,89 & abcae \\
\hline 28 & $17,41 \mathrm{ab}$ & 20 & 16,89 & $a b c d e$ \\
\hline 45 & $17,39 \mathrm{ab}$ & 39 & 16,88 & abccie \\
\hline 46 & $17,39 \mathrm{ab}$ & 8 & 16,86 & abcde \\
\hline 10 & 17,29 abc & 27 & 16,86 & abcde \\
\hline 68 & 17,24 a)ca & 64 & 16,86 & abcace \\
\hline 1.3 & $1.7,20$ abiu & iô & 10,04 & ajucie \\
\hline 34 & ].7, 19 abcde & 43 & 16,84 & abocie \\
\hline 36 & 17,19 abcde & 55 & 16,84 & abcole \\
\hline 42 & 17,19 abcde & 62 & 16,84 & abcde \\
\hline 31 & 17,19 abche & 35 & 16,82 & abcde. \\
\hline 65 & 17,16 abccie & 54 & 16,82 & abcde. \\
\hline 40 & 17,16 abcale & 33 & 16,81 & abcae \\
\hline$\Delta 8$ & 17,15 abcale & 19 & 16,80 & abcde \\
\hline 58 & 17,14 abcde & 6.1 & 16,79 & abcde \\
\hline 70 & 17,12 abcde & 29 & 16,79 & abcde \\
\hline 53 & 17,11 abcde & 14 & 16,78 & abcde \\
\hline 21 & 17,11 abcale & 32 & 16,77 & abcde \\
\hline 24 & 17,10 abcde & 44 & 16,76 & abcde \\
\hline 30 & 17,10 abcde & 37 & 16,75 & abcde \\
\hline 41 & 17,08 abcde & 6 & 16,75 & abcde \\
\hline 17 & 17,07 abcde & 47 & 16,75 & abcde \\
\hline 57 & 17,04 abcde & 49 & 16,73 & bcde \\
\hline 22 & 17,03 abccie & 5 & 16,71 & bcde \\
\hline 3 & 17,01 abcde & 52 & 16,69 & bcde \\
\hline 1 & 17,00 abcde. & 56 & 16,66 & cde \\
\hline 71 & 16,99 abcde & 72 & 16,63 & cle \\
\hline 7 & 16,99 abcde & 9 & 16,62 & cde \\
\hline 11 & 16,99 abcde & 16 & 16,61 & cde \\
\hline 63 & 16,98 abcde & 51 & 16,60 & cde \\
\hline 12 & 16,98 abcde & 15 & 16,59 & cde \\
\hline 38 & 16,95 abcaje & 67 & 16,55 & $\mathrm{de}$ \\
\hline 59 & 16,94 abcde & 26 & 16,55 & $\mathrm{de}$ \\
\hline 23 & 16,94 abcde & 60 & 16,48 & e \\
\hline
\end{tabular}


TABELA 18 - Análise da variāncia como blocos ao acaso e resultados da aplicaçāo do teste de Duncan a $5 \%$ às médias das progēnies para o caráter rendimento Café 'Acaiā'. Estaçāo Experimental de Mococa, SP. 1973 e 1979.

\begin{tabular}{lcccc}
\hline \multicolumn{1}{c}{ F.V. } & G.1. & S.Q. & Q.M. & S \\
\hline Blocos & 2 & 0,086014 & 0,043022 & \\
Progêties & 71 & $5,078.988$ & 0,071528 & $3,32 \%$ \\
Residuo & 142 & $3,05 \% 307$ & 0,021530 & \\
\hline
\end{tabular}

TCIA] 215

Médica geral $=5,65$

Coeficiente de variação $=2,60 \%$

Teste de Duncar a 58 :

\begin{tabular}{|c|c|c|}
\hline Progênie. & & $\overline{\mathrm{X}}$ \\
\hline 62 & 5,40 & $a$ \\
\hline 59 & 5,40 & 2 \\
\hline 12 & 5,43 & $a b$ \\
\hline 36 & 5,44 & $a b$ \\
\hline 6 & 5,44 & $a b$ \\
\hline 53 & 5,46 & $a b c$ \\
\hline 23 & 5,47 & $a b c$ \\
\hline $6 \bar{I}$ & 5,49 & abcd \\
\hline $7 \hat{0}$ & 5,40 & ảjこ文 \\
\hline 5 & 5,50 & abcde \\
\hline 32 & 5,51 & abcdef \\
\hline 19 & 5,52 & abcdef \\
\hline 34 & 5,52 & abcdef \\
\hline 54 & 5,52 & abcdef \\
\hline 20 & 5,53 & abcdefg \\
\hline 18 & 5,54 & abcdefg \\
\hline 3 & 5,54 & abcdefg \\
\hline 55 & 5,55 & abcdefgh \\
\hline 11 & 5,55 & abcdefgh \\
\hline 35 & 5,56 & abcdefgh \\
\hline 41 & 5,56 & abcdefgh \\
\hline 50 & 5,57 & abcdefoh \\
\hline 9 & 5,58 & abcdefghi \\
\hline 27 & 5,59 & abcdefghi \\
\hline 49 & 5,58 & abcdefghi \\
\hline 58 & 5,58 & abcde fghi \\
\hline 16 & 5,59 & abcdefghi \\
\hline 1 & 5,60 & abcdefghi \\
\hline 25 & 5,60 & abcalefghi \\
\hline 60 & 5,60 & abçdefghi \\
\hline 22 & $5,6 i$ & abcdefghi \\
\hline 14 & 5,61 & abcdefghi. \\
\hline 4 & 5,61 & abcdefghi \\
\hline 17 & 5,61 & abcdefghj. \\
\hline 44 & 5,62 & abcdefghij \\
\hline 72 & 5,62 & abcciefghj.j \\
\hline
\end{tabular}

\begin{tabular}{|c|c|c|}
\hline Progênjece & & $\overrightarrow{\mathrm{x}}$ \\
\hline 52 & 5,62 & abcdefghij \\
\hline 38 & 5,63 & abcdefoghij \\
\hline 37 & 5,63 & abcocfghij \\
\hline 7 & 5,64 & abcdefghi j \\
\hline 69 & 5,65 & abcdefighij \\
\hline 10 & 5,65 & abcdefghij \\
\hline 29 & 5,66 & abcdefghi $\bar{j}$ \\
\hline 46 & 5,67 & abcderghi \\
\hline$A_{1} 8$ & 5,67 & 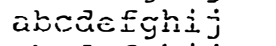 \\
\hline 56 & 5,68 & abcdefgin $\dot{i}$ \\
\hline 15 & 5,68 & abcdefghij \\
\hline 64 & 5,68 & abcdefghij \\
\hline 13 & 5,70 & abcōefghij \\
\hline 31 & 5,70 & abcdefcihij \\
\hline .33 & 5,71 & bcdefghij \\
\hline 43 & 5,72 & bodefghij \\
\hline 47 & 5,72 & bcdefghij \\
\hline 2 & 5,74 & cdefglij.j \\
\hline 12 & 5,75 & cdefghij \\
\hline 21 & 5,78 & defogh $\dot{i} j$ \\
\hline 66 & 5,79 & defghj. \\
\hline 28 & 5,80 & defghij \\
\hline 24 & 5,80 & efori $i j$ \\
\hline 71 & 5,80 & efghij \\
\hline 26 & 5,81 & efghij \\
\hline 40 & 5,82 & ghij \\
\hline 51 & 5,82 & $h i j$ \\
\hline 30 & 5,84 & $h i \vec{j}$ \\
\hline 8 & 5,84 & $h i j$ \\
\hline 45 & 5,84 & $h i \hat{j}$ \\
\hline 39 & 5,87 & hij \\
\hline 57 & 5,87 & hij \\
\hline 68 & 5,88 & $h i \vec{j}$ \\
\hline 67 & 5,91 & $j k$ \\
\hline 65 & 6,14 & $\mathrm{k}$ \\
\hline 63 & 6,20 & 1 \\
\hline
\end{tabular}


TABHezl 19 - Análise da variância como blocos ao acaso e resultạ closs da aplicação do teste de Duncan a $5 \%$ às médias de proyenics para o caráter altura da copa en metros. Café 'Acaiá'. Estação Experimental de Mococa, SP. 1979

\begin{tabular}{lrrrr}
\hline F.V. & G.l. & S.Q. & Q.M. & $F$ \\
\hline B.locos & 2 & 0,183273 & 0,091637 & \\
$\begin{array}{l}\text { Progénies } \\
\text { Resíduo }\end{array}$ & 71 & 2,991441 & 0,042133 & $2,40 * *$ \\
\hline & 142 & 2,491698 & 0,017547 & \\
\hline & TOTAL 215 & $5,66641.2$ &
\end{tabular}

Média geral $=3,02 \mathrm{~m}$

Coeficiente de variação $=2,53:$

Teste de Duncan a $5 \%$ :

\begin{tabular}{|c|c|c|}
\hline Frogẹnie & & $\bar{x}$ \\
\hline 13 & 3,25 & a \\
\hline 10 & 3,25 & $a$ \\
\hline 43 & 3,22 & $a b$ \\
\hline 45 & 3,21 & $a b$ \\
\hline 71 & $3,1.8$ & $a b c$ \\
\hline 30 & 3,17 & $\mathrm{abc}$ \\
\hline 28 & 3,14 & abcd \\
\hline 31 & 3,13 & abcd \\
\hline 46 & 3,12 & ābcüe \\
\hline 63 & 3,12 & abcde \\
\hline 58 & 3,10 & abcdef \\
\hline 12 & 3,10 & abscdef \\
\hline 10 & 3,10 & abcdef \\
\hline 2 & 3,10 & abcdef \\
\hline 21 & 3,10 & abcdef \\
\hline 53 & 3,10 & abcclex \\
\hline 69 & 3,10 & abccief \\
\hline 27 & 3,10 & abcdef \\
\hline 24 & 3,10 & abcdef \\
\hline 9 & 3,10 & abcdef \\
\hline 3 & 3,10 & abcdef \\
\hline 48 & 3,09 & abcdef \\
\hline 62 & 3,08 & abcdefg \\
\hline 56 & 3,08 & abcdef \\
\hline 25 & 3,08 & $a b c c e f g$ \\
\hline 54 & 3,07 & abcdefg \\
\hline 65 & 3,07 & abcdefg \\
\hline 22 & 3,07 & abcciefg \\
\hline 7 & 3,06 & abcdefg \\
\hline 57 & 3,06 & abcdefg \\
\hline 72 & 3,05 & ábcdefgh \\
\hline 68 & 3,05 & abcdefgh \\
\hline 47 & 3,05 & abcdefgh \\
\hline 51 & 3,05 & abcdefgh \\
\hline 64 & 3,05 & abcdefgh \\
\hline 20 & 3,04 & abcdefgh \\
\hline
\end{tabular}

\begin{tabular}{|c|c|c|}
\hline Progēnie & & $\bar{x}$ \\
\hline 49 & 3,04 & abcdefgh \\
\hline 19 & 3,03 & abcdefigh \\
\hline 32 & 3,03 & $a b c d e f g h$ \\
\hline 39 & 3,03 & abcdefgh \\
\hline 70 & 3,03 & abcdefgh \\
\hline 38 & 3,03 & abcclefgh \\
\hline 41. & 3,02 & $a b c:$ efgh \\
\hline 1.4 & 3,01 & abccie fogh \\
\hline 36 & 3,01 & $a^{2}, c d=f g^{2}$ \\
\hline 8 & 3,01 & abcaefgh \\
\hline 23 & 3,01 & abcde fgh \\
\hline 50 & 3,00 & abcdefgh \\
\hline 11. & 3,00 & abcdefgh \\
\hline 55 & 3,00 & abcdefgh \\
\hline 16 & 2,99 & abcdefigh \\
\hline 1 & 2,98 & abcdef:gh \\
\hline 42 & 2,98 & bcdergh \\
\hline 61 & 2,98 & bcdefgh \\
\hline 52 & 2,97 & bcdefgh \\
\hline 6 & 2,95 & bcdefgh \\
\hline 59 & 2,95 & bcclefgh \\
\hline 44 & 2,95 & bcdefgh \\
\hline 4 & 2,94 & cdefigh \\
\hline 5 & 2,94 & cdefgh \\
\hline 29 & 2,94 & cdefgh \\
\hline 33 & 2,94 & cdefgh \\
\hline 34 & 2,94 & cdefgh \\
\hline 15 & 2,91 & defgh \\
\hline 37 & 2,90 & defgh \\
\hline 35 & 2,89 & defgh \\
\hline 18 & 2,85 & efgh \\
\hline 17 & 2,84 & $\mathrm{fgh}$ \\
\hline 67 & 2,82 & ghi \\
\hline 60 & 2,79 & hi \\
\hline 26 & 2,51 & $i j$ \\
\hline 65 & 2,58 & $\mathbf{j}$ \\
\hline
\end{tabular}


ThBEIA 20 - Análise da variância como blocos ao acaso e resulta dos da aplicação do teste cle Duncan a 58 às médias das progénies para o caräter diämetro da copa em me tros. Cafó 'Acaiá'. Estação Experimental de Mococa. $19 \%$.

\begin{tabular}{lrrrr}
\hline F.V. & G.l. & S.Q. & Q.M. & $F$ \\
\hline Blocos & 2 & 0,156985 & 0,078493 & \\
Progênie & 71 & 1,119397 & 0,015766 & $1,28(\mathrm{P}=0,89)$ \\
Resíduo & 142 & 1,750302 & 0,012326 & \\
\hline & TO'TAL 215 & 3,026684 & &
\end{tabular}

Média geral $=1,81$

Coeficiente de variação $=6,13 \%$

Teste de Duncan a 58 :

\begin{tabular}{|c|c|}
\hline Progenties & $\bar{x}$ \\
\hline 13 & 1,96 a \\
\hline 62 & $1,95 a$ \\
\hline 66 & 1,95 a \\
\hline 47 & 1,93 ab \\
\hline 38 & $1,93 \mathrm{ab}$ \\
\hline 40 & $1,9.3 \mathrm{ab}$ \\
\hline 19 & $1,90 \mathrm{ab}$ \\
\hline 30 & 1.,90 ab \\
\hline 24 & $1,90 \mathrm{ab}$ \\
\hline 68 & $1,90 \mathrm{ab}$ \\
\hline 27 & $1,90 \mathrm{ab}$ \\
\hline 3 & 1.89 ab \\
\hline 12 & $1,89 \mathrm{ab}$ \\
\hline 14 & 1,89 als \\
\hline 10 & $1,88 \mathrm{ab}$ \\
\hline 70 & 1,88 a \\
\hline 43 & 1,87 abc \\
\hline 61 & 1,87 abc \\
\hline 57 & $1,87 \mathrm{abc}$ \\
\hline 9 & $1,86 a b c$ \\
\hline 22 & 1,85 abco \\
\hline 48 & 1,85 abc \\
\hline 55 & $1,85 \mathrm{abc}$ \\
\hline 53 & 1,85 aisc \\
\hline 64 & 1,84 abC \\
\hline 72 & $1,84 \mathrm{abc}$ \\
\hline 16 & 1,83 abo \\
\hline 1 & 1,83 abo \\
\hline 7 & 1,83 abc \\
\hline 8 & $1,83 \mathrm{abc}$ \\
\hline 2 & $1,8.3 \mathrm{abc}$ \\
\hline 2.1 & $1,83 \mathrm{abc}$ \\
\hline 69 & 1,82 absc \\
\hline 50 & 1,82 abc \\
\hline 37 & 1,81 abc \\
\hline 59 & 1,81 abc \\
\hline
\end{tabular}

\begin{tabular}{|c|c|c|}
\hline Progenenjes & $\overline{\mathrm{x}}$ & \\
\hline 54 & ]., 80 & $a b c$ \\
\hline 35 & 1,80 & aijoc \\
\hline 39 & 1,80 & abc \\
\hline 42 & 1,80 & $a b c$ \\
\hline 15 & 1,80 & $a b c$ \\
\hline 18 & 1,79 & $a b c$ \\
\hline 4 & 1,79 & abc \\
\hline 31 & 1,79 & $a b c$ \\
\hline 41 & 1,78 & $\mathrm{abc}$ \\
\hline 45 & 1,78 & $a b c$ \\
\hline 34 & 1,78 & $a b c$ \\
\hline 29 & 1., 78 & $\mathrm{abc}$ \\
\hline 6 & 1,77 & $a b c$ \\
\hline 53 & 1,77 & $\mathrm{abc}$ \\
\hline 65 & 1,75 & abcc \\
\hline 46 & 1,76 & $a b c$ \\
\hline 25 & 1,76 & abc \\
\hline 36 & 1,75 & $a b c$ \\
\hline 33 & 1.75 & $a b c$ \\
\hline 5.1 & 1,75 & $a b c$ \\
\hline 32 & 1,74 & $\mathrm{abc}$ \\
\hline 71 & 1,74 & $a b c$ \\
\hline 23 & 1,74 & $a b c$ \\
\hline 26 & 1,71 & $a b c:$ \\
\hline 60 & 1,74 & $a b c$ \\
\hline 17 & 1,73 & bc \\
\hline 28 & 1,73 & be \\
\hline 49 & 1,73 & bc \\
\hline 63 & 1.73 & $\mathrm{bc}$ \\
\hline 55 & 1,72 & $\mathrm{bc}$ \\
\hline 20 & 1,71 & $\mathrm{bc}$ \\
\hline .11 & 1,71 & $\mathrm{bc}$ \\
\hline 52 & 1,71 & bc \\
\hline 44 & 1,70 & $\mathrm{bc}$ \\
\hline 5 & 1,66 & $\mathrm{C}$ \\
\hline 67 & 1,65 & C \\
\hline
\end{tabular}


IMripga 21 - Anáiise da variância como blocos ao acaso e resultados äa ajulicação do teste de Duncan a 5 o às médias das progênjes para o caráter porcentagem de grãos chatos. Café 'Acajá'. Estạão Experimental de Mocọ ca, SP, $1.973^{\circ}$.

\begin{tabular}{lrrrr}
\hline F.V. & G.1. & S.Q. & Q.M. & F \\
\hline Rlocos & 2 & 65,5678 & 32,7839 & \\
Proyenies & 71 & 924,1567 & $13,01.63$ & $2,63 * *$ \\
Ressiduo & 142 & 703,0851 & 4,9513 & \\
\hline & TOTAL 215 & $1.692,8096$ & &
\end{tabular}

Média çeral $=84,13 \%$

Coeficiente de variạ̧ão $=2,64 \%$

Teste de Juncar a $58:$

\begin{tabular}{|c|c|}
\hline Progênie & $\ddot{\mathrm{x}}$ \\
\hline 59 & 88,2 a \\
\hline 36 & $87,4 a b$ \\
\hline 11 & $87,2 \quad a b c$ \\
\hline 49 & 86,8 ab:cal \\
\hline 60 & 86,8 abca \\
\hline 18 & 86,6 abcd \\
\hline 2 & 86,6 a b $c a$ \\
\hline $5 \%$ & 86,5 absecie \\
\hline$E \frac{A}{2}$ & 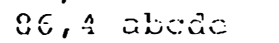 \\
\hline 7 & 86,1 abcaef \\
\hline 14 & 86,0 abculef \\
\hline 33 & 86,0 abcuef \\
\hline 35 & 85,8 abcuef. \\
\hline 29 & 85,7 abcclef \\
\hline 37 & 85,7 abouery \\
\hline 20 & 85,7 abcciefig \\
\hline 53 & 85,6 abcdefg \\
\hline 26 & 85,5 abcdelig \\
\hline 34 & 85,3 abcdefg \\
\hline 15 & 85,2 abcdefg \\
\hline 58 & 85,2 abcdetig \\
\hline 32 & 85,1 abodefor \\
\hline 61 & 85,1 abcdefg \\
\hline 6 & 85,0 abcrief:g \\
\hline 8 & 85,0 abodefy \\
\hline 70 & 85,0 abcaefg \\
\hline 4 & 34,8 abcdefg \\
\hline 47 & 84,8 abcaiefg \\
\hline 3 & 84,7 abcdefg \\
\hline 10 & 84,7 abcdetg \\
\hline 16 & 84,6 ábcclefg \\
\hline 51 & 84,6 abcdefg \\
\hline 69 & 84,6 abcdetg \\
\hline 13 & 84,5 abcdefg \\
\hline 44 & 84,5 abcdefg \\
\hline j. & 84,4 abcdefy \\
\hline
\end{tabular}

\begin{tabular}{|c|c|c|}
\hline Progênie & & $\overline{\mathrm{x}}$ \\
\hline 42 & 84,4 & aus:tefg \\
\hline 41 & 84,3 & abodefor \\
\hline 72 & 84,1 & abrodefry \\
\hline 17 & 84,0 & abcdery \\
\hline 12 & 83,9 & $a b c c e f y$ \\
\hline 30 & 83,9 & abcrictey \\
\hline 19 & 83,7 & abcdefgh \\
\hline 4.3 & 83,7 & abeciefuin \\
\hline 64 & 83,6 & bocedgh \\
\hline 56 & 83,5 & beciefgh \\
\hline 66 & 83,5 & bcrergh \\
\hline 63 & 83,3 & bcdefgh \\
\hline 9 & 83,3 & bcdefgh \\
\hline 68 & 83,3 & bcdefgh \\
\hline 31 & 83,2 & bcdefgin \\
\hline 23 & 83,1 & bodefgh \\
\hline 50 & 83,1 & bcdef:gh \\
\hline 57 & 83,0 & bedefgh \\
\hline 39 & 82,9 & bcciefgh \\
\hline 46 & 82,9 & bcaleigh \\
\hline 62 & 82,9 & bcrefgh \\
\hline 5 & 82,8 & cdefgh \\
\hline 48 & 82,7 & cdefogh \\
\hline 55 & 82,5 & defgh \\
\hline J. 5 & 82,4 & def:gh \\
\hline 21 & 82,2 & efgh \\
\hline 28 & 82,2 & $\in \mathrm{Egh}$ \\
\hline 40 & 82,2 & efgh \\
\hline 24 & 82,0 & efgh \\
\hline 25 & 82,0 & efgh \\
\hline 38 & 81,8 & fgh \\
\hline 22 & 81,6 & fgh \\
\hline 71 & 81,2 & gh \\
\hline 67 & 81,1 & gh \\
\hline 27 & 79,2 & $\mathrm{~h}$ \\
\hline 65 & 73,9 & $i$ \\
\hline
\end{tabular}




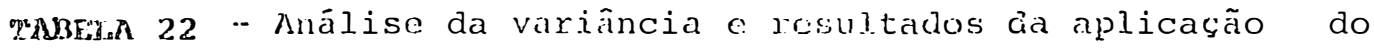
teste de Duncan a 58 às módias das progênies para o cáráter porcentagem de gräcs moca. Dados transforma dos por $\sqrt{x}$. Café 'Acaí̄'. Estaçĩo Experimental. de Mocosa, SP, 1.973.

\begin{tabular}{|c|c|c|c|c|}
\hline F.V. & G.I. & S. . • & $Q \cdot M$. & $F$ \\
\hline Blocos & 2 & 1,184109 & 0,592055 & \\
\hline Prog̣ênies & 71 & 14,046655 & 0,197840 & $2,34 * x$ \\
\hline Resî̉ duo & 142 & 12,005575 & 0,084546 & \\
\hline
\end{tabular}

Média geral $=13,68 \%$

Coeficiente de variação $=7,86 \%$

Teste de Duncan a $5 \varepsilon$ :

\begin{tabular}{|c|c|c|}
\hline Progênie & & $\bar{x}$ \\
\hline 59 & 9,36 & $\mathrm{a}$ \\
\hline 11 & $11,0 ?$ & $a b$ \\
\hline 52 & 11,42 & $a . b c$ \\
\hline 2 & 11,49 & abcc \\
\hline 60 & 11,63 & abcd \\
\hline 49 & 11,70 & abcd \\
\hline 36 & 11,70 & $a b c d$ \\
\hline 54 & 11,70 & abcd \\
\hline 10 & 11,70 & a)uc? \\
\hline 53 & 11,76 & abcd \\
\hline 14 & 11,90 & abcde \\
\hline 33 & 11,90 & abcde \\
\hline 34 & 1].,90 & abcde \\
\hline 20 & 12,04 & abcdef \\
\hline 63 & 12,04 & abcder \\
\hline $3 \%$ & 12,25 & abcdief \\
\hline 26 & 12,32 & abcdef \\
\hline 7 & 12,39 & abcdef \\
\hline $2 ?$ & 12,39 & abcder: \\
\hline 35 & 12,39 & a\}scdef \\
\hline 70 & 12,53 & abccief \\
\hline 8 & 12,89 & abcaiefg \\
\hline 61 & 12,89 & abcdefg \\
\hline 3 & 13,03 & abcdefg \\
\hline 42 & 13,10 & abcdefg \\
\hline 16 & $1.3,10$ & abcaiefg \\
\hline 4 & 1. 3,13 & abcdefg \\
\hline 1 & 13,25 & abcdefics \\
\hline 6 & 13,25 & abcaefg \\
\hline 44 & 13,25 & abcdefg \\
\hline 51 & 13,32 & abcderg \\
\hline 45 & $1.3,32$ & abcdefg \\
\hline 32 & 13,40 & abcetefos \\
\hline 58 & 13,40 & abcdefg \\
\hline 43 & 13,54 & bcdefg \\
\hline 1.7 & 13,54 & bcdefg \\
\hline
\end{tabular}

\begin{tabular}{|c|c|c|}
\hline Progenie & & $\overline{\mathrm{x}}$ \\
\hline 10 & 13,61 & bcderg \\
\hline 47 & $13,6.1$ & brdefg \\
\hline 41 & 13,61 & bcdefg \\
\hline 30 & 13,84 & bucdefg \\
\hline 63 & 13,91 & bcdefg \\
\hline 13 & 14,06 & bcdefgh \\
\hline 66 & 14,06 & bcaefgh \\
\hline 72 & 14,06 & brecefgr: \\
\hline 3 & $1 \hat{4}, 21$ & 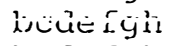 \\
\hline 62 & 14,21 & bcdefgh \\
\hline 19 & 14,29 & bcdefgh \\
\hline 12 & 14,52 & bcdefgh \\
\hline 57 & 14,59 & bcdefgh \\
\hline 64 & 14,67 & bcdefgh \\
\hline 50 & 14,75 & bcclefgh \\
\hline 56 & 14,75 & bcāefgh \\
\hline 22. & 14,90 & borefgh \\
\hline 23 & 14,90 & bccefgh \\
\hline 46 & 15,05 & bcdefgh \\
\hline 15 & 15,13 & bodefgh \\
\hline 31 & 15,13 & bcảe figh \\
\hline 63 & 15,13 & hodefich \\
\hline 39 & 15,21 & bcale fogh \\
\hline 48 & 15,29 & bcdefgh \\
\hline 5 & 15,29 & bcdefgh \\
\hline 55 & 15,44 & cdefgh \\
\hline 21. & 15,76 & cicfogh \\
\hline 28 & 15,92 & defgh \\
\hline 10 & 15,92 & defgh \\
\hline 67 & 16,06 & defgh \\
\hline 25 & 16,16 & efgh \\
\hline 23 & 16,48 & fgh \\
\hline 38 & 16,48 & fgh \\
\hline 71 & 17,14 & gh \\
\hline 27 & 18,75 & hi \\
\hline 65 & 22,56 & i \\
\hline
\end{tabular}


TABbilan 23 - Análige da variâncía como bilocos ao acaso e resultea dos da apjicação no teste de Duncan a $5 \%$ às médias de progénies para o caráter porcentagen de sementes conchas. Dados analisados após transformação por: $\sqrt{x+0,5}$. Café 'Acaíá'. Estação Experimental de Mo COCa, SP, 1973.

\begin{tabular}{lrrrr}
\multicolumn{1}{c}{ F.V. } & G.I. & S.Q. & Q.M. & F \\
\hline Blocos & 2 & 0,037608 & 0,018804 & \\
Progênies & 71 & 3,501487 & 0,049317 & $1,67 * *$ \\
Resĩduo & 142 & 4,205237 & 0,029614 & \\
\hline & TOIAL & 2.15 & 7,744332 &
\end{tabular}

Média goral $=2,00$

Coeficiente de variação $=10,88 \%$

Teste de Duncan a $5 \%$

\begin{tabular}{|c|c|c|}
\hline Progênje & & $\bar{x}$ \\
\hline 58 & 1., 40 & $\mathrm{a}$ \\
\hline 45 & 1,43 & $\mathrm{a}$ \\
\hline 49 & 1,47 & $a b$ \\
\hline 31 & 1,48 & $a b$ \\
\hline 7 & 1., 50 & $a b$ \\
\hline 60 & 1,52 & $a b$ \\
\hline 13 & 1,52 & $a b$ \\
\hline 68 & 1,53 & $a b$ \\
\hline 36 & 1,54 & $a b$ \\
\hline 32 & 1,54 & $a b$ \\
\hline 24 & 1,55 & $a b$ \\
\hline 12 & 1,56 & $a b c$ \\
\hline 47 & 1,60 & $a b c:$ \\
\hline 71 & 1,63 & $a b c$ \\
\hline 10 & 1,65 & abcd \\
\hline 18 & 1,66 & $a b c d$ \\
\hline 6 & 1,67 & abca \\
\hline 64 & 1,70 & abcde \\
\hline 11 & 1,73 & abcrle \\
\hline 56 & 1,75 & abcoe \\
\hline 28 & 1,78 & abcale \\
\hline 35 & 1,79 & abcde \\
\hline 23 & 1,82 & abcde \\
\hline 22 & 1,82 & abcde \\
\hline 39 & 1,84 & abcde \\
\hline 72 & 1,85 & abode \\
\hline 2 & 1., 87 & abcde \\
\hline 5 & 1,88 & ałscde \\
\hline 54 & 1,88 & abcde \\
\hline 30 & 1,89 & abcale \\
\hline 40 & 1,90 & abode \\
\hline 41 & 1,90 & abcde \\
\hline 29 & 1,91 & $a b c: d e$ \\
\hline 25 & 1,92 & abcde \\
\hline 21 & 1,98 & abccle \\
\hline 48 & 1,98 & abcde \\
\hline
\end{tabular}

\begin{tabular}{|c|c|c|}
\hline Progênie & & $\bar{x}$ \\
\hline 4 & 2,00 & abcde \\
\hline 46 & 2,01 & abcidef \\
\hline 59 & 2,01 & abcdef. \\
\hline 34 & 2,02 & abcder \\
\hline 61 & $2 ., 03$ & abcdef \\
\hline 38 & 2,04 & abcdef \\
\hline 52 & 2,05 & abcỏef \\
\hline 37 & 2,05 & abcdef \\
\hline 27 & $2, \bar{U} \overline{6}$ & aixcōe $\tilde{I}$ \\
\hline 8 & 2,07 & abcdef: \\
\hline 33 & 2,08 & abcdef \\
\hline 55 & 2,09 & abcdef \\
\hline 51 & 2,09 & abcdef \\
\hline 14 & 2,10 & abcdef \\
\hline 3 & 2,17 & abcdef \\
\hline 50 & 2,18 & abcdef: \\
\hline 15 & 2,19 & abcdef \\
\hline 26 & 2,21 & abcdef: \\
\hline 3.9 & 2,25 & abcdef \\
\hline 16 & 2,26 & abcdef \\
\hline 20 & 2,29 & abcdef \\
\hline 44 & $2,3]$ & abcdefg \\
\hline 57 & 2,33 & abcảefg \\
\hline 1 & 2,35 & abcdefg \\
\hline 66 & 2,38 & abcdefg \\
\hline 42 & 2,43 & abcdefg \\
\hline 70 & 2,44 & abcdefg \\
\hline 17 & 2,45 & abcdefg \\
\hline 43 & 2,50 & abcdefg \\
\hline 9 & 2,59 & bcdefg \\
\hline 53 & 2,66 & cdefg \\
\hline 67 & 2,78 & defg \\
\hline 63 & 2,80 & efg \\
\hline 62 & 2,82 & efg \\
\hline 69 & 3,26 & $\mathrm{fg}$ \\
\hline 65 & 3,54 & g \\
\hline
\end{tabular}




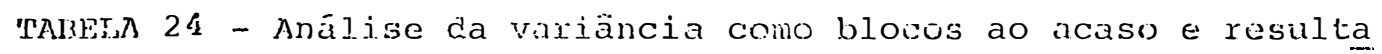
dos da aplicação do testi: de Duncan a 5 o às linéctias das progênies para o caráter precocidade de producão medido pola produção cereja em quilogramas no primeirs biênio. Café 'Acaiá'. Estação Experimen-tal. de Mococa, Sp, $1972 / 73$.

\begin{tabular}{lrrrr}
\hline F.V. & G.1. & G.S. & Q.M. & F \\
\hline Blocios & 2 & 6,502319 & 3,251174 & \\
Progenties & 71 & 293,878628 & 4,139136 & $1,93 * *$ \\
Residino & 142 & 304,331520 & 2,143180 & \\
\hline & TOTAL 215 & 604,714966 &
\end{tabular}

Média geräi]. $=11,614 \mathrm{Kợ}$

Coeficiente de variaçäo := 12,698

Teste de Duncan a 5\%:

\begin{tabular}{|c|c|c|}
\hline Progenente & $\bar{\gamma}$ & $\bar{x}$ \\
\hline 62 & 14,852 & $\mathrm{a}$ \\
\hline .13 & $14: 273$ & $a b$ \\
\hline 53 & J. 3,720 & $\mathrm{abc}$ \\
\hline 66 & 13,457 & $\therefore$ bcd \\
\hline 3 & 13,416 & abcá \\
\hline 42 & 13,368 & abcd \\
\hline 50 & 13,193 & abcd \\
\hline 69 & 13,091 & $a \bar{b} c \ddot{a}$ \\
\hline 36 & 12,969 & abca \\
\hline 49 & $12,7 \cong 7$ & abcde \\
\hline 4 & 12.791 & abcde \\
\hline 14 & 12,760 & abcder \\
\hline 67 & I. 2,749 & abcāef \\
\hline 25 & 12,716 & abccief \\
\hline 5.5 & 12,642 & abcỏef: \\
\hline 56 & 12,606 & abccief \\
\hline 65 & 12,404 & abcdofg \\
\hline 70 & 12,370 & abcdefog \\
\hline 43 & 12,367 & abcciefg \\
\hline 54 & 12,347 & abcdefic \\
\hline 2 & 12,255 & $a b c c \in f g$ \\
\hline 38 & 12,233 & abcaefo \\
\hline 15 & 12,20 & abcacrg \\
\hline 44 & 12,026 & abcdefo \\
\hline 7 & 11,964 & bcaeflg \\
\hline 57 & $3.1,837$ & bodefog \\
\hline 9 & 11,818 & bcdefg \\
\hline 6 & 11,719 & bcdefo \\
\hline 31 & 11,709 & bcāefg \\
\hline 61. & 11,686 & bcalefig \\
\hline 39 & 11,658 & bcdefg \\
\hline 46 & 11,623 & bcalefg \\
\hline 32 & 11,537 & bcdefg \\
\hline 48 & 11,528 & bcdefg \\
\hline 8 & 11,518 & bcdefg \\
\hline 16 & 11,518 & bcdefg \\
\hline
\end{tabular}

\begin{tabular}{|c|c|c|}
\hline Procyênic & & $\overline{\mathrm{x}}$ \\
\hline $4 \grave{j}$ & 11,365 & bcdefgh \\
\hline 71 & 1.1. 361 & hodefg \\
\hline 22 & $.11,352$ & bcdefg \\
\hline 1.0 & 11,328 & br:defg \\
\hline 52 & 11,326 & bedefoy \\
\hline 63 & 11,308 & bcde $f g$ \\
\hline 72 & 11,293 & bcdefg \\
\hline 37 & 11,240 & cüefgh \\
\hline 20 & 11,232 & canigh \\
\hline 35 & 11,195 & cdefgh \\
\hline $1 \%$ & 11,133 & cdefgh \\
\hline 18 & 11,327 & criefgh \\
\hline 29 & $11,0 \% 2$ & cdefgh \\
\hline 64 & 11,033 & cdefgh \\
\hline 51 & 11,004 & cdefciil \\
\hline 58 & 10,999 & cdefgh \\
\hline 34 & 10,973 & cdefgh \\
\hline 40 & 10,969 & cdefgh \\
\hline 11. & 10,883 & cdeEghi \\
\hline 59 & 10,875 & cdefchi \\
\hline 19 & ]. 0,827 & cdefghi \\
\hline 23 & 10,825 & cdefighi \\
\hline 30 & 10,755 & cdefghj. \\
\hline 17 & 10,716 & cdefghi \\
\hline 21 & 10,609 & defghi \\
\hline 41 & 10,650 & defghi \\
\hline 1 & $10,5.98$ & defghi \\
\hline 24 & 10,594 & defoghi \\
\hline 12 & 10,583 & de foghi. \\
\hline 58 & 10,437 & defghij \\
\hline 33 & 9,993 & efghij \\
\hline 60 & 9,779 & fghij \\
\hline 5 & 9,431 & ghij \\
\hline 28 & 8,280 & hij \\
\hline 27 & 8,020 & $i j$ \\
\hline 26 & 7,811 & $j$ \\
\hline
\end{tabular}


TABjL 25 - Análise da vinxiäncia como blocos ao acáso e resultâ dos da aplicação do teste de Duncan a 5\% às médias de progēnies para o caráter incremento anual da pro dução nos três primeiros anos medido pelo coeficien te: de regressão sobre os anos en quilogramas. Café 'Acaía'. Estação Hixperimental de Hococa, SP, 1972i 73.

\begin{tabular}{lrrrr}
\multicolumn{1}{c}{ F.V. } & G.1. & S.Q. & Q.M. & F \\
\hline Blocos & 2 & 18,421285 & $9,21.0643$ & \\
Progénies & 71 & 60,146944 & 0,847140 & $1,53 * *$ \\
Resíduo & 142 & 78,649793 & 0,553872 & \\
\hline
\end{tabular}

TOTAL 215

$157,21.8022$

Média geral $=1,216 \mathrm{Kg}$

Coeficiente de variação $=61,20 \%$

Tesete de Duncen a 5 s:

\begin{tabular}{|c|c|c|}
\hline Progêni.e & $\bar{y}$ & 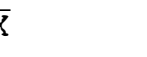 \\
\hline 28 & 2,527 & $\mathrm{a}$ \\
\hline 24 & 2,485 & als \\
\hline 40 & 2,312 & $a b c$ \\
\hline 25 & 2,151 & $a b c d$ \\
\hline 71 & 2,113 & abcd \\
\hline 31 & 1,993 & abcase \\
\hline 57 & 1,853 & abcdef: \\
\hline 58 & $i, 764$ & abc:aef \\
\hline 12 & 1,736 & abcdef \\
\hline 66 & $1 ., 707$ & $a b c d e f$ \\
\hline 22 & 1,699 & abcdef \\
\hline 5 & $1 \cdot 683$ & abcas \\
\hline 59 & ]., 665 & abcdef \\
\hline 2 & 1,622 & abcdef \\
\hline 54 & 1,614 & absclef \\
\hline 7 & 1,550 & abcdef \\
\hline 35 & 1,549 & abcdef \\
\hline 68 & 1,530 & abcdef \\
\hline 15 & 1,517 & abcoles \\
\hline 39 & $1,51.3$ & abcder: \\
\hline 56 & 1,511 & abcdef \\
\hline 9 & 1,486 & abockir \\
\hline 11 & 1,475 & abcdef \\
\hline 43 & 1,458 & abccief \\
\hline 64 & 1,454 & abcảef \\
\hline 27 & 1,443 & abcdef \\
\hline 38 & 1,388 & abcaef \\
\hline 46 & 1,374 & abcdef \\
\hline 10 & 1,350 & abcdef: \\
\hline 19 & 1,336 & abcidef \\
\hline 51. & 1,332 & abcdef \\
\hline 21 & 1,328 & abccier: \\
\hline 45 & 1,308 & abcdef \\
\hline 63 & 1,270 & abcde $\bar{x}$ \\
\hline 6 & 1,249 & abcosef \\
\hline 17 & 1,241 & abcdef \\
\hline
\end{tabular}

\begin{tabular}{|c|c|c|}
\hline Progênie & & $\overline{\mathrm{X}}$ \\
\hline 32 & 1,208 & abcủef \\
\hline 29 & 1,193 & abcdeE \\
\hline 65 & 1,193 & abcdef: \\
\hline 61 & 1,182 & abcde \\
\hline 72 & 1., 165 & abcdef \\
\hline 48 & 1,158 & abcdef \\
\hline 70 & 1,148 & abcdef \\
\hline 55 & 1,131 & abcdef́ \\
\hline 30 & 1,083 & a)xcalefg \\
\hline 16 & 1,040 & abcalefg \\
\hline 69 & 1,033 & abcclefg \\
\hline 47 & 0,985 & bcdefg \\
\hline 44 & 0,984 & bcảefg \\
\hline 2.3 & 0,965 & bcdefg \\
\hline 33 & 0,924 & cdefy \\
\hline 44 & 0,894 & colefg \\
\hline ]. 3 & 0,891 & cdefg \\
\hline 41 & 0,846 & cdefos \\
\hline 1 & 0,842 & cdefg \\
\hline 3 & 0,830 & ccle fig \\
\hline 20 & 0,807 & cdefg \\
\hline 53 & 0,774 & def:g \\
\hline 4 & 0,766 & defg \\
\hline 50 & 0,639 & defg \\
\hline 14 & 0,675 & detig \\
\hline 34 & 0,655 & deig \\
\hline 67 & 0,645 & $d \in f g$ \\
\hline 37 & 0,644 & dof.g \\
\hline 3 & 0,561 & efg \\
\hline 52 & 0,480 & efg \\
\hline 36 & 0,423 & fg \\
\hline 18 & 0,400 & fig \\
\hline 62 & 0,398 & fg \\
\hline 42 & 0,397 & $\mathrm{Fg}$ \\
\hline 26 & 0,369 & $\mathrm{fg}$ \\
\hline 60 & $-0,398$ & g \\
\hline
\end{tabular}


TABEla 26- Análise da variância como blocos ao acaso e resulta dos da apjicacão do teste de Dunciun a 58 para o caráter oscílação anual dä produção nos três primejros anos de colheita medido pelo coeficiente de variação sobre os anos cm porcentagen. Café 'Acaiá'. Estação Exper:imental de Mococa, SP, 1972-74.

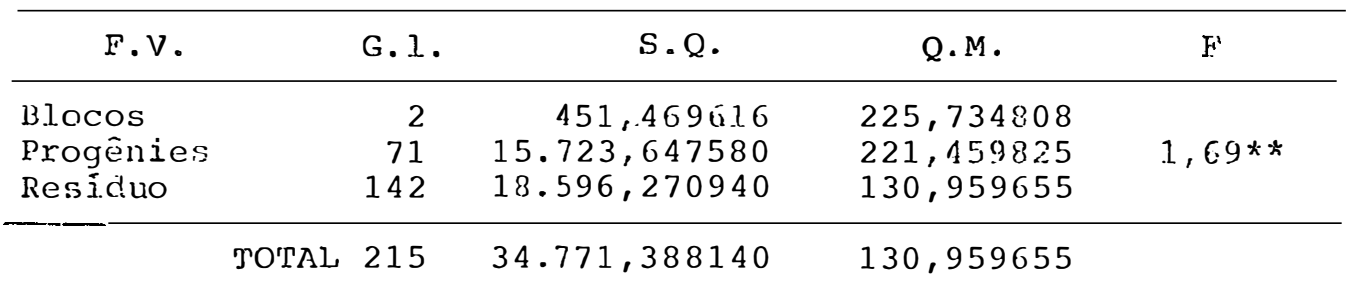

Média geral $=46,73 \%$

Coeficiente de variação $=24,49$ g

Teste de Duncan a $5 \%$ :

\begin{tabular}{|c|c|c|}
\hline Progēnie & & $\overline{\mathrm{x}}$ \\
\hline 49 & 26,90 & $\mathrm{a}$ \\
\hline 13 & 27,96 & abs \\
\hline 53 & 29,67 & $\mathrm{abc}$ \\
\hline 66 & 31,19 & abcd \\
\hline 42 & 31,32 & abca \\
\hline 70 & 31,77 & abcd \\
\hline 50 & 33,61 & abcde \\
\hline 44 & 34,98 & abcdef \\
\hline 14 & 36,20 & abcaei \\
\hline 36 & 36,74 & abodef \\
\hline 62 & 37,16 & abcdef \\
\hline 69 & $38,1.5$ & abcdefg \\
\hline 7 & 38,48 & $a b c d e f g$ \\
\hline 3 & 39,37 & abcdefg \\
\hline 55 & 40,09 & abcdefg \\
\hline 4 & 10,32 & abcdefg \\
\hline 6 & 40,32 & abcdefg \\
\hline 25 & 40,52 & abcdefg \\
\hline 10 & 41,08 & abcdefg \\
\hline 56 & 42,18 & abcdefgh \\
\hline 9 & 42,29 & abcdefgh \\
\hline 65 & 42,51 & abcdefon \\
\hline 54 & 43,16 & abccleforh \\
\hline 61 & 43,50 & abcdefigh \\
\hline 57 & 43,60 & abcdef(y) \\
\hline 52 & 43,90 & aucdefgh \\
\hline 67 & 43,91 & abcdefgh \\
\hline 43 & 45,16 & abcdefgh \\
\hline 38 & $45,21$. & abcdefogh \\
\hline 20 & 45,69 & abcdefgh \\
\hline 34 & 45,92 & abcdefgh \\
\hline 17 & 46,07 & abcdefgh \\
\hline 29 & 46,55 & abcalefgh \\
\hline 3.8 & 46,60 & abcdefgh \\
\hline 46 & 46,74 & abcdefgh \\
\hline 16 & 47,07 & abcdefgh \\
\hline
\end{tabular}

\begin{tabular}{|c|c|c|}
\hline Progênie & & $\overline{\mathrm{x}}$ \\
\hline 48 & $47,50$. & abcdefgh \\
\hline 45 & 48,33 & abcalefgh \\
\hline 59 & 48,59 & abcdefgh \\
\hline 8 & 48,69 & abcdefgh \\
\hline 58 & 48,71 & abcdefgh \\
\hline 23 & 49,22 & abcdefgh \\
\hline 15 & 49,47 & abcdefgh \\
\hline 22 & 49,49 & abcdefgh. \\
\hline 63 & $5 \mathrm{u}, 11$ & abcoefgh \\
\hline 37 & 50,13 & abcdefgh \\
\hline 40 & 50,69 & bcdefgh \\
\hline 1.8 & 50,85 & bcdefgh \\
\hline 32 & 51,49 & bcdefgh \\
\hline 31 & 51,54 & bcrefgh \\
\hline 41 & 51,56 & cdefigh \\
\hline 30 & 51,69 & cdefgh \\
\hline 1 & 52,00 & cdefgh \\
\hline 2 & 52,29 & cdefgh \\
\hline 12 & 52,40 & cdefgh \\
\hline 64 & $53,1.9$ & crefgh \\
\hline 27 & 53,20 & defgh \\
\hline 23 & 53,40 & defgh \\
\hline 35 & 54,23 & defgh \\
\hline 51 & 54,45 & defgh \\
\hline 47 & 55,71 & efgh \\
\hline 21 & 55,87 & efgh \\
\hline 33 & 56,10 & efgh \\
\hline 11 & 56,70 & efgh \\
\hline 5 & 56,89 & efgh \\
\hline 39 & 57,10 & efgh \\
\hline 68 & 57,46 & fgh \\
\hline 72 & 57,95 & fgh \\
\hline 24 & 60,80 & $\mathrm{gh}$ \\
\hline 60 & 61,21 & gh \\
\hline 26 & 64,55 & $\mathrm{~h}$ \\
\hline 71 & 65,01 & $\mathrm{~h}$ \\
\hline
\end{tabular}


Trujur 27 - Anälise da variância corno blocos ao acaso e resulta dos da aplicação do testic de vuncan á $5 \%$ às médias das progênics para o caräter incremento anual de produção nos oito prineixos anos dado pelo coeficientc de regressão sobre os anos em quilogramas.ca féé 'Acaiá', Estação Experimental de Mococú, Sp,1972

-79 .

\begin{tabular}{lrrrr}
\multicolumn{1}{c}{ l.V. } & G.1. & S.Q. & Q.M. & F \\
\hline Blocos & 2 & 0,010835 & 0,005418 & \\
Progínies & 71 & 4,789642 & 0,067460 & $2,61 * *$ \\
Resídio & 142 & 3,664931 & 0,025809 & \\
\hline & TOTAL 215 & 8,465407 &
\end{tabular}

Média geral $=0,109 \mathrm{Kg}$

Coeficiente de variação $=147,71 \%$

Teste de Duncan a 5을

\begin{tabular}{|c|c|c|}
\hline Progēnie & & $\bar{X}$ \\
\hline 30 & 0,444 & $\mathrm{a}$ \\
\hline 40 & 0,439 & $a b$ \\
\hline 28 & 0,379 & $\mathrm{abc}$ \\
\hline 68 & 0,353 & abcd \\
\hline 45 & 0,343 & abcde \\
\hline 12 & 0,334 & abcde \\
\hline 1.3 & 0,304 & abcdef \\
\hline 51 & 0,286 & abcdefg \\
\hline is & $\hat{u}, \hat{2} \overline{8} \dot{4}$ & aivecuefgin \\
\hline 46 & 0,277 & abcdefghi \\
\hline 8 & 0,267 & abcdefghi \\
\hline 21 & $0,2.62$ & $a b c d e f g h i$ \\
\hline 2.4 & 0,261 & abcde fghi \\
\hline 26 & 0,252 & abcdefghi \\
\hline 2 & 0,248 & abcdefghi \\
\hline 1 & 0,226 & abcdefghij \\
\hline 25 & 0,223 & abcdefghij \\
\hline 48 & 0,220 & abcdefghij \\
\hline 10 & $0,2.13$ & abrojefghij \\
\hline 54 & 0,201 & $a b c d e f g h j . j k$ \\
\hline 39 & 0,197 & abcde fghj jkl \\
\hline 71 & 0,179 & abcdefghijkl \\
\hline 11 & 0,170 & abcdefghijkl \\
\hline 7 & 0,167 & abciefghijkj. \\
\hline 33 & 0,164 & obcciefghijk] \\
\hline 47 & 0,161 & abcdefghijkI \\
\hline 66 & $0,3.48$ & abcdefghijkl \\
\hline 22 & 0,146 & abcaeighijkl \\
\hline 59 & 0,143 & abcdefghijk] \\
\hline 60 & $0,12.3$ & abcdiefghijkl \\
\hline 31 & 0,121 & akcdefghijkl \\
\hline 41 & 0,119 & abcäefghijki \\
\hline 70 & 0,114 & bcdetghijkJ. \\
\hline 17 & 0,111 & bcdefghijkl \\
\hline 4.3 & 0,107 & cdefghijkl \\
\hline 16 & 0,106 & cclefghijki \\
\hline
\end{tabular}

\begin{tabular}{|c|c|c|}
\hline Progênie & & $\overline{\mathrm{X}}$ \\
\hline 3 & 0,104 & cdefghijkl \\
\hline 49 & $0,08]$ & chefghijkl \\
\hline 72 & 0,080 & cdefghijkl \\
\hline 69 & 0,080 & cdefghijkl \\
\hline 62 & 0,075 & cdefghijkl \\
\hline 29 & 0,074 & cdefghijkl \\
\hline 34 & 0,068 & cdefghijk! \\
\hline 61 & 0,052 & cdefghijkl \\
\hline 27 & $\hat{U}, \bar{U} \bar{L}$ & cciefgnijoi \\
\hline 37 & 0,054 & cdefghijkl \\
\hline 57 & 0,052 & chefghijk? \\
\hline 38 & 0,052 & cdefighijkl \\
\hline 53 & 0,051 & clefghijkl \\
\hline 23 & 0,039 & defghijkl \\
\hline 14 & 0,037 & defghijkl \\
\hline 9 & 0,032 & defghijkl \\
\hline 58 & 0,029 & defghijklm \\
\hline 64 & 0,016 & ef:ghijk]m \\
\hline 56 & $0,0] 2$ & efghijk lm \\
\hline 63 & 0,001 & fghijklm \\
\hline 5 & $\ldots 0,000$ & fghijklm \\
\hline 36 & $-0,019$ & Eghijklmn \\
\hline 4.4 & $-0,025$ & fghijklmn \\
\hline 50 & $-0,027$ & ghijklmn \\
\hline 32 & $-0,028$ & ghijklmn \\
\hline 55 & $-0,032$ & ghijklmn \\
\hline 20 & $-0,037$ & ghijklmn \\
\hline 6 & $-0,045$ & hijklmn \\
\hline 18 & $-0,045$ & nijklmn \\
\hline 4 & $-0,047$ & hijklmn \\
\hline 42 & $-0,053$ & $i j k l m n$ \\
\hline 52 & $-0,083$ & jklmn \\
\hline 15 & $-0,116$ & $\mathrm{k} \operatorname{lmn}$ \\
\hline 35 & $-0,127$ & $\operatorname{lmn}$ \\
\hline 67 & $-0,301$ & $m n$ \\
\hline 65 & $-0,338$ & $n$ \\
\hline
\end{tabular}




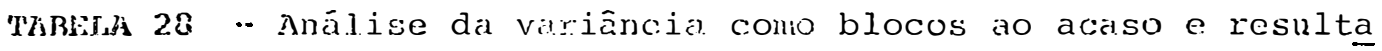
dos da apljccaça do teste de Duncan a 5 ơ às médias das progênies para o caráter oscilação anual da produção nos oito primeiros anos mediclo pelo coeficiente de variação anual. sobre os anos de produção medicioem porccntagem. Café 'Acajá'. Estação Expẹe rimental de Mococa, SP, 1972-79

\begin{tabular}{lrrrr}
\hline \multicolumn{1}{c}{ F.V. } & G.I. & \multicolumn{1}{c}{ S.Q. } & Q.M. & F \\
\hline Blocos & 2 & 25,960110 & 12,980055 & \\
Progénies & 71. & $7.287,501100$ & 102,640861 & $1,65 * *$ \\
Resíno & 142 & $8.836,672310$ & 62,230087 & \\
\hline
\end{tabular}

тотлL $215 \quad 16.150,133550$

Média geral $=81,26 \%$

Coeficiente de variação $=9,71$.

Teste de Duncan a 5\%:

\begin{tabular}{|c|c|c|}
\hline Progênie & & $\pi$ \\
\hline 65 & 63,96 & $\mathrm{a}$ \\
\hline 53 & 69,31 & $a b$ \\
\hline 42 & 73,35 & $a b c$ \\
\hline 66 & 73,55 & $a b c$ \\
\hline 70 & 73,60 & $a b c$ \\
\hline 50 & 73,63 & $a b c$ \\
\hline 44 & 73,65 & $a b c$ \\
\hline 13 & 73,99 & abc \\
\hline 7 & 74,02 & $a b c$ \\
\hline 9 & 74,38 & $\mathrm{abcd}$ \\
\hline 62 & 74,42 & a.bcd \\
\hline 49 & 75,31 & abcde \\
\hline 4 & 75,64 & abchef \\
\hline 69 & 75,86 & abcclef \\
\hline 3 & 75,92 & abcdef \\
\hline 36 & 76,27 & abcdef \\
\hline 14 & 76,59 & abcdef. \\
\hline 20 & 77,06 & abcdefg \\
\hline 10 & 77,36 & abcde $f \bar{y}$ \\
\hline 54 & 77,51 & abcdefg \\
\hline 38 & 77,71 & abcdefg \\
\hline 6 & 77,94 & abcdefg \\
\hline 56 & 78,27 & abcảefgh \\
\hline 17 & 78,39 & abcdefgh \\
\hline 43 & 78,60 & abcdefgh \\
\hline 34 & 79,28 & abcdefgh \\
\hline 57 & 79,31 & abcdefgh \\
\hline 67 & 79,35 & abcdefgh \\
\hline 61 & 79,77 & abcdefgh \\
\hline 59 & 79,95 & abcdefgh \\
\hline 25 & 80,46 & bcde fgh \\
\hline 2 & 80,70 & bcdefgh \\
\hline 46 & 80,83 & bcdefgh \\
\hline 48 & 81,04 & bcdefgh \\
\hline 52 & 81,65 & bcdefgh \\
\hline 16 & 81,96 & bcdefgh \\
\hline
\end{tabular}

\begin{tabular}{|c|c|c|}
\hline Progênie & & $\overline{\mathrm{x}}$ \\
\hline 63 & 82,09 & bcdefgh \\
\hline 55 & 82,21 & bcdefgh \\
\hline 29 & 82,34 & bcdefgh \\
\hline 19 & 82,35 & bcdefgh \\
\hline 1 & 82,45 & bcdefgh \\
\hline 18 & 82,50 & bcde Egh \\
\hline 22 & 82,59 & bcrefogh \\
\hline 32 & 82,73 & bodefăh \\
\hline 35 & 82,91 & brdefgh \\
\hline 37 & $8.3,37$ & bcdefgh \\
\hline 12 & 83,73 & bcde $f(y)$ \\
\hline 58 & 83,85 & bcỏefogh \\
\hline 61 & 84,38 & iscdefogh \\
\hline 72 & 84,43 & bcdefgh \\
\hline 30 & 84,53 & bcdefgh \\
\hline 23 & 84,55 & brode figh \\
\hline 41 & 85,29 & cdefogh \\
\hline 45 & 85,54 & cdefigh \\
\hline 31 & 86,33 & cdefçh \\
\hline 27 & 86,52 & cdefigh \\
\hline 40 & 86,99 & cdefgh \\
\hline 39 & 87,19 & cdefgh \\
\hline 15 & 87,32 & cdefgh \\
\hline 24 & 87,48 & cdefgh \\
\hline 51 & 87,56 & cdefgh \\
\hline 71. & 88,32 & cdefgh \\
\hline 26 & 88,75 & cdefgh \\
\hline 21 & 89,16 & cdefgh \\
\hline 68 & 89,22 & cdefgh \\
\hline 5 & 39,23 & cdefgh \\
\hline 8 & 90,56 & defigh \\
\hline 47 & 90,60 & defgh \\
\hline 11 & 90,95 & efgh \\
\hline 33 & 91,53 & $\mathrm{fgh}$ \\
\hline 28 & 93,01 & çh \\
\hline 60 & 94,39 & $\mathrm{~h}$ \\
\hline
\end{tabular}


.129.

TIABEILA 29- Médias gerais $\left(\bar{x}_{0}\right)$, amplitudes de variação, estimativas de coeficientes de determinação genutípica ao nível de progênies $\left(\bar{b}_{p}\right)$, progresso genético esperado na seleção $\left(\widehat{G}_{S}\right)$ e média melhorada esperada $\left(\bar{X}_{M}\right)$ para os caracteres avaliados, exceto para a produção beneficiada total, para as progênies $10 \%$ mais produtivas. Café 'Acaiá'. Estação Experimental de Mococa, SP, $1972-79$.

\begin{tabular}{|c|c|c|c|c|c|c|}
\hline Caráter & $\bar{x}_{0}$ & Ampl & litude & ${ }^{5} p$ & $\mathrm{G}_{\mathrm{S}}$ & $\overline{\mathrm{X}}_{\mathrm{M}}$ \\
\hline Tamanho dos grãos & 16,95 & $17,47-$ & $-16,48$ & 0,2897 & $0,24 \%$ & 16,99 \\
\hline Renda & 5,65 & 5,40 & $-0,20$ & 0,6990 & $0,88 \%$ & $\begin{array}{l}5,70 \\
5,60\end{array}$ \\
\hline Altura da copa & $3,02 \mathrm{~m}$ & $3,25 \cdots$ & $-2,58 \mathrm{~m}$ & 0,5835 & $2,65 \%$ & $3,10 \mathrm{~m}$ \\
\hline Diāmetro da copa & $1,81 \mathrm{~m}$ & 1,96 & $-1,65 \mathrm{~m}$ & 0,3865 & $1,65 \%$ & $1,84 \mathrm{~m}$ \\
\hline \% de grãos chato & $84,1 \%$ & 88,2 & $-73,9 \%$ & 0,6196 & $-0,04 \%$ & $84,06 \%$ \\
\hline \% de grãos moca & $13,8 \%$ & 9,4 & $-22,6 \%$ & 0,5727 & $-0,65 \%$ & $13,77 \%$ \\
\hline \% de grãos concha & $2,3 \%$ & 1,4 & $-3,5 \%$ & 0,6766 & $5,22 \%$ & $2,18 \%$ \\
\hline Produçāo do 10 biēnio & $11,614 \mathrm{Kg}$ & 14,852 & $-8,017 \mathrm{Kg}$ & 0,4822 & $3,39 \%$ & $12,008 \mathrm{Kg}$ \\
\hline Incremento da produção 3 & $1,216 \mathrm{Kg}$ & 2,527 & $-(-0,398) \mathrm{Kg}$ & 0,3462 & $0,56 \%$ & $1,225 \mathrm{Kg}$ \\
\hline Estabilidade de produção 3 & $46,73 \%$ & 26,9 & $-65,0 \%$ & 0,4087 & $7,40 \%$ & $43,27 \%$ \\
\hline Incremento da produção 8 & $0,109 \mathrm{Kg}$ & 0,444 & $+-(-0,338) \mathrm{Kg}$ & 0,6174 & $12,58 \%$ & $0,165 \mathrm{Kg}$ \\
\hline Estabilidade de produção 8 & $81,26 \%$ & 64,0 & $-94,4 \%$ & 0,3937 & $2,10 \%$ & $79,55 \%$ \\
\hline
\end{tabular}




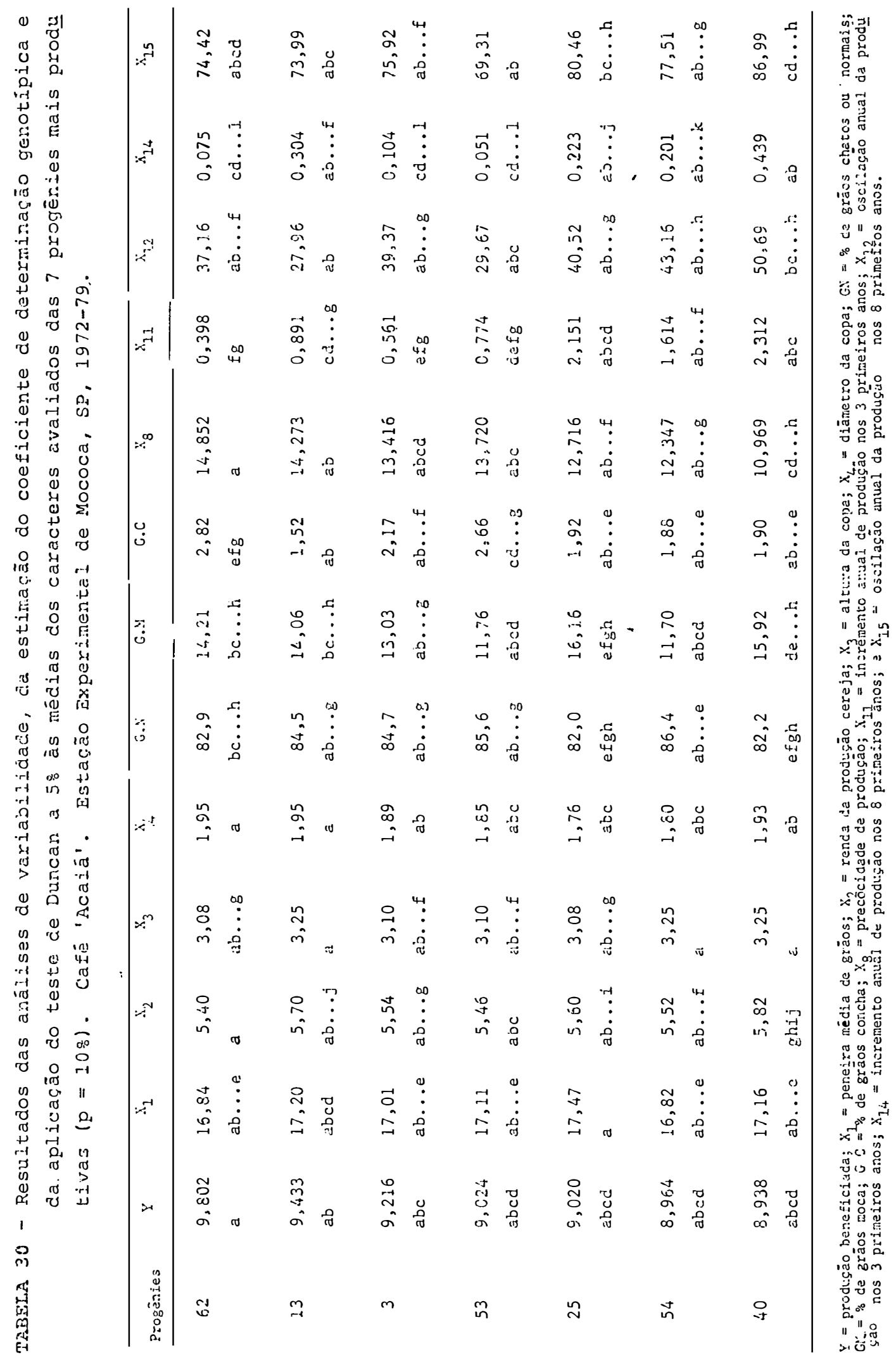


TABELA 31 - Coeficientes de correlação ( $r$ ) estimadas entre a produçãu total de oito anos e diferentes combinações de produções anuais de café cereja obtidas de 72 progênies de 'Acaiá' em Mococa, SP no período 1972-1979.

\begin{tabular}{|c|c|c|c|c|c|}
\hline $\begin{array}{c}\text { Combinações de produções } \\
\text { anuais }\end{array}$ & $\overline{\mathrm{X}}$ & $r \underline{1} /$ & $\%$ & \multicolumn{2}{|c|}{$\begin{array}{l}\text { relativa } \\
\text { do } r\end{array}$} \\
\hline \multicolumn{6}{|l|}{ Anos: } \\
\hline $1 \underline{a}$ & 7,291 & 0,2622 & 100 & 39 & 33 \\
\hline $2 \underline{a}$ & 4,323 & 0,5155 & 197 & 77 & 65 \\
\hline $3 \underline{a}$ & 9,726 & 0,5408 & 206 & 81 & 68 \\
\hline $4 \underline{a}$ & 1,040 & 0,2505 & 96 & 38 & 32 \\
\hline $5 \underline{a}$ & 2,056 & 0,5121 & 195 & 77 & 65 \\
\hline $6 \underline{a}$ & 10,295 & 0,7951 & 303 & 119 & 100 \\
\hline $7 \underline{a}$ & 0,496 & 0,2173 & 83 & 33 & 27 \\
\hline $8 \underline{a}$ & 10,919 & 0,8176 & 312 & 123 & 103 \\
\hline
\end{tabular}

Biênios:

$\begin{array}{rrrrrr}1 \underline{a}+2 \underline{a} & 11,614 & 0,6657 & 254 & 100 & 84 \\ 3 \underline{a}+4 \underline{a} & 10,766 & 0,7390 & 282 & 111 & 93 \\ 5 \underline{a}+6 \underline{a} & 12,351 & 0,8575 & 327 & 129 & 108 \\ 7 \underline{a}+8 \underline{a} & 1 j, 415 & 0,8368 & 319 & 126 & 105\end{array}$

Acumulados:

$\begin{array}{llllll}1 \underline{a}+2 \underline{a}+3 \underline{a} & 21,340 & 0,7938 & 302 & 119 & 100 \\ 1 \underline{a}+2 \underline{a}+3 \underline{a}+4 \underline{a} & 22,380 & 0,8332 & 318 & 125 & 105 \\ 1 \underline{a}+2 \underline{a}+3 \underline{a}+4 \underline{a}+5 \underline{a} & 24,436 & 0,8691 & 331 & 131 & 109 \\ 1 \underline{a}+2 \underline{a}+3 \underline{a}+4 \underline{a}+5 \underline{a}+6 \underline{a} & 34,731 & 0,9608 & 366 & 144 & 121 \\ 1 \underline{a}+2 \underline{a}+3 \underline{a}+4 \underline{a}+5 \underline{a}+6 \underline{a}+7 \underline{a} & 35,227 & 0,9607 & 366 & 144 & 121\end{array}$

II Prob. $t=0,00001$ (para todas as combinações) 
TABELA 32 - Estimativas de coeficientes de correlação genotipica $\left(r_{G}\right)$, fenotipica $\left(r_{F}\right)$ e simples $(r)$, dos caracteres avaliados com a produção beneficiada total de oito anos. Café 'Acaiá'. Es tação Experimental de Mococa, SP, 1972-1979.

\begin{tabular}{|c|c|c|c|}
\hline Caracteres & $r_{G}$ & $r_{F}$ & $r$ \\
\hline Tamanho dos grãos & 0,6432 & $0,3738 * *$ & $0,3707 * *$ \\
\hline Rendimento & $-0,0909$ & $-0,1038 \mathrm{~ns}$ & $-0,2473^{*}$ \\
\hline Altura da copa & 0,4262 & $0,7314 * *$ & 0,7514 ** \\
\hline Diâmetro da copa & 0,2849 & $0,5861 * *$ & $0,6184 * *$ \\
\hline 1a produção cereja & $-0,7716$ & $0,0691 \mathrm{~ns}$ & $0,2652 * *$ \\
\hline 2a produção cereja & 0,6846 & $0,5796 * *$ & 0,5531 ** \\
\hline 3a produção cereja & 0,2191 & $0,3684 * *$ & $0,4841 * *$ \\
\hline $1 \underline{a}+2 \underline{a}$ produção cereja & 0,5847 & $0,6453 * *$ & 0,6992 ** \\
\hline $2 \underline{a}+3 \underline{a}$ produção cereja & 0,8701 & $0,7655 * *$ & $0,7840 * *$ \\
\hline $1 \underline{a}+2 a+3 a$ produção cereja & 0,8369 & $0,7501 * *$ & $0,7730 * *$ \\
\hline \% de grãos normais & 0,0000 & $0,0547 \mathrm{~ns}$ & $0,0353 \mathrm{~ns}$ \\
\hline \& de grãos moca & 0,0000 & $-0,3681 * *$ & $-0,0276 \mathrm{~ns}$ \\
\hline : de grãos concha & $-0,1515$ & $-0,2218 \mathrm{~ns}$ & $-0,1067 \mathrm{~ns}$ \\
\hline $\begin{array}{l}\text { Incremento da produção } \\
\text { anual nos } 3 \text { primeiros } \\
\text { anos }\end{array}$ & 0,3761 & $0,2858 * *$ & $0,3309 * *$ \\
\hline $\begin{array}{l}\text { Oscilação anual de pro- } \\
\text { dução nos } 3 \text { primeiros } \\
\text { anos }\end{array}$ & $-0,6568$ & $-0,4741 * *$ & $-0,3210 * *$ \\
\hline $\begin{array}{l}\text { Incremento da produção } \\
\text { anual nos } 8 \text { primeiros } \\
\text { anos }\end{array}$ & 0,2941 & $0,3402 * *$ & $0,3407 * *$ \\
\hline $\begin{array}{l}\text { Oscilação anual de pro- } \\
\text { dução nos } 8 \text { prımeiros } \\
\text { anos }\end{array}$ & $-0,3340$ & $-0,3097 * *$ & $-0,2390 *$ \\
\hline
\end{tabular}




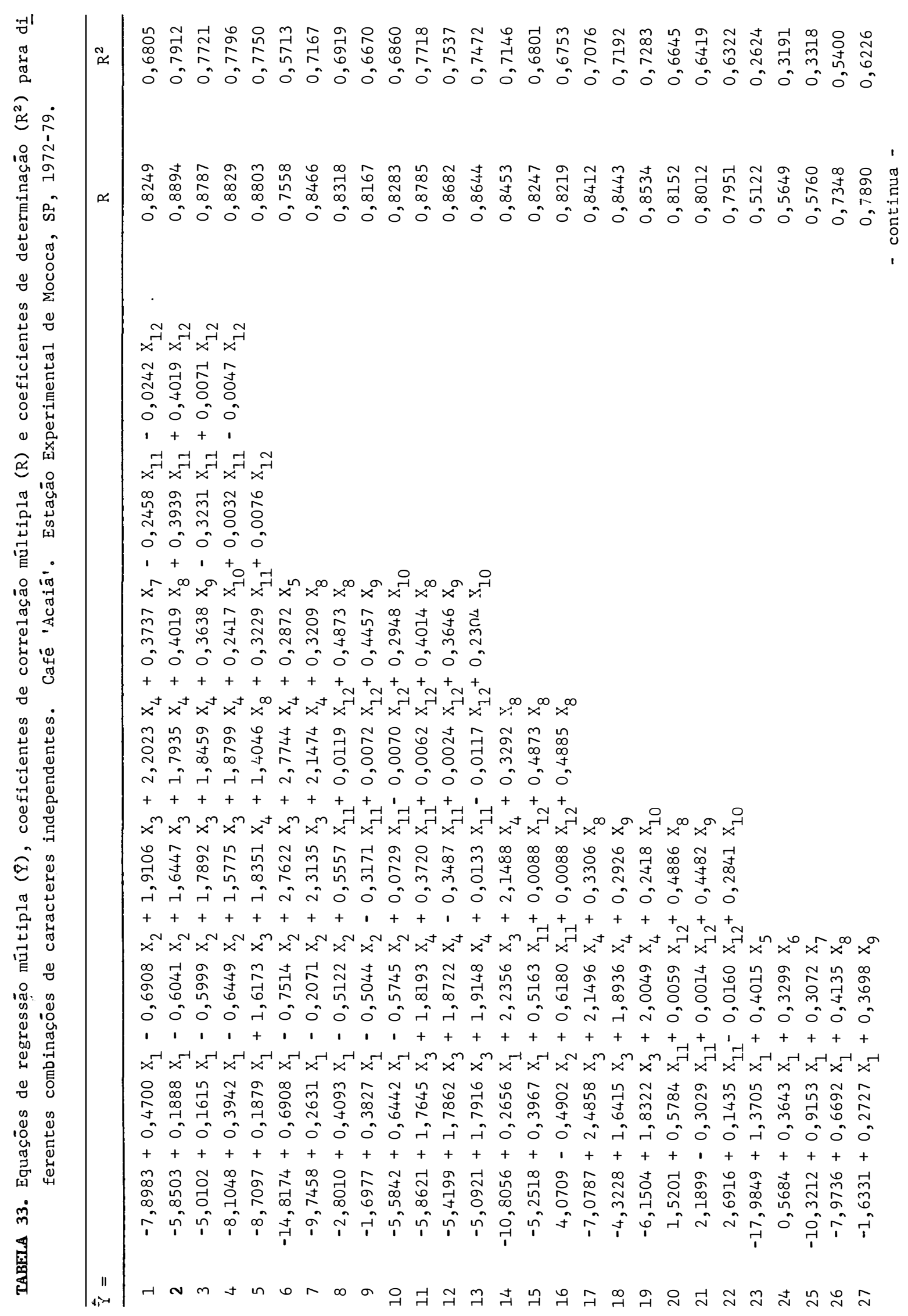




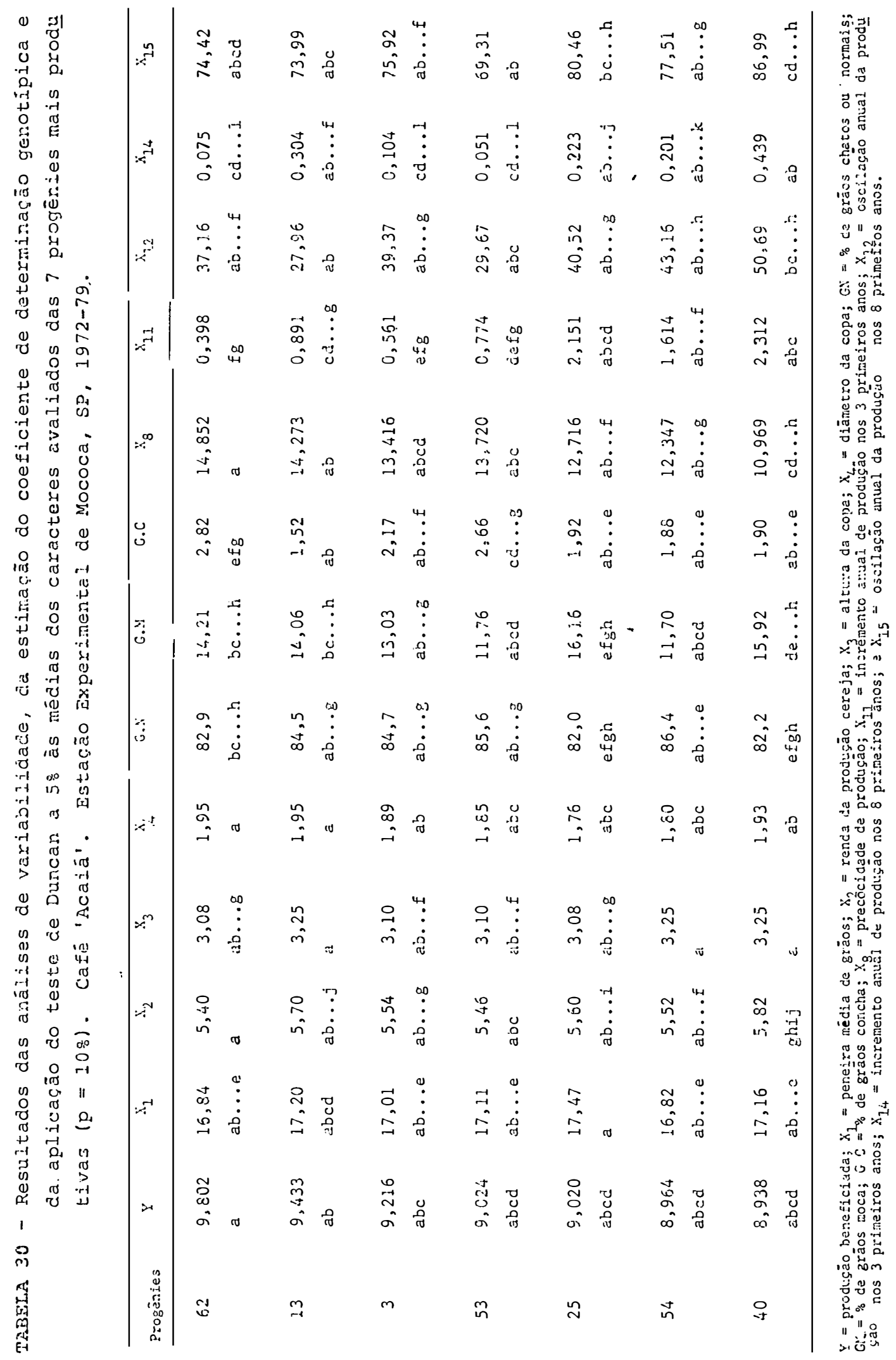




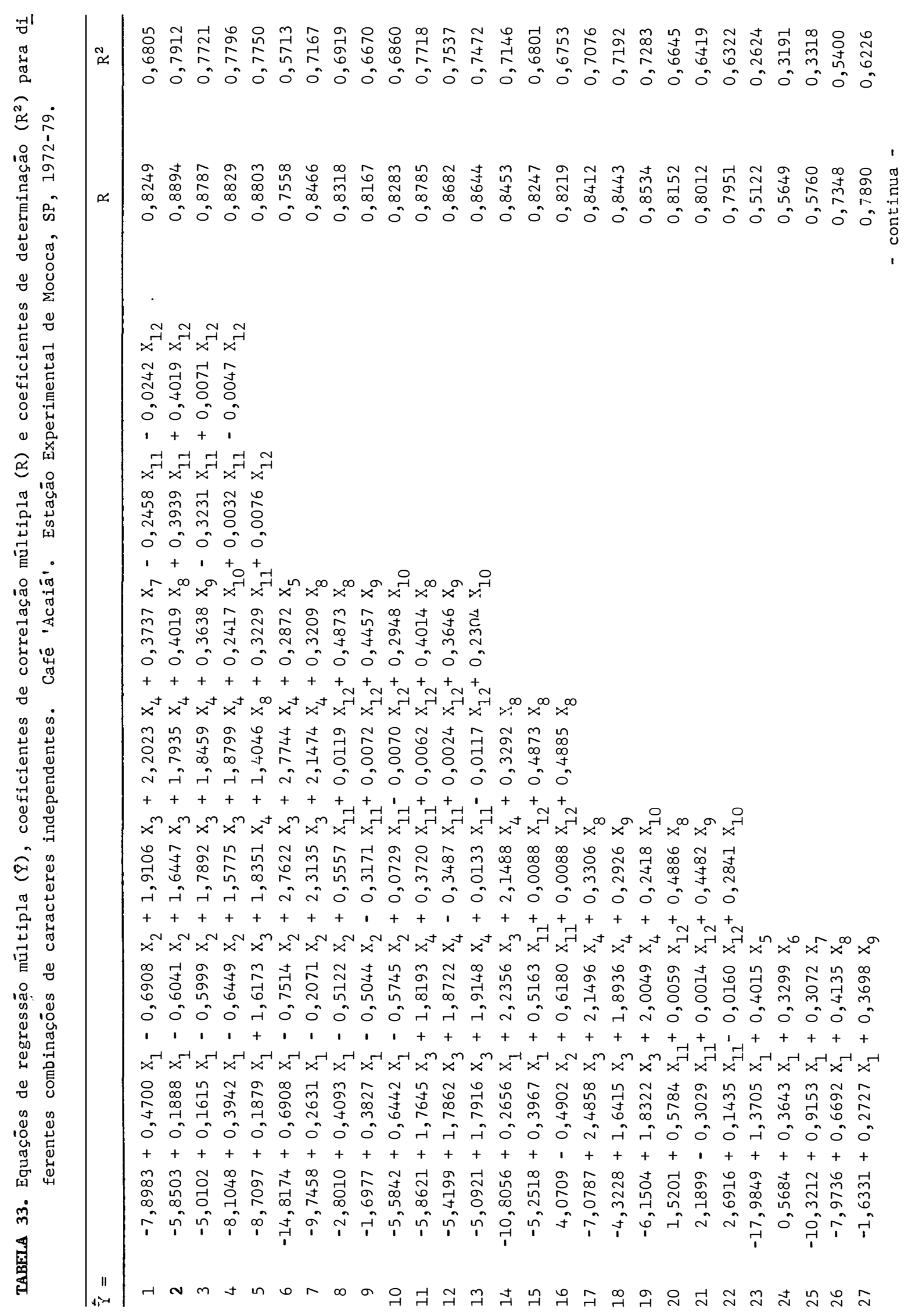




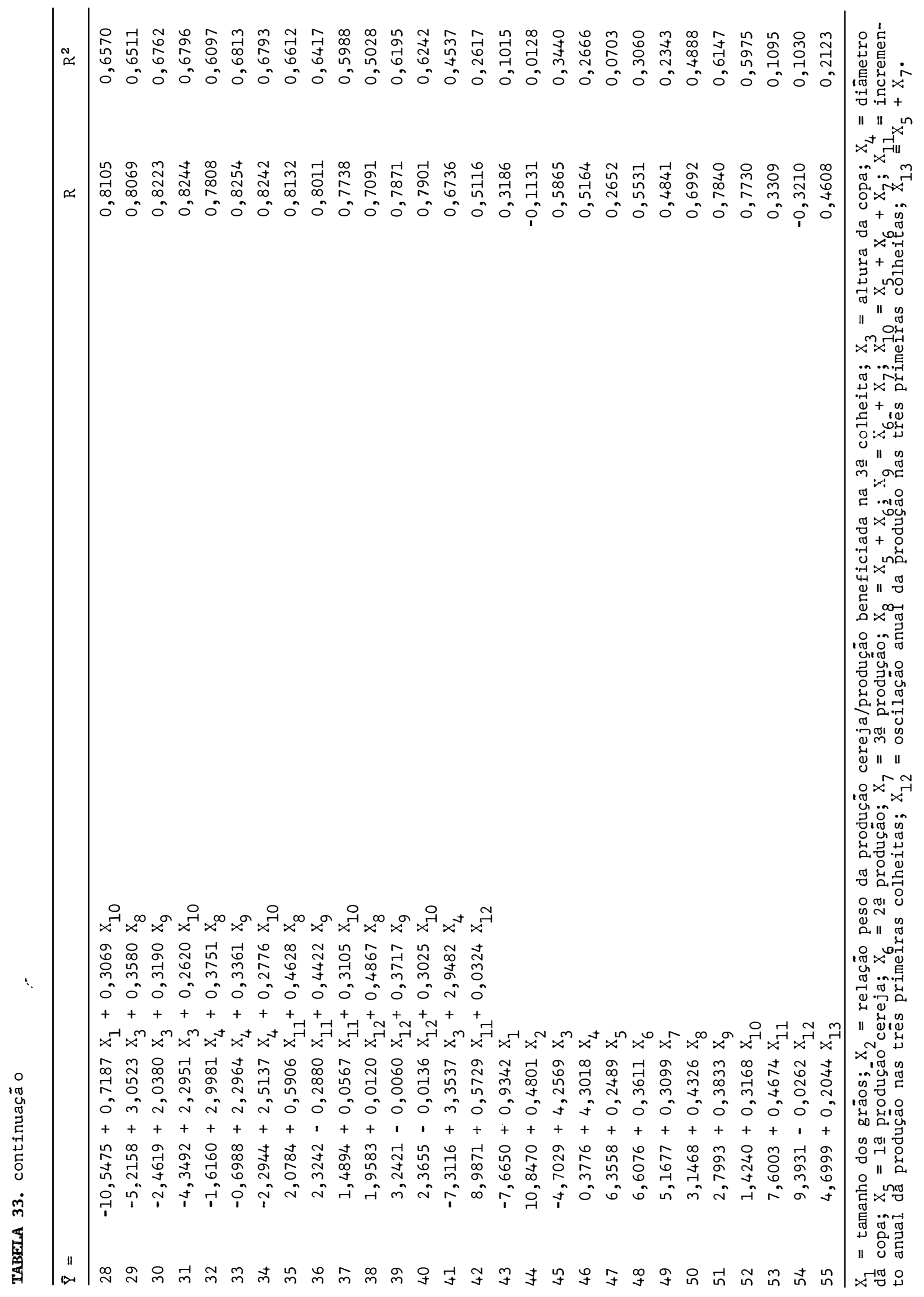


TABELA 34 - Valores de produçäo beneficiada de do\%c plintas por oito anos observados (Y) e estimados ( $(\bar{Y})$ para as 72 progēnies de 'Acaiá' pela equação de regressāo múltipla no 2 e produção cereja do primeiro biēnio $\left(\mathrm{x}_{8}\right)$ com suas classificaçōes (en tre parēntesis).

\begin{tabular}{|c|c|c|c|c|c|c|c|}
\hline Progēnies & $Y$ & $P$ & $x_{8}$ & Progēnics & Y & $\overline{\mathrm{Y}}$ & $x_{8}$ \\
\hline 1 & 96,715 & 91,392 & 10,596 & 37 & 93,000 & 91,340 & (46) 11,248 \\
\hline 2 & 106,827 & (9) 106,530 & ( 21$) 12,255$ & 38 & 103,675 & 103,899 & ( 22$) 12,233$ \\
\hline 3 & (3) 110,594 & ( 7) 106,824 & (5) 13,416 & 39 & 101,700 & 98,650 & (33) 11,658 \\
\hline 4 & 98,192 & 98,080 & (11) 12,791 & 40 & ( 7) 107,255 & (8) 106,600 & $(54) 10,969$ \\
\hline 5 & 82,729 & 86,508 & 9,430 & 41 & 89,829 & 93,733 & 10,650 \\
\hline 6 & 97,169 & 96,515 & (30) 11,719 & 42 & 101,211 & 101,540 & (6) 13,368 \\
\hline 7 & 103,475 & 101,205 & (27) 11,964 & 43 & 105,326 & (5) 107,998 & $(18) 12,367$ \\
\hline 8 & 96,644 & 94,193 & (37) 11,518 & 44 & 93,655 & 92,406 & (26) 12,028 \\
\hline 9 & 100,949 & 101,541 & (29)11,818 & 45 & 100,214 & 99,176 & (39) 11,365 \\
\hline 10 & 101,944 & 101,539 & (43) 11,328 & 46 & 102,774 & 100,183 & $(34) 11,622$ \\
\hline 11 & 99,398 & 95,031 & 10,883 & 47 & 97,755 & 98,191 & (48) 11,133 \\
\hline 12 & 102,386 & 98,376 & 10,583 & 48 & 100,788 & 99,492 & (36) 11,528 \\
\hline 13 & (2) 113,190 & (1) 116,234 & (2) 14,523 & 49 & 100,150 & 98,664 & (10) 12,797 \\
\hline 14 & 102,414 & 101,670 & (12) 12,760 & 50 & 103,401 & 102,283 & ( 7) 13,192 \\
\hline 15 & 95,911 & 98,817 & (25) 12,204 & 51 & 98,804 & 93,549 & (53) 11,004 \\
\hline 16 & 96,526 & 96,422 & (38) 11,517 & 52 & 86,880 & 90,806 & (42) 11,351 \\
\hline 17 & 91,558 & 88,811 & 10,722 & 53 & (4) 108,292 & (4) 108,009 & (3) 13,720 \\
\hline 18 & 90,876 & 89,161 & (49) 11,127 & 54 & (6) 107,565 & (13) 103,954 & (20) 12,347 \\
\hline 19 & 102,743 & $98, .71$ & 10,827 & 55 & 98,883 & 100,155 & (15) 12,646 \\
\hline 20 & 94,647 & 97,847 & $(24) 12,233$ & 56 & 102,969 & (10) 105,628 & (16) $12 ; 606$ \\
\hline 21 & 95,664 & 96,383 & 10,669 & 57 & 97,583 & 101,911 & (28) 11,837 \\
\hline 22 & 105,369 & 102,026 & $(41) 11,352$ & 58 & 96,442 & 98,982 & (52) 11,008 \\
\hline 23 & 93,115 & 93,383 & 10,825 & 59 & 100,100 & 97,301 & 10,875 \\
\hline 24 & 101,405 & $1.02,541$ & 10,594 & 60 & 79,841 & 75,719 & 9,779 \\
\hline 25 & (5) 108,240 & (6) & $(14) 12,718$ & 61 & 101,054 & 99,013 & (32) 11,686 \\
\hline 26 & 64,980 & 65,417 & 7,811 & 62 & (1) 117,628 & (2) 114,337 & (1) 14,852 \\
\hline 27 & 86,989 & 97,010 & 10,067 & 63 & 86,685 & 93,474 & $(44) 11,308$ \\
\hline 28 & 90,822 & 87,405 & 8,276 & 64 & 95,716 & 98,606 & (51) 11,033 \\
\hline 29 & 94,727 & 92,034 & (50)11,072 & 65 & 79,453 & 88,946 & (17) 12,404 \\
\hline 30 & 102,932 & 97,307 & 10,755 & 66 & 104,448 & ( 3$) 111,464$ & (4) 13,457 \\
\hline 31 & 100,865 & (12) 104,102 & (31) 11,709 & 67 & 83,939 & 90,564 & (13) 12,749 \\
\hline 32 & 97,964 & 98,137 & (35) 11,537 & 68 & 99,927 & 96,087 & 10,436 \\
\hline 33 & 85,847 & 86,017 & 9,993 & 69 & 104,299 & (11) 105,139 & (8)13,091 \\
\hline 34 & 94,212 & 91,669 & 10,973 & 70 & 103,293 & 103,258 & (19) 12,370 \\
\hline 35 & 91,846 & 96,430 & $(47) 11,195$ & 71 & 106,351 & 103,661 & $(40) 11,361$ \\
\hline 36 & 97,521 & 100,715 & (9) 12,968 & 72 & 98,543 & 98,698 & (45) 11,293 \\
\hline
\end{tabular}

Equação de regressão múltipla:

$P_{2}=-5,8503+0,1888 x_{1}-0,6041 x_{2}+1,7447 x_{3}+1,7935 x_{4}+0,4019 x_{8}+0,3938 x_{11}+$ $+0,0111 x_{12}$ 
TABELA 35 - Valores observados $(Y)$ c estimados $(P)$ de produçio benericiada total de do ze plantas por oito anos para as 72 progēnies de café 'Acaiá' pela equação de regressão múltipla no 7 e suas classificaçōes (entre parēntesis).

\begin{tabular}{|c|c|c|}
\hline Progēnie & $Y$ & $\overline{\mathrm{Y}}$ \\
\hline 1 & 96,715 & 93,511 \\
\hline 2 & (8) 106,827 & (9) 104,583 \\
\hline 3 & (3) 110,594 & (5) 109,866 \\
\hline 4 & 98,192 & 99,388 \\
\hline 5 & 82,729 & 82,997 \\
\hline 6 & 97,168 & 95,354 \\
\hline 7 & 103,474 & 100,959 \\
\hline 8 & 96,644 & 96,848 \\
\hline 9 & 100,948 & 101,104 \\
\hline 10 & 101,944 & 102,465 \\
\hline 11 & 99,398 & 92,239 \\
\hline 12 & 102,385 & 97,996 \\
\hline 13 & (2) 113,190 & (1) 116,481 \\
\hline 14 & (22) 102,413 & (14) 103,922 \\
\hline 15 & 95,912 & 95,481 \\
\hline 16 & 96,526 & 96,491 \\
\hline 17 & 91,558 & 88,015 \\
\hline 18 & 90,876 & 90,856 \\
\hline 19 & 102,743 & 97,748 \\
\hline 20 & 94,646 & 98,386 \\
\hline 21 & 95,663 & 96,992 \\
\hline 22 & 105,369 & 99,792 \\
\hline 23 & 93,114 & 93,303 \\
\hline 24 & 101,405 & 98,126 \\
\hline 25 & (5) 108,248 & (15) 103,808 \\
\hline 26 & 64,980 & 68,272 \\
\hline 27 & 86,989 & 96,516 \\
\hline 28 & 90,822 & 86,601 \\
\hline 29 & 94,727 & 92,016 \\
\hline 30 & 102,933 & 100,882 \\
\hline 31 & 100,865 & 101,306 \\
\hline 32 & 97,964 & 96,183 \\
\hline 33 & 85,846 & 87,164 \\
\hline 34 & 94,212 & 95,535 \\
\hline 35 & 91,846 & 92,540 \\
\hline 36 & $(44) 97,521$ & (18) 102,904 \\
\hline
\end{tabular}

\begin{tabular}{|c|c|c|}
\hline Progēnie & Y & $P$ \\
\hline 37 & 93,000 & 92,707 \\
\hline 38 & (15) 103,674 & (17) 103,388 \\
\hline 39 & 101,700 & 97,224 \\
\hline 40 & ( 7) 107,255 & (8) 104,759 \\
\hline 41 & 89,829 & 94,476 \\
\hline 42 & (28) 101,210 & (11) 104,489 \\
\hline 43 & (11) 105,326 & (6) 107,766 \\
\hline 44 & 93,655 & 94,054 \\
\hline 45 & (32) 100,215 & (19) 101,935 \\
\hline 46 & 103,773 & 100,770 \\
\hline 47 & 97,755 & 99,226 \\
\hline 48 & 100,787 & 101,067 \\
\hline 49 & (33) 100,150 & (10) 104,490 \\
\hline 50 & (17) 103,401 & (13) 103,982 \\
\hline 51 & 98,803 & 93,050 \\
\hline 52 & 86,880 & 92,700 \\
\hline 53 & (4) 108,292 & (4) 110,171 \\
\hline 54 & (6) 107,565 & (20) 101,732 \\
\hline 55 & 98,883 & 98,985 \\
\hline 56 & (19) 102,969 & (16) 103,625 \\
\hline 57 & 97,583 & 100,999 \\
\hline 58 & 96,441 & 97,325 \\
\hline 59 & 100,101 & 93,750 \\
\hline 60 & 79,841 & 80,974 \\
\hline 61 & 102,054 & 98,456 \\
\hline 62 & (1) 117,628 & (2) 116,026 \\
\hline 63 & 86,685 & 96,041 \\
\hline 64 & 95,716 & 94,015 \\
\hline 65 & 79,453 & 87,354 \\
\hline 66 & (12) 104,447 & (3) 111,304 \\
\hline 67 & 83,939 & 90,842 \\
\hline 68 & 99,927 & 96,644 \\
\hline 69 & (13) 104,299 & ( 7) 106,011 \\
\hline 70 & (18) 103,293 & (12) 104,062 \\
\hline 71 & 106,351 & 99,231 \\
\hline 72 & 98,543 & 97,487 \\
\hline
\end{tabular}

Equaçāo de regressāo mú1tipla:

$P_{7}=-9,7458+0,2631 x_{1}-0,2071 x_{2}+2,3134 x_{3}+2,1474 x_{4}+0,3209 x_{8}$ 
TABELA 36 - Valores observados $(Y)$ e estimados $(\bar{Y})$ de produção beneficiada total de doze plantas por oito anos para as 72 progēnies de 'Acaiā' pela equação de regressão múltipla no 8 e suas classificaçōes (entre parentesis).

\begin{tabular}{|c|c|c|}
\hline Progēnie & $\mathrm{Y}$ & $\overline{\mathrm{Y}}$ \\
\hline 1 & 96,715 & 90,323 \\
\hline 2 & 106,827 & $107,477(5)$ \\
\hline 3 & $110,594(3)$ & $104,979(7)$ \\
\hline 4 & 98,192 & 100,465 \\
\hline 5 & 82,729 & 89,511 \\
\hline 6 & 97,169 & 97,223 \\
\hline 7 & 103,475 & 101,088 \\
\hline 8 & 96,644 & 93,321 \\
\hline 9 & 100,949 & 97,756 \\
\hline 10 & 101,944 & 98,964 \\
\hline 11 & 99,398 & 97,605 \\
\hline 12 & 102,386 & 95,263 \\
\hline 13 & $113,190(2)$ & $110,809(4)$ \\
\hline 14 & 102,414 & 99,670 \\
\hline 15 & 95,911 & $101,880(20)$ \\
\hline 16 & 96,526 & 95,137 \\
\hline 17 & 91,558 & 93,715 \\
\hline 18 & 90,876 & 90,711 \\
\hline 19 & 102,743 & 94,852 \\
\hline 20 & 94,647 & 99,240 \\
\hline 21 & 95,664 & 94,409 \\
\hline 22 & 105,369 & 101,029 \\
\hline 23 & 93,115 & 93,691 \\
\hline 24 & 101,405 & 101,421 \\
\hline 25 & $108,240(5)$ & $111,661(2)$ \\
\hline 26 & 64,980 & 69,409 \\
\hline 27 & 86,989 & 92,096 \\
\hline 28 & 90,822 & 87,683 \\
\hline 29 & 94,727 & 93,641 \\
\hline 30 & 102,932 & 91,487 \\
\hline 31 & 100,865 & $104,677(8)$ \\
\hline 32 & 97,964 & 98,662 \\
\hline 33 & 85,847 & 86,724 \\
\hline 34 & 94,212 & 92,921 \\
\hline 35 & 91,846 & 99,146 \\
\hline 36 & 97,521 & $102,330(18)$ \\
\hline
\end{tabular}

\begin{tabular}{|c|c|c|}
\hline Progēnie & $\mathrm{Y}$ & $\overline{\mathrm{Y}}$ \\
\hline 37 & 93,000 & 91,864 \\
\hline 38 & 103,675 & $102,326(19)$ \\
\hline 39 & 101,700 & 99,571 \\
\hline 40 & $107,255(7)$ & $101,800(22)$ \\
\hline 41 & 89,829 & 95,881 \\
\hline 42 & 101,211 & $103,239(14)$ \\
\hline 43 & 105,326 & $103,423(13)$ \\
\hline 44 & 93,655 & 95,554 \\
\hline 45 & 100,214 & 97,493 \\
\hline 46 & 103,774 & $101,265(24)$ \\
\hline 47 & 97,755 & 93,756 \\
\hline 48 & 100,788 & 97,591 \\
\hline 49 & 100,150 & 99,977 \\
\hline 50 & 103,401 & $102,605(16)$ \\
\hline 51 & 98,804 & 93,488 \\
\hline 52 & 86,880 & 91,437 \\
\hline 53 & $108,292(4)$ & $107,002(6)$ \\
\hline 54 & $107,565(6)$ & $104,207(10)$ \\
\hline 55 & 98,883 & $103,045(15)$ \\
\hline 56 & 102,969 & $104,387(9)$ \\
\hline 57 & 97,583 & $101,880(21)$ \\
\hline 58 & 96,442 & 99,230 \\
\hline 59 & 100,100 & 98,691 \\
\hline 60 & 79,841 & 76,163 \\
\hline 61 & 102,054 & 98,111 \\
\hline 62 & $117,628(1)$ & $111,166(3)$ \\
\hline 63 & 86,685 & 93,819 \\
\hline 64 & 95,716 & 97,204 \\
\hline 65 & 79,453 & 100,957 \\
\hline 66 & 104,448 & $111,779(1)$ \\
\hline 67 & 83,939 & 97,508 \\
\hline 68 & 99,927 & 94,250 \\
\hline 69 & 104,299 & $104,178(11)$ \\
\hline 70 & 103,293 & $102,341(17)$ \\
\hline 71 & 106,351 & $103,868(12)$ \\
\hline 72 & 98,543 & 96,261 \\
\hline
\end{tabular}

Equaçāo de regressāo múltipla $\left(x_{1}=\right.$ peneira; $x_{2}=$ rendimento; $x_{11}=$ regressāo $3 ; x_{12}=$ = CV\% 3);

$P_{8}=-2,8010+0,4093 x_{1}-0,5122 x_{2}+0,5557 x_{11}+0,0119 x_{12}+0,4873 x_{8}$ 
TABELA 37 - Valores observados (Y) e estimados ( $\bar{Y}$ ) de produção beneficiada total de doze plantas por oito anos para as 72 progēnies de café 'Acaiá' pela equa ção de regressão múltipla no 6 e suas classificações.

\begin{tabular}{|c|c|c|c|c|c|}
\hline Progēnies & $\mathrm{Y}$ & $\bar{Y}$ & Progēnies & Y & $\mathrm{P}$ \\
\hline 1 & 96,715 & $98,108(42)$ & 37 & 93,000 & $95,488(52)$ \\
\hline 2 & 106,827 & $104,538(8)$ & 38 & 103,674 & $103,046(13)$ \\
\hline 3 & $110,594(3)$ & $108,918(2)$ & 39 & 101,700 & $98,055(43)$ \\
\hline 4 & 98,192 & $95,419(53)$ & 40 & $107,255(7)$ & $106,766(4)$ \\
\hline 5 & 82,729 & 86,455 & 41 & 89,829 & $97,841(45)$ \\
\hline 6 & 97,168 & 94,092 & 42 & 101,210 & $100,950(28)$ \\
\hline 7 & 103,474 & $98,169(41)$ & 43 & 105,326 & $106,816(3)$ \\
\hline 8 & 96,644 & $95,577(51)$ & 44 & 93,655 & 89,684 \\
\hline 9 & 100,948 & $99,887(33)$ & 45 & 100,215 & $104,447(9)$ \\
\hline 10 & 101,944 & $102,196(18)$ & 46 & 103,773 & $98,724(38)$ \\
\hline 11 & 99,398 & $95,913(49)$ & 47 & 97,755 & $104,086(10)$ \\
\hline 12 & 102,385 & $101,623(23)$ & 48 & 100,787 & $102,131(19)$ \\
\hline 13 & $113,190(2)$ & $111,192(1)$ & 49 & 100,150 & 91,457 \\
\hline 14 & 102,413 & $102,391(16)$ & 50 & 103,401 & $101,529(24)$ \\
\hline 15 & 95,912 & 93,055 & 51 & 98,803 & 92,617 \\
\hline 16 & 96,526 & $96,284(47)$ & 52 & 86,880 & 94,543 \\
\hline 17 & 91,558 & 86,597 & 53 & $108,292(4)$ & $104,612(7)$ \\
\hline 18 & 90,876 & 94,232 & 54 & $107,565(6)$ & $95,357(54)$ \\
\hline 19 & 102,743 & $100,807(29)$ & 55 & 98,883 & $96,186(48)$ \\
\hline 20 & 94,646 & $97,843(44)$ & 56 & 102,969 & $101,740(22)$ \\
\hline 21 & 95,663 & $101,043(26)$ & 57 & 97,583 & $98,562(39)$ \\
\hline 22 & 105,369 & $102,740(15)$ & 58 & 96,441 & $99,365(36)$ \\
\hline 23 & 93,114 & $98,786(37)$ & 59 & 100,101 & $95,595(50)$ \\
\hline 24 & 101,405 & $100,722(30)$ & 60 & 79,841 & 85,543 \\
\hline 25 & $108,240(5)$ & $97,485(46)$ & 61 & 102,054 & $99,460(35)$ \\
\hline 26 & 64,980 & 74,255 & 62 & $117,628(1)$ & $106,137(5)$ \\
\hline 27 & 86,980 & $102,092(21)$ & 63 & 86,685 & 95,270 \\
\hline 28 & 90,822 & 92,929 & 64 & 95,716 & $100,975(27)$ \\
\hline 29 & 94,727 & 92,694 & 65 & 79,453 & 75,057 \\
\hline 30 & 102,933 & $105,271(6)$ & 66 & 104,447 & $103,823(11)$ \\
\hline 31 & 100,865 & $102,110(20)$ & 67 & 83,939 & 84,261 \\
\hline 32 & 97,964 & $99,640(34)$ & 68 & 99,927 & $103,077(12)$ \\
\hline 33 & 85,846 & 90,285 & 69 & 104,299 & $101,443(25)$ \\
\hline 34 & 94,212 & $98,320(40)$ & 70 & 103,293 & $102,832(14)$ \\
\hline 35 & 91,846 & 94,126 & 71 & 106,351 & $102,275(17)$ \\
\hline 36 & 97,521 & $100,706(31)$ & 72 & 98,543 & $100,507(32)$ \\
\hline
\end{tabular}

Equação de regressão múltipla:

$\hat{Y}_{6}=-14,8174+0,6908 x_{1}-0,7514 x_{2}+2,7622 x_{3}+2,7744 x_{4}+0,2872 x_{5}$ 
TABELA 38 - Produção beneficiada total ( $Y$ ) e suas estimativas ( $P$ ), através da equação de regressāo múltipla no 41 e suas classificaçōes (entre parentesis).

\begin{tabular}{|c|c|c|}
\hline Progēnies & $\mathrm{Y}$ & $\bar{Y}$ \\
\hline 1 & 96,715 & 97,039 \\
\hline 2 & 106,827 & $101,752(20)$ \\
\hline 3 & 110,594 ( 3) & 103,777 (12) \\
\hline 4 & 98,192 & 93,867 \\
\hline 5 & 82,729 & 89,297 \\
\hline 6 & 97,168 & 93,800 \\
\hline 7 & 103,474 & 100,225 (29) \\
\hline 8 & 96,644 & 98,045 \\
\hline 9 & 100,948 & $102,744(14)$ \\
\hline 10 & 101,944 & 103,818 (11) \\
\hline 11 & 99,398 & 93,435 \\
\hline 12 & 102,385 & $104,113(8)$ \\
\hline 13 & $113,190(2)$ & $112,339(1)$ \\
\hline 14 & 101,413 & 100,275 (28) \\
\hline 15 & 95,912 & 92,841 \\
\hline 16 & 96,526 & 96,520 \\
\hline 17 & 91,558 & 87,946 \\
\hline 18 & 90,876 & 90,345 \\
\hline 19 & 101,743 & 101,704 (22) \\
\hline 20 & 94,646 & 95,110 \\
\hline 21 & 95,663 & $101,587 \quad(23)$ \\
\hline 22 & 105,369 & $101,277 \quad(27)$ \\
\hline 23 & 93,114 & 94,800 \\
\hline 24 & 101,405 & $104,073(9)$ \\
\hline 25 & $108,240(5)$ & $98,370(37)$ \\
\hline 26 & 64,980 & 78,870 \\
\hline 27 & 86,989 & $104,050(10)$ \\
\hline 28 & 90,822 & 99,769 (33) \\
\hline 29 & 94,727 & 93,227 \\
\hline 30 & 102,933 & $107,240(4)$ \\
\hline 31 & 100,865 & 101,747 (21) \\
\hline 32 & 97,964 & 95,955 \\
\hline 33 & 85,846 & 92,391 \\
\hline 34 & 94,212 & 93,277 \\
\hline 35 & 91,846 & 92,465 \\
\hline 36 & 97,821 & 95,412 \\
\hline
\end{tabular}

\begin{tabular}{|c|c|c|}
\hline Progēnies & $\mathrm{Y}$ & $\bar{Y}$ \\
\hline 37 & 93,000 & 93,097 \\
\hline 38 & 103,674 & 102,254 (17) \\
\hline 39 & 101,700 & 98,019 \\
\hline 40 & $107,255(7)$ & $110,993(2)$ \\
\hline 41 & 89,829 & 96,759 \\
\hline 42 & 101,216 & 95,672 \\
\hline 43 & 105,326 & $108,218(3)$ \\
\hline 44 & 93,655 & 91,107 \\
\hline 45 & 100,215 & $104,347(7)$ \\
\hline 46 & 103,773 & $100,045 \quad(32)$ \\
\hline 47 & 97,755 & $103,239(13)$ \\
\hline 48 & 100,787 & $102,281(16)$ \\
\hline 49 & 100,150 & 95,848 \\
\hline 50 & 103,401 & 97,416 \\
\hline 51 & 98,803 & 96,603 \\
\hline 52 & 86,880 & 92,259 \\
\hline 53 & $108,292(4)$ & $102,322(15)$ \\
\hline 54 & $107,565(6)$ & $99,676(35)$ \\
\hline 55 & 98,883 & 93,710 \\
\hline 56 & 102,969 & $101,466(25)$ \\
\hline 57 & 97,583 & $101,550 \quad(24)$ \\
\hline 58 & 96,441 & $99,690(34)$ \\
\hline 59 & 100,101 & 94,959 \\
\hline 60 & 79,841 & 85,912 \\
\hline 61 & 102,054 & 98,178 \\
\hline 62 & $117,628(1)$ & $105,337(5)$ \\
\hline 63 & 86,685 & $98,865(36)$ \\
\hline 64 & 95,716 & 91,128 \\
\hline 65 & 79,453 & 78,414 \\
\hline 66 & 104,447 & $104,687(6)$ \\
\hline 67 & 83,939 & 83,991 \\
\hline 68 & 99,939 & $102,226(18)$ \\
\hline 69 & 104,299 & $101,437(26)$ \\
\hline 70 & 103,293 & $100,182(31)$ \\
\hline 71 & 106,351 & 101,991 (19) \\
\hline 72 & 98,543 & $100,182(30)$ \\
\hline
\end{tabular}

Equaçāo de regressão múltipla:

$Q_{41}=-7,3116+3,3537 x_{3}+2,9482 x_{4}$ 
TABELA 39. Seleção praticada dentro das melhores progēnies classificadas pela equação de regressāo múltipla ( $\bar{Y})$ no 2, para incluir as progēnies $10 \%$ superiores (Y) com $25 \%$ de intensidade de seleçāo (classificaçōes entre parēntesis).

\begin{tabular}{|c|c|c|c|}
\hline Ordem & Progēnie/Repetiçāo/Planta & Y & q \\
\hline \multirow[t]{3}{*}{1} & $13 / 1 / 4$ & 9,864 (5) & 11,941 \\
\hline & $13 / 1 / 3$ & $9,366 \quad(7)$ & 11,246 \\
\hline & $13 / 3 / 2$ & $11,076 \quad(3)$ & 10,784 \\
\hline \multirow[t]{3}{*}{2} & $62 / 2 / 4$ & $12,064 （ 2)$ & 12,943 \\
\hline & $62 / 3 / 2$ & 12,713 (1) & 12,213 \\
\hline & $62 / 3 / 4$ & 11,360 (3) & 10,986 \\
\hline \multirow[t]{3}{*}{3} & $66 / 3 / 2$ & 12,429 (1) & 12,403 \\
\hline & $66 / 3 / 1$ & $9,945 \quad(3)$ & 11,332 \\
\hline & $66 / 1 / 3$ & $8,714(4)$ & 10,863 \\
\hline \multirow[t]{3}{*}{4} & $53 / 2 / 1$ & 10,769 (1) & 10,885 \\
\hline & $53 / 1 / 3$ & $9,910 \quad(2)$ & 10,458 \\
\hline & $53 / 3 / 2$ & 9,841 (3) & 10,142 \\
\hline \multirow[t]{3}{*}{5} & $43 / 1 / 3$ & $9,826 \quad(3)$ & 10,655 \\
\hline & $43 / 2 / 3$ & $10,031(2)$ & 10,264 \\
\hline & $43 / 1 / 1$ & 10,233 (1) & 9,771 \\
\hline \multirow[t]{3}{*}{6} & 25/1/1 & 11,244 (3) & 12,072 \\
\hline & $25 / 1 / 3$ & 12,284 (2) & 11,466 \\
\hline & $25 / 1 / 4$ & $13,156(1)$ & 11,009 \\
\hline \multirow[t]{3}{*}{7} & $3 / 1 / 2$ & 12,158 (1) & 10,762 \\
\hline & $3 / 3 / 2$ & $9,838(4)$ & 10,692 \\
\hline & $3 / 3 / 1$ & $10,866 \quad(2)$ & 9,891 \\
\hline \multirow[t]{3}{*}{8} & $40 / 1 / 4$ & 12,507 (1) & 12,358 \\
\hline & $40 / 2 / 3$ & $9,003(6)$ & 9,898 \\
\hline & $40 / 1 / 2$ & 9,578 (4) & 9,584 \\
\hline \multirow[t]{3}{*}{9} & $2 / 3 / 2$ & 11,570 (1) & 12,078 \\
\hline & $2 / 2 / 3$ & 10,607 (2) & 11,642 \\
\hline & 2/1/1 & 10,249 (3) & 9,818 \\
\hline \multirow[t]{3}{*}{10} & $56 / 1 / 3$ & 10,606 (1) & 10,750 \\
\hline & $56 / 3 / 2$ & 9,951 (2) & 9,513 \\
\hline & $56 / 2 / 4$ & 9,039 (3) & 9,218 \\
\hline \multirow[t]{3}{*}{11} & $69 / 1 / 4$ & 12,827 (1) & 11,456 \\
\hline & $69 / 3 / 1$ & 9,944 (3) & 10,709 \\
\hline & $69 / 3 / 2$ & $8,806 \quad(5)$ & 9,099 \\
\hline \multirow[t]{3}{*}{12} & $31 / 1 / 1$ & 10,237 (2) & 10,846 \\
\hline & $31 / 2 / 2$ & 10,776 (1) & 10,560 \\
\hline & $31 / 2 / 4$ & $10,226 \quad(3)$ & 9,798 \\
\hline \multirow[t]{3}{*}{13} & $54 / 3 / 4$ & $11,956(1)$ & 10,413 \\
\hline & $54 / 1 / 3$ & $9,148 \quad(6)$ & 9,915 \\
\hline & $54 / 3 / 2$ & $10,045 \quad(4)$ & 9,528 \\
\hline
\end{tabular}


TABELA 40 - Selesajo praticada (lentro dals melhore plogénies classi ficalas através da equaçāo de regressāo múltipla $(\bar{Y})$ no 7 para incluir as progēnies $10 \%$ supe riores $(Y)$, com $25 \%$ de intensidade de seleçāo (classificaçöes entre parên tesis).

\begin{tabular}{|c|c|c|c|}
\hline Ordem & Progēnie/Repetiçāo/Planta & $\mathrm{Y}$ & $\overline{\mathrm{Y}}$ \\
\hline 1 & $\begin{array}{l}13 / 1 / 3 \\
13 / 1 / 4 \\
13 / 3 / 2\end{array}$ & $\begin{array}{r}9,366(7) \\
9,864 \text { (5) } \\
11,076(3)\end{array}$ & $\begin{array}{l}12,128 \\
11,750 \\
11,623\end{array}$ \\
\hline 2 & $\begin{array}{l}62 / 3 / 1 \\
62 / 3 / 2 \\
62 / 2 / 4\end{array}$ & $\begin{array}{l}12,064 \quad(2) \\
12,713(1) \\
10,457 \quad(5)\end{array}$ & $\begin{array}{l}13,633 \\
11,543 \\
11,228\end{array}$ \\
\hline 3 & $\begin{array}{l}62 / 2 / 4 \\
66 / 3 / 2 \\
66 / 3 / 1 \\
66 / 1 / 2\end{array}$ & $\begin{array}{r}12,429(1) \\
9,945(2) \\
8,536(6)\end{array}$ & $\begin{array}{l}11,288 \\
11,355 \\
10,600\end{array}$ \\
\hline 4 & $\begin{array}{l}53 / 2 / 1 \\
53 / 1 / 3 \\
53 / 3 / 2\end{array}$ & $\begin{array}{r}10,769 \text { (1) } \\
9,910 \text { (2) } \\
9,841 \text { (3) }\end{array}$ & $\begin{array}{l}11,271 \\
10,539 \\
10,338\end{array}$ \\
\hline 5 & $\begin{array}{l}3 / 3 / 2 \\
3 / 3 / 1 \\
3 / 2 / 3\end{array}$ & $\begin{aligned} 9,838 & (4) \\
10,866 & (2) \\
8,413 & (10)\end{aligned}$ & $\begin{array}{l}11,461 \\
10,429 \\
10,194\end{array}$ \\
\hline 6 & $\begin{array}{l}43 / 2 / 2 \\
43 / 1 / 1 \\
43 / 1 / 4\end{array}$ & $\begin{array}{r}10,131 \\
10,233(1) \\
9,826 \quad(3)\end{array}$ & $\begin{array}{r}10,198 \\
9,965 \\
9,710\end{array}$ \\
\hline 7 & $\begin{array}{l}69 / 1 / 4 \\
69 / 3 / 1 \\
69 / 3 / 2\end{array}$ & $\begin{array}{r}12,832 \quad(1) \\
9,944 \text { (3) } \\
8,806 \text { (5) }\end{array}$ & $\begin{array}{r}11,228 \\
10,998 \\
9,312\end{array}$ \\
\hline 8 & $\begin{array}{l}40 / 1 / 4 \\
40 / 3 / 4 \\
40 / 1 / 2\end{array}$ & $\begin{array}{r}12,506 \text { (1) } \\
10,122 \text { (2) } \\
9,578\end{array}$ & $\begin{array}{r}11,539 \\
9,425 \\
9,370\end{array}$ \\
\hline 9 & $\begin{array}{l}2 / 3 / 2 \\
2 / 2 / 3 \\
2 / 2 / 2\end{array}$ & $\begin{array}{l}11,571 \text { (1) } \\
10,607 \text { (2) } \\
10,230\end{array}$ & $\begin{array}{l}12,003 \\
11,926 \\
10,090\end{array}$ \\
\hline 10 & $\begin{array}{l}49 / 1 / 1 \\
49 / 1 / 2 \\
49 / 2 / 1\end{array}$ & $\begin{aligned} 11,563 & (1) \\
9,862 & (2) \\
7,413 & (10)\end{aligned}$ & $\begin{array}{r}10,375 \\
9,079 \\
8,810\end{array}$ \\
\hline 11 & $\begin{array}{l}42 / 3 / 3 \\
42 / 1 / 1 \\
42 / 1 / 2\end{array}$ & $\begin{array}{l}9,486 \text { (2) } \\
9,651 \text { (1) } \\
9,436 \quad(3)\end{array}$ & $\begin{array}{r}10,798 \\
9,749 \\
9,575\end{array}$ \\
\hline 12 & $\begin{array}{l}70 / 1 / 3 \\
70 / 3 / 1 \\
70 / 1 / 4\end{array}$ & $\begin{array}{l}9,272(4) \\
9,560(3) \\
9,903(2)\end{array}$ & $\begin{array}{l}10,512 \\
10,199 \\
10,064\end{array}$ \\
\hline 13 & $\begin{array}{l}50 / 1 / 1 \\
50 / 3 / 3 \\
50 / 1 / 2\end{array}$ & $\begin{array}{r}10,160 \\
10,366 \text { (1) } \\
9,729 \text { (3) }\end{array}$ & $\begin{array}{r}10,183 \\
9,841 \\
9,300\end{array}$ \\
\hline 14 & $\begin{array}{l}14 / 2 / 2 \\
14 / 1 / 1 \\
14 / 3 / 1\end{array}$ & $\begin{array}{r}8,995 \text { (4) } \\
10,145 \text { (1) } \\
8,497(7)\end{array}$ & $\begin{array}{l}9,761 \\
9,563 \\
9,312\end{array}$ \\
\hline 15 & $\begin{array}{l}25 / 1 / 4 \\
25 / 1 / 3 \\
25 / 1 / 1\end{array}$ & $\begin{array}{l}13,156 \text { (1) } \\
12,284 \text { (2) } \\
11,244\end{array}$ & $\begin{array}{l}11,142 \\
10,880 \\
10,474\end{array}$ \\
\hline 16 & $\begin{array}{l}56 / 1 / 3 \\
56 / 3 / 2 \\
56 / 1 / 4\end{array}$ & $\begin{array}{r}10,606 \text { (1) } \\
9,951 \text { (2) } \\
8,129 \text { (9) }\end{array}$ & $\begin{array}{r}10,875 \\
9,546 \\
9,343\end{array}$ \\
\hline 17 & $\begin{array}{l}38 / 3 / 4 \\
38 / 2 / 2 \\
38 / 3 / 1\end{array}$ & $\begin{array}{l}10,440(2) \\
10,299(3) \\
10,788\end{array}$ & $\begin{array}{r}10,184 \\
9,945 \\
9,773\end{array}$ \\
\hline 18 & $\begin{array}{l}36 / 1 / 2 \\
36 / 3 / 1 \\
36 / 3 / 2\end{array}$ & $\begin{array}{r}11,779 \\
10,602 \quad(1) \\
9,860\end{array}$ & $\begin{array}{r}10,827 \\
10,273 \\
9,441\end{array}$ \\
\hline 19 & $\begin{array}{l}45 / 1 / 4 \\
45 / 1 / 1 \\
45 / 2 / 2 \\
54 / 1 / 3 \\
54 / 2 / 2 \\
54 / 3 / 2\end{array}$ & $\begin{array}{r}9,801 \\
10,329(1) \\
9,198 \text { (4) } \\
9,148 \text { (6) } \\
9,518 \text { (5) } \\
10,045(4)\end{array}$ & $\begin{array}{r}10,368 \\
9,787 \\
9,584 \\
9,849 \\
9,746 \\
9,635\end{array}$ \\
\hline
\end{tabular}


TABEIA 41 - Produçāo média/ano/planta de café cereja em quilogramas das progēnies de café 'Acaiá'.

\begin{tabular}{|c|c|c|c|c|c|c|c|c|}
\hline Progēnies & Ano 1 & Ano 2 & Ano 3 & Ano 4 & Ano 5 & Ano 6 & ヘno 7 & Ano 8 \\
\hline 1 & 7.525834 & 3.072500 & $9.45916 \epsilon$ & 0.483333 & 2.811667 & 9.590834 & 0.625833 & 11.879170 \\
\hline 2 & 7.181667 & 5.073334 & 10.425830 & 1.376667 & 2.1 .21667 & 12.095000 & 0.790000 & 12.094170 \\
\hline 3 & 8.185000 & 5.230833 & 9.307500 & 1.425833 & 2.881667 & 11.643330 & 0.669167 & 11.765830 \\
\hline 4 & 7.800000 & 4.990834 & 9.331666 & 1.206667 & 2.562500 & 8.791666 & 0.447500 & 10.525000 \\
\hline 5 & 6.411667 & 3.0191 .67 & 9.776667 & 0.190000 & 1.174167 & 7.990000 & 0.259167 & 9.006667 \\
\hline 6 & 7.156667 & 4.562500 & 9.656667 & 0.782500 & ). 442500 & 9.653332 & 0.371667 & 9.375000 \\
\hline 7 & 6.790000 & 4.851667 & 9.889167 & 1.614167 & 2.630000 & 10.894170 & 0.640833 & 11.230000 \\
\hline 8 & 7.377500 & 4.140834 & 9.037499 & 0.440000 & 1.635833 & 12.385000 & 0.587500 & 11.785000 \\
\hline 9 & 7.445001 & 4.373333 & 10.416670 & 1.240000 & 2.569167 & $9.33000 \mathrm{C}$ & 0.733333 & 10.701670 \\
\hline 10 & 6.145833 & 5.182500 & 8.845000 & 2.764167 & 1.504167 & 12.209170 & 0.665000 & 10.648330 \\
\hline 11 & 7.596667 & 3.286667 & 10.545830 & 0.381667 & 2.019167 & 10.597500 & 0.241667 & 11.219170 \\
\hline 12 & 7.213333 & 3.370000 & 10.685830 & 0.823333 & 2.896667 & 10.814170 & 0.369167 & 13.038330 \\
\hline 13 & 6.554167 & 7.719167 & 8.336666 & 2.104167 & 2.630834 & 11.820000 & 0.805833 & 13.574170 \\
\hline 14 & 7.965833 & 4.794167 & 9.316667 & i. 426667 & 2.344167 & 10.923330 & 0.410833 & 10.721670 \\
\hline 15 & 8.075835 & 4.128333 & 11.105830 & 0.397500 & 1.597500 & 9.540834 & 0.245833 & 9.960834 \\
\hline 16 & 7.474167 & 4.043334 & 9.554167 & 0.360833 & 2.136667 & 9.830000 & 0.505000 & 10.904170 \\
\hline 17 & 6.091667 & 4.624167 & 8.574166 & 1.385000 & 1.690000 & 9.217500 & 0.493333 & 10.129170 \\
\hline 18 & 7.927501 & 3.199167 & 8.728334 & 0.967500 & 2.146667 & 9.784166 & 0.376667 & 8.780833 \\
\hline 19 & 6.885834 & 3.940834 & 9.558333 & 1.325000 & 2.177500 & 10.933330 & 0.335000 & 12.163330 \\
\hline 20 & 7.677500 & 3.831667 & 9.291 .667 & 0.708333 & 2.970000 & 8.992500 & 0.647500 & 9.311666 \\
\hline 21 & 7.320000 & 3.349167 & 9.976666 & $0.415 c .00$ & 2.020000 & 10.254170 & 0.323333 & 12.279170 \\
\hline 22 & 7.585834 & 3.932500 & 10.984170 & 1.175000 & 2.075833 & 11.465000 & 0.549167 & 11.414170 \\
\hline 23 & 7.701667 & 3.123333 & 9.631666 & 0.648333 & 1.236667 & 9.430000 & 0.471667 & 1.0 .070000 \\
\hline 24 & 6.953334 & 3.640834 & 11.923330 & 0.585000 & 2.151667 & 10.516670 & 0.381667 & 12.795000 \\
\hline 25 & 6.170833 & 6.546666 & 9.819167 & 2.176667 & 1.673333 & 11.061670 & 0.355000 & 12.805830 \\
\hline 26 & 6.589167 & 1.427500 & 7.326667 & 0.107500 & 1.874167 & 6.387501 & 0.2300000 & 7.347500 \\
\hline 27 & 7.269167 & 3.773334 & 10.330000 & 0.705000 & 1.239167 & 9.485833 & 0.448333 & 10.992500 \\
\hline 28 & 5.576667 & 2.951667 & 10.884170 & 1.850000 & 9.076667 & 0.262500 & 0.262500 & 12.828330 \\
\hline 29 & 7.418333 & 3.653334 & 9.804166 & 0.570000 & 1.961 .667 & 11.170830 & 0.380000 & 9.860001 \\
\hline 30 & 7.467500 & 3.287500 & 9.740000 & 0.412500 & 2.427500 & 13.107500 & 0.899167 & 12.774170 \\
\hline 31 & 7.446667 & 4.262500 & 11.432500 & 0.050000 & 2.011667 & 10.238330 & 0.497500 & 11.816670 \\
\hline 32 & 8.206666 & $3.33000 \mathrm{C}$ & 10.622500 & 0.352500 & 1.778333 & 9.851666 & 0.687500 & 10.176670 \\
\hline 33 & 7.034167 & 2.959167 & 8.882500 & 0.306667 & 1.229167 & 9.454168 & 0.201667 & 10.599170 \\
\hline 34 & 7.420834 & 3.552500 & 8.731667 & 1.056667 & 1.871667 & 10.619170 & 0.597500 & 9.422501 \\
\hline 35 & 7.425834 & 3.769167 & 10.524170 & 0.814167 & 1.970000 & 8.321667 & 0.456667 & 9.050000 \\
\hline 36 & 7.371667 & 5.595834 & 8.216667 & 0.972500 & 2.160833 & 9.187500 & 0.290000 & 10.298330 \\
\hline
\end{tabular}


TABELA 41 - continuação

\begin{tabular}{|c|c|c|c|c|c|c|c|c|}
\hline Progēnies & Ano 1 & Ano 2 & Ano 3 & Ano 4 & Ano 5 & Ano 6 & Ano 7 & Ano 8 \\
\hline 37 & 8.095834 & 3.151667 & 9.384167 & 0.940833 & 1. 350833 & 9.729167 & 0.470833 & 10.454170 \\
\hline 38 & 7.710834 & 4.522500 & 10.487500 & 1.712500 & 2.173334 & 10.006670 & 0.423333 & 11.401670 \\
\hline 39 & 8.267500 & 3.390000 & 11.293330 & 0.277500 & 2. 140000 & L. L. 530000 & 0.589167 & 12.265830 \\
\hline 40 & 6.672500 & 4.296667 & 11.295830 & 0.348333 & 2.215834 & 12.815000 & 0.546667 & 13.704170 \\
\hline 41 & 6.575000 & 4.075000 & 8.267500 & 1.055833 & 1.376667 & 9.937500 & 0.344167 & 9.900833 \\
\hline 42 & 7.530834 & 5.837500 & 8.325001 & 2.483333 & 1.456667 & 9.190834 & 0.325833 & 10.694170 \\
\hline 43 & 7.535834 & 4.830834 & 10.452500 & 1.120833 & 2.836667 & 11.318330 & 0.575000 & 11.240830 \\
\hline 44 & 7.171667 & 4.855834 & 8.960000 & 1.275000 & 2.118333 & 9.177500 & 0.441667 & 9.816667 \\
\hline 45 & 7.380834 & 3.845833 & 9.996667 & 0.360000 & 2.321667 & 11.097500 & 0.396667 & 13.200830 \\
\hline 46 & 6.028334 & 5.594167 & 8.775833 & 2.900000 & 1.725833 & 11.402500 & 0.488333 & 12.028330 \\
\hline 47 & 8.235835 & 2.897500 & 10.205000 & 0.439167 & 1.564167 & 11.565000 & 0.391667 & 11.210000 \\
\hline 48 & 7.211667 & 4.316667 & 9.527500 & 1.116667 & 2.399167 & 10.340830 & 0.700000 & 11.905000 \\
\hline 49 & 6.321667 & 6.475000 & 8.287501 & 1.905000 & 1.894167 & 10.508330 & 0.276667 & 10.772500 \\
\hline 50 & 8.106667 & 5.085834 & 9.485001 & 1.514167 & 2.472500 & 10.335000 & 0.400833 & 10.624170 \\
\hline 51 & 7.478334 & 3.525833 & 10.142500 & 0.341667 & 2.564167 & 11.244170 & 0.624167 & 12.185830 \\
\hline 52 & 7.760000 & 3.565833 & 8.719999 & 0.465000 & 1.695000 & 9.679167 & 0.313333 & 8.500834 \\
\hline 53 & 7.2 .15000 & 6.505000 & 8.762500 & 2.141667 & 2.480000 & 10.160000 & 0.695833 & 11.330000 \\
\hline 54 & 6.282501 & 6.064167 & 9.510834 & 1.515833 & 2.525000 & 11.095000 & 0.683333 & 11.712500 \\
\hline 55 & 7.723334 & 4.918334 & 9.984999 & 0.435000 & 1.665000 & 10.117500 & 0.306667 & 10.402500 \\
\hline 56 & 7.927500 & 4.678334 & 1.0 .955830 & $0.6 \nvdash 9167$ & 2.301667 & 10.624170 & 0.493333 & 10.982500 \\
\hline 57 & 7.045000 & 4.791667 & 10.750000 & 1.285000 & 2.130000 & 10.442500 & 0.440833 & 10.793330 \\
\hline 58 & 6.91 .6667 & $4.08 \% 500$ & $10.444] 70$ & 0.7408333 & 1.862500 & 10.549170 & 0.273333 & 9.786667 \\
\hline 59 & 6.598334 & 4.276667 & 9.928333 & 0.8341067 & 2.105833 & 9.810833 & 0.645833 & 10.774170 \\
\hline 60 & 7.845001 & 1.934167 & 7.048333 & 0.21 .9167 & 1.089167 & 9.551666 & 0.065833 & 9.455000 \\
\hline 61 & 7.503333 & 4.182500 & 9.866667 & 1.334167 & 2.141667 & 10.078330 & 0.409167 & 10.739170 \\
\hline 62 & 7.330000 & 7.521667 & 8.125000 & 2.960833 & 1.739167 & 12.815830 & 0.614167 & 11.332500 \\
\hline 63 & 7.775000 & 3.533333 & 10.564170 & 0.964167 & 1.644167 & 10.310830 & 0.920833 & 9.177500 \\
\hline 64 & 7.686667 & 3.346667 & 10.590000 & 0.595000 & 1.948333 & 10.875830 & 0.559167 & 9.550000 \\
\hline 65 & 5.707500 & 6.696667 & 8.093335 & 3.652500 & 1.835000 & 6.969167 & 1.430000 & 6.158334 \\
\hline 66 & 6.237500 & 7.219167 & 9.650833 & 1.369167 & 2.445000 & 10.834170 & 0.747500 & 11.970830 \\
\hline 67 & 8.235001 & 4.514167 & 9.525833 & 1.156667 & 1.889167 & 7.163333 & 0.510833 & 8.392500 \\
\hline 68 & 7.785834 & 2.650833 & 10.846670 & 1.129167 & 1.427500 & 11.891670 & 0.511667 & 12.888330 \\
\hline 69 & 7.486667 & 5.604167 & 9.551666 & 1.290000 & 2.318334 & 10.322500 & 0.845833 & 11.360830 \\
\hline 70 & 6.870834 & 5.499167 & 9.166666 & 1.076667 & 3.140833 & 9.755834 & 0.456667 & 11.295000 \\
\hline 71 & 8.200000 & 3.160833 & 12.425830 & 0.625000 & 2.724167 & 11.191670 & 0.245000 & 12.655830 \\
\hline 72 & 8.060001 & 3.233333 & 10.183330 & 0.215000 & 1.843334 & 10.157500 & 0.262500 & 12.157500 \\
\hline
\end{tabular}


TABElA 42 - Produção cereja bienal de café em quilogramas. Média de trēs repetiçōes e quatro plantas por repetiçāo nos quatro biēnios (B).

\begin{tabular}{|c|c|c|c|c|c|c|c|c|c|}
\hline Progēnies & B1 & B2 & B3 & B4 & Progēnics & B1 & B2 & B3 & B4 \\
\hline 1 & 10,598 & 9,943 & 12,403 & 12,505 & 37 & 11,248 & 10,325 & 11,080 & 10,925 \\
\hline 2 & 12,255 & 1.1.,803 & $14,2.1 .7$ & 12,884 & 8 & 12,233 & 12,200 & 12,180 & 11,825 \\
\hline 3 & 13,415 & 10,733 & 14,525 & 12,435 & 9 & 11,658 & 11,571 & 13,670 & 12,855 \\
\hline 4 & 12,791 & $1.0,538$ & 11,354 & $1.0,973$ & 40 & 10,969 & 11,644 & 15,031 & 14,251 \\
\hline 5 & 9,431 & 9,967 & 9,164 & 9,266 & 1 & 10,650 & 9,323 & 11,314 & 10,245 \\
\hline 6 & 11,719 & 10,439 & 12,096 & 9,747 & 2. & 13,368 & 10,808 & 10,648 & 11,020 \\
\hline 7 & 11,642 & 11,503 & 13,524 & 11,871 & 3 & 12,367 & 11,573 & 14,155 & 11,816 \\
\hline 8 & 11,518 & 9,478 & 14,021 & 12,373 & 4 & 12,028 & 10,235 & 11,296 & 10,258 \\
\hline 9 & 11,818 & 11,657 & 11,899 & 11,435 & 5 & 11,227 & 10,357 & 13,419 & 13,598 \\
\hline 10 & 11,328 & 11,609 & 13,713 & 11,313 & 6 & 11,623 & 11,676 & 13,128 & 12,516 \\
\hline 1 & 10,883 & 10,927 & 12,617 & 11,407 & 7 & 11,133 & 10,644 & 13,129 & 11,602 \\
\hline 2 & 10,583 & 11,509 & 13,711 & 13,408 & 8 & 11,528 & 10,644 & 12,740 & 12,605 \\
\hline 3 & 14,273 & 10,441 & 14,451 & 14,380 & 9 & 12,797 & 10,193 & 12,403 & 11,049 \\
\hline 4 & 12,760 & 10,743 & 13,268 & 11,133 & 50 & 13,193 & 10,990 & 12,808 & 11,025 \\
\hline 5 & 12,204 & 11,503 & 11,138 & 10,207 & 1 & 11,004 & 10,484 & 13,808 & 12,810 \\
\hline 6 & 11,518 & 9,915 & 11,967 & 11,408 & 2 & 11,326 & 9,185 & 11,374 & 8,814 \\
\hline 7 & 10,716 & 10,459 & 10,908 & 10,623 & 3 & 13,720 & 10,904 & 12,640 & 12,026 \\
\hline 8 & 11,127 & 9,696 & 11,931 & 9,158 & 4 & 12,347 & 11,027 & 13,620 & 12,396 \\
\hline 9 & 10,827 & 10,883 & 13,111 & 12,498 & 5 & 12,642 & 10,420 & 11,783 & 10,709 \\
\hline 20 & 11,509 & 10,000 & 11,963 & 9,959 & 6 & 12,606 & 11,625 & 12,926 & 11,476 \\
\hline 1 & 10,669 & 10,392 & 12,274 & 12,603 & 7 & 11,837 & 12,035 & 12,573 & 11,234 \\
\hline 2 & 11,518 & 12,159 & 13,541 & 11,963 & 8 & 10,999 & 11,185 & 12,412 & 10,060 \\
\hline 3 & 10,825 & 10,280 & 10,667 & 10,542 & 9 & 10,875 & 10,763 & 11,917 & 11,420 \\
\hline 4 & 10,594 & 12,508 & 12,668 & 13,177 & 60 & 9,779 & 7,268 & 10,641 & 9,521 \\
\hline 5 & 12,718 & 11,996 & 12,735 & 13,161 & 1 & 11,686 & 11,208 & 12,220 & 11,148 \\
\hline 6 & 8,017 & 7,434 & 8,262 & 7,578 & 2 & 14,852 & 11,086 & 14,555 & 11,947 \\
\hline 7 & 11,043 & 11,035 & 10,725 & 11,441 & 3 & 11,308 & 11,528 & 11,955 & 10,098 \\
\hline 8 & 8,528 & 11,051 & 10,927 & $1.3,091$ & 4 & 11,033 & 11,185 & 12,824 & 10,109 \\
\hline 9 & 11,072 & 10,374 & 13,133 & $1.0,240$ & 5 & 12,404 & 11,746 & 8,804 & 7,588 \\
\hline 30 & 10,755 & 10,153 & 15,535 & 13,673 & 6 & $13,4.57$ & 11,020 & 13,279 & 12,718 \\
\hline 1 & 11,709 & 11,483 & 12,250 & 12,315 & 7 & 12,749 & 10,683 & 9,053 & 8,903 \\
\hline 2 & 11,537 & 10,975 & 11,630 & 10,864 & 8 & 10,437 & 11,976 & 13,319 & 13,400 \\
\hline 3 & 9,993 & 9,189 & 10,683 & 10,801 & 9 & 13,091 & 10,842 & 12,641 & 12,207 \\
\hline 4 & 10,973 & 9,788 & 12,491 & 10,020 & 70 & 12,370 & 10,243 & 12,897 & 11,752 \\
\hline 5 & 11,195 & 11,338 & 10,292 & 9,507 & 1 & 11,361 & 13,051 & 13,916 & 12,901 \\
\hline 6 & 12,967 & 9,189 & 11,348 & 10,588 & 2 & 11,293 & 10,398 & 12,001 & 12,420 \\
\hline
\end{tabular}




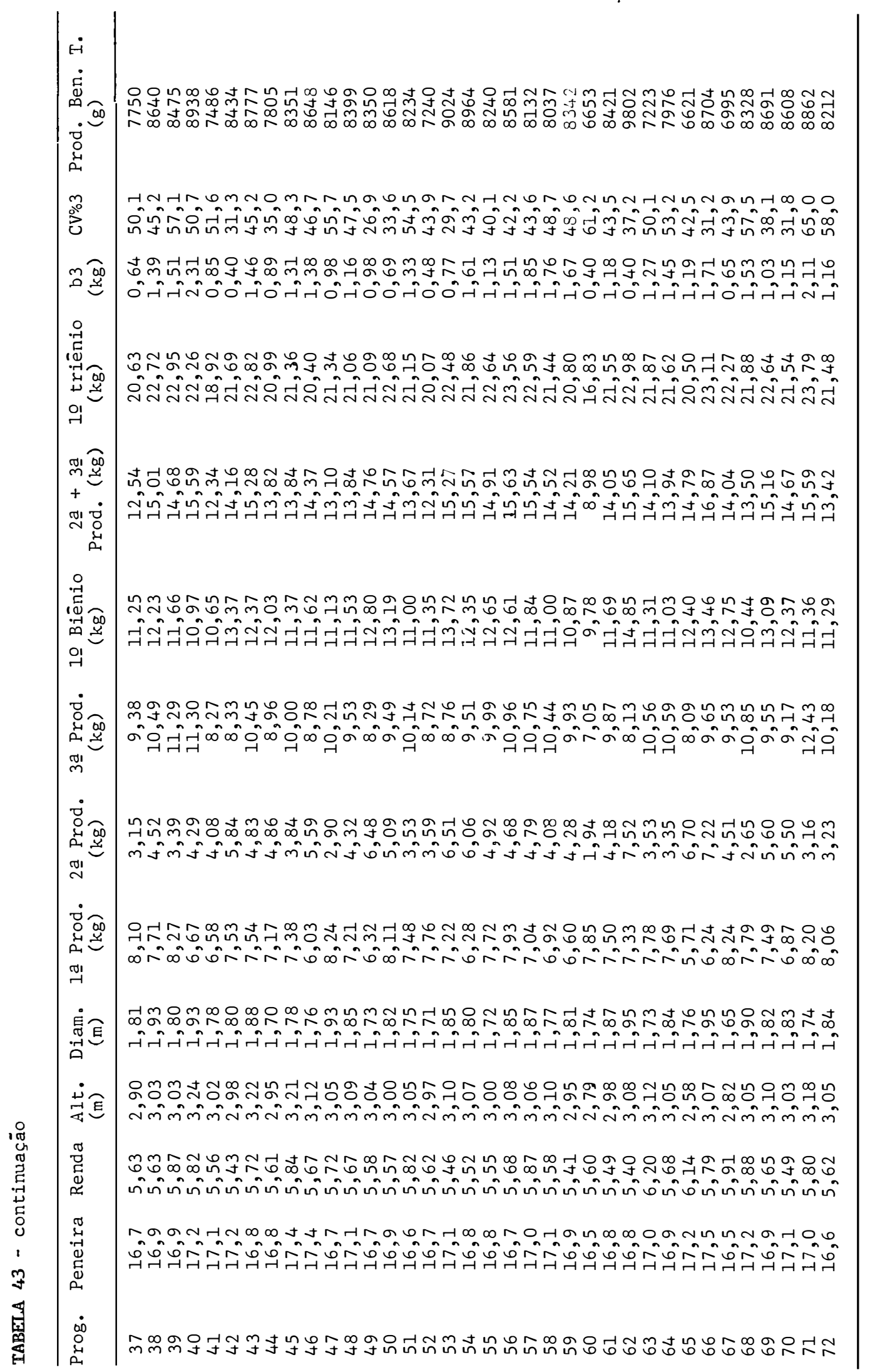


APÊNDICE 1 - Dados mensais de chuva (mm) e temperatura mí nima absoluta $\left({ }^{\circ} \mathrm{C}\right)$ ocorridos no período 1971 -1979 em Mococa, SP. Fonte: Seção de Climatologia Agrícola do Instituto Agronômico de Campinas.

\begin{tabular}{|c|c|c|c|c|c|c|c|c|c|c|}
\hline \multirow{2}{*}{ Meses } & \multirow{2}{*}{ Observaçōes } & \multicolumn{9}{|c|}{ Anos } \\
\hline & & 1971 & 1972 & 1973 & 1974 & 1975 & 1976 & 1977 & 1978 & 1979 \\
\hline Jan. & Chuva & 58,2 & 227,9 & 226,9 & 336,0 & 162,4 & 220,5 & 362,7 & 264,3 & 196,3 \\
\hline Fev. & Chuva & 136,6 & 276,4 & 151,7 & 167,6 & 307,4 & 362,4 & 27,1 & 68,8 & 246,2 \\
\hline Mar。 & Chuva & 145,6 & 171,2 & 152,7 & 184,2 & 33,6 & 224,1 & 157,4 & 126,5 & 68,6 \\
\hline \multirow[t]{2}{*}{ Abr. } & Chuva & 99,0 & 23,9 & 104,5 & 68,4 & 82,8 & 107,5 & 181,5 & 44,0 & 48,4 \\
\hline & Temp. min. & 6,2 & 9,2 & 17,4 & 9,4 & 13,0 & 10,8 & 13,6 & 13,0 & 9,2 \\
\hline \multirow[t]{2}{*}{ Mai. } & Chuva & 31,4 & 71,9 & 61,1 & 9,2 & 19,9 & 91,1 & 5,9 & 102,5 & 114,1 \\
\hline & Temp. miñ. & 8,4 & 10,0 & 4,8 & 6,8 & 7,8 & 8,8 & 5,4 & 6,2 & 1,4 \\
\hline \multirow[t]{2}{*}{ Jun . } & Chuva & 95,5 & 0,0 & 8,8 & 82,9 & 4,9 & 59,0 & 47,6 & 33,2 & 0,0 \\
\hline & Temp. min. & 5,2 & 4,6 & 5,7 & 8,6 & 5,6 & 7,2 & 10,0 & 4,4 & 0,0 \\
\hline \multirow[t]{2}{*}{ Jul. } & Jhuva & 43,3 & 136,1 & 20,4 & 0,0 & 21,7 & 93,0 & 5,0 & 46,2 & 20,8 \\
\hline & Temp. min. & 6,8 & 2,2 & 3,6 & 8,4 & 1,8 & 5,2 & 11,6 & 9,2 & 3,0 \\
\hline \multirow[t]{2}{*}{ Ago. } & Chuva & 0,2 & 52,4 & 5,7 & 14,0 & 0,0 & 109,4 & 43,0 & 0,8 & 23,2 \\
\hline & Temp. min. & 7,0 & 7,7 & 6,2 & 6,2 & 10,2 & 9,0 & 8,6 & 2,0 & 10,6 \\
\hline Set. & Chuva & 57,7 & 67,2 & 43,3 & 17,8 & 44,4 & 221,5 & 116,4 & 61,3 & 178,8 \\
\hline 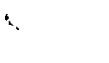 & Temp. min. & 9,8 & 5,4 & 11,0 & 6,5 & 13,6 & 11,4 & 10,6 & 10,1 & 7,0 \\
\hline Out. & Chuva & 167,6 & 206,7 & 103,6 & 102,3 & 92,7 & 85,4 & 121,0 & 87,3 & 93,0 \\
\hline Nov. & Chuva & 127,6 & 382,1 & 151,5 & 108,7 & 364,2 & 210,2 & 156,8 & 324,8 & 179,9 \\
\hline Dez. & Chuva & 411,4 & 246,0 & 382,2 & 309,7 & 170,7 & 318,7 & 232,2 & 250,1 & 299,8 \\
\hline
\end{tabular}

